Supporting Information for

\title{
Iron-catalyzed Hydrogen Transfer Reduction of \\ Nitroarenes with Alcohols. Synthesis of Imines and Aza Heterocycles
}

Jiajun Wu, Christophe Darcel*

UnivRennes, CNRS ISCR (Institut des Sciences Chimiques de Rennes)

UMR 6226, F-35000, Rennes, France

\section{Contents:}

1) Optimization conditions for the synthesis of $N$-(4-methoxyphenyl)-1-phenylmethanimine 3a $\mathrm{S} 2$

2) Optimization conditions for the synthesis of 2-phenyl-1H-benzo[ $d]$ imidazole $\mathbf{6 a} \quad \mathrm{S} 2$

3) Optimization conditions for the synthesis of 2-phenylquinoxaline 8a $\quad$ S3

4) Complementary control experiments $\quad$ S3

5) Reference $\quad$ S4

$\begin{array}{lr}\text { 6) NMR spectra } & \text { S5 }\end{array}$

$\begin{array}{lr}\text { 7) HR-MS spectra } & \text { S57 }\end{array}$ 
1) Optimization conditions for the synthesis of $N$-(4-methoxyphenyl)-1-phenylmethanimine 3a
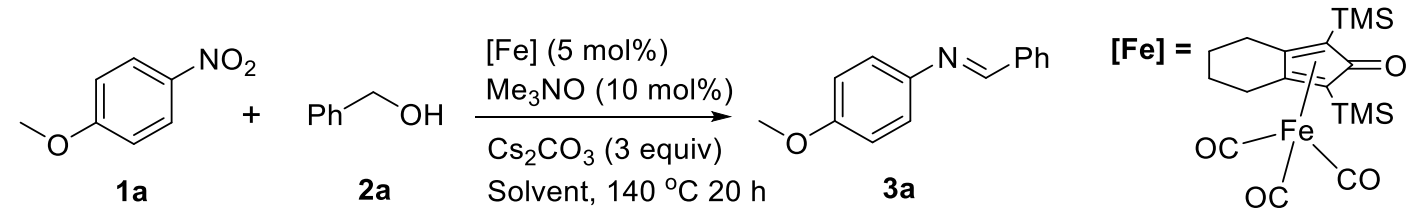

Table S1 - Screening of the solvents ${ }^{a}$

\begin{tabular}{|cccc|}
\hline Entry & $\mathbf{2 a}$ & Solvent $(\mathbf{m L})$ & Yield $^{\boldsymbol{b}}(\mathbf{\%})$ \\
\hline $\mathbf{1}$ & 4 equiv. & Toluene (2) & 84 \\
\hline $\mathbf{2}$ & 4 equiv. & Benzonitrile (2) & trace \\
\hline $\mathbf{3}$ & 4 equiv. & CPME (2) & 69 \\
\hline $\mathbf{4}$ & 4 equiv. & Anisole (2) & 75 \\
\hline $\mathbf{5}$ & $0.5 \mathrm{~mL}$ & - & 44 \\
\hline
\end{tabular}

${ }^{a}$ Reaction condition: 1a (0.2 mmol), 2a, [Fe] (5 mol\%), $\mathrm{Me}_{3} \mathrm{NO}$ (10 mol\%), $\mathrm{Cs}_{2} \mathrm{CO}_{3}$ (3 equiv.), solvent, $140{ }^{\circ} \mathrm{C}, 20 \mathrm{~h} .{ }^{b}$ Determined by GC using dodecane as an internal standard. $\mathrm{CPME}=$ cyclopentylmethylether.

2) Optimization conditions ${ }^{a}$ for the synthesis of 2-phenyl- $1 H$-benzo $[d]$ imidazole 6 a<smiles>Nc1ccccc1[N+](=O)[O-]</smiles>

$5 a$

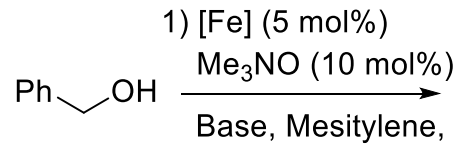
$160^{\circ} \mathrm{C}, \mathrm{t}$

2) Additive, $\mathrm{T}, \mathrm{t}$<smiles>O=[PH](c1ccccc1)c1nc2ccccc2[nH]1</smiles>

$6 a$

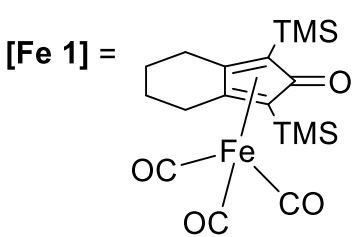<smiles>CN(CCN(C)c1ccccc1)C1=C(P(C)C=O)C(=O)C(=O)C1(P)c1ccccc1</smiles>

Table S2- Optimization of $6 a$

\begin{tabular}{|c|c|c|c|c|c|c|}
\hline Entry & Base (equiv.) & Additive (equiv.) & {$[\mathrm{Fe}]$} & t (h) & Atmosphere & Yield $^{b}(\%)$ \\
\hline 1 & $\mathrm{~K}_{3} \mathrm{PO}_{4} \cdot \mathrm{H}_{2} \mathrm{O}(3)$ & - & {$[\mathrm{Fe} 1]$} & 24 & $\mathrm{Ar}$ & 20 \\
\hline 2 & $\mathrm{~K}_{3} \mathrm{PO}_{4} \cdot \mathrm{H}_{2} \mathrm{O}(1)$ & - & {$[\mathrm{Fe} 1]$} & 24 & $\mathrm{Ar}$ & 28 \\
\hline 3 & $\mathrm{~K}_{3} \mathrm{PO}_{4} \cdot \mathrm{H}_{2} \mathrm{O}(1)$ & - & {$[\mathrm{Fe} 2]$} & 24 & $\mathrm{Ar}$ & 17 \\
\hline 4 & $\mathrm{~K}_{3} \mathrm{PO}_{4} \cdot \mathrm{H}_{2} \mathrm{O}(1)$ & - & {$[\mathrm{Fe} 1]$} & 48 & $\mathrm{Ar}$ & 22 \\
\hline 5 & $\mathrm{~K}_{3} \mathrm{PO}_{4} \cdot \mathrm{H}_{2} \mathrm{O}$ & - & {$[\mathrm{Fe} 1]$} & 72 & Air & 32 \\
\hline 6 & $\mathrm{~K}_{3} \mathrm{PO}_{4} \cdot \mathrm{H}_{2} \mathrm{O}(1)$ & $\mathrm{FeCl}_{3}(0.2)$ & {$[\mathrm{Fe} 1]$} & $24+24$ & $\mathrm{Ar}$ & 29 \\
\hline 7 & $\mathrm{~K}_{3} \mathrm{PO}_{4} \cdot \mathrm{H}_{2} \mathrm{O}(1)$ & DDQ (0.5) & {$[\mathrm{Fe} 1]$} & $24+24$ & $\mathrm{Ar}$ & 53 \\
\hline 8 & $\mathrm{~K}_{3} \mathrm{PO}_{4} \cdot \mathrm{H}_{2} \mathrm{O}(1)$ & DDQ (0.6) & {$[\mathrm{Fe} 1]$} & $24+24$ & $\mathrm{Ar}$ & 51 \\
\hline 9 & $\mathrm{~K}_{3} \mathrm{PO}_{4} \cdot \mathrm{H}_{2} \mathrm{O}(1)$ & DDQ (0.5) & {$[\mathrm{Fe} 1]$} & $15+24$ & Ar & 64 \\
\hline
\end{tabular}

${ }^{a}$ Reaction conditions: 1) 5a $(0.5 \mathrm{mmol}), \mathbf{2 a}$ (4 equiv.), [Fe] (5 mol\%), $\mathrm{Me}_{3} \mathrm{NO}(10 \mathrm{~mol} \%)$, $\mathrm{K}_{3} \mathrm{PO}_{4} \cdot \mathrm{H}_{2} \mathrm{O}$ (1-3 equiv.), Mesitylene ( $3 \mathrm{~mL}$ ), $160{ }^{\circ} \mathrm{C}, 24-72 \mathrm{~h}$, then 2 ) DDQ (0.5-0.6 equiv.) $160{ }^{\circ} \mathrm{C}, 24 \mathrm{~h}$ under Argon atmosphere or air. ${ }^{b}$ Yields. 
3) Optimization conditions ${ }^{a}$ for the synthesis of 2-phenylquinoxaline 8a

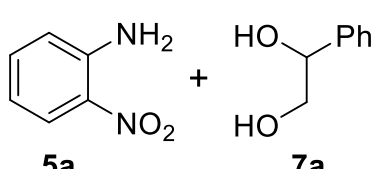

$5 a$

$7 a$

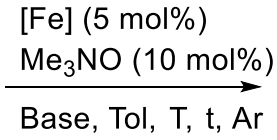<smiles>O=C(c1ccccc1)c1nc2ccccc2[nH]1</smiles>

$8 \mathrm{a}$
$6 a$

Table S3 - Optimization of 8a

\begin{tabular}{|cccccc|}
\hline Entry & $\mathbf{6 a}$ (equiv.) & Base (equiv.) & $\mathbf{T}\left({ }^{\mathbf{C}} \mathbf{C}\right)$ & $\mathbf{t}(\mathbf{h})$ & Yield $^{\boldsymbol{b}}(\mathbf{\%})$ \\
\hline 1 & 1.5 & $\mathrm{~K}_{3} \mathrm{PO}_{4} \cdot \mathrm{H}_{2} \mathrm{O}(3)$ & 150 & 48 & $51(20)^{c}$ \\
\hline 2 & 2 & $\mathrm{~K}_{3} \mathrm{PO}_{4} \cdot \mathrm{H}_{2} \mathrm{O}(3)$ & 150 & 48 & 62 \\
\hline 3 & $\mathbf{3}$ & $\mathrm{K}_{3} \mathrm{PO}_{4} \cdot \mathrm{H}_{2} \mathbf{O}(3)$ & $\mathbf{1 5 0}$ & $\mathbf{4 8}$ & $\mathbf{8 0}$ \\
\hline 4 & 2 & $\mathrm{~K}_{3} \mathrm{PO}_{4} \cdot \mathrm{H}_{2} \mathrm{O}(4)$ & 150 & 48 & 59 \\
\hline 5 & 2 & $\mathrm{~K}_{3} \mathrm{PO}_{4} \cdot \mathrm{H}_{2} \mathrm{O}(3)$ & 150 & 24 & 48 \\
\hline
\end{tabular}

${ }^{a}$ Reaction conditions: $5 \mathbf{a}(0.5 \mathrm{mmol}), 7 \mathbf{a}\left(1.5-3\right.$ equiv.), [Fe] (5 mol\%), $\mathrm{Me}_{3} \mathrm{NO}(10 \mathrm{~mol} \%)$, $\mathrm{K}_{3} \mathrm{PO}_{4} \cdot \mathrm{H}_{2} \mathrm{O}$ (3-4 equiv.), Toluene $(2.5 \mathrm{~mL}), 150{ }^{\circ} \mathrm{C}, 24-48 \mathrm{~h}$, under Argon atmosphere. ${ }^{b}$ Yields. ${ }^{c}$ Value in parentheses indicated the yield of $\mathbf{6 a}$.

\section{4) Complementary control experiments and characterization data for intermediates}

\section{Scheme S1 - Control experiments}

(a) Reaction ${ }^{a}$ of $1 \mathbf{a}$ with 2 equiv. of $\mathbf{2 a}$

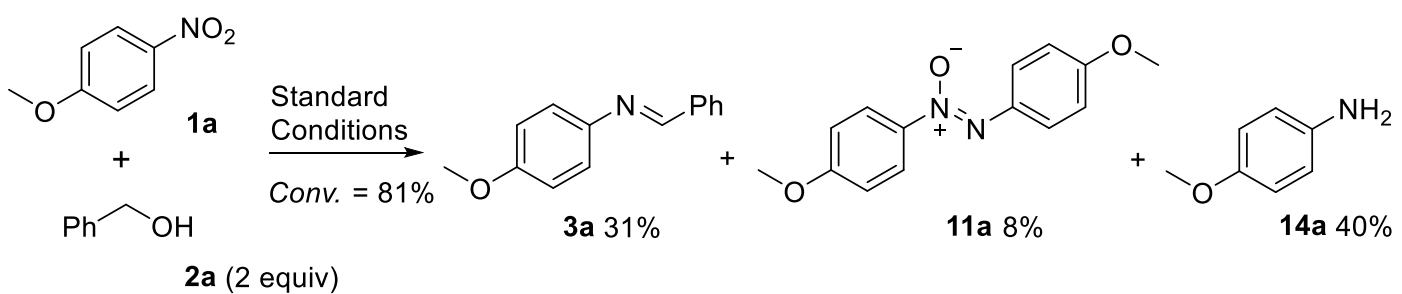

${ }^{a}$ Reaction conditions: 1a $(0.2 \mathrm{mmol}), \mathbf{2 a}$ (2 equiv.), [Fe] (5 mol\%), $\mathrm{Me}_{3} \mathrm{NO}(10 \mathrm{~mol} \%), \mathrm{K}_{3} \mathrm{PO}_{4} \cdot \mathrm{H}_{2} \mathrm{O}$ ( 3 equiv.), Toluene $(2 \mathrm{~mL}), 140^{\circ} \mathrm{C}, 20 \mathrm{~h}$, under argon atmosphere. Yields were determined by GCMS.

(b) Reaction ${ }^{a}$ of $\mathbf{1} \mathbf{k}$ with $\mathbf{2 a}$ under standard conditions<smiles>O=[N+]([O-])c1ccc(Br)cc1</smiles>

${ }^{a}$ Reaction conditions: $1 \mathbf{k}(0.5 \mathrm{mmol}), \mathbf{2 a}$ (4 equiv.), [Fe] (5 mol\%), $\mathrm{Me}_{3} \mathrm{NO}(10 \mathrm{~mol} \%), \mathrm{K}_{3} \mathrm{PO}_{4} \cdot \mathrm{H}_{2} \mathrm{O}$ (3 equiv.), Toluene $(2 \mathrm{~mL}), 140{ }^{\circ} \mathrm{C}, 20 \mathrm{~h}$, under Argon atmosphere. ${ }^{b}$ Yields were determined by ${ }^{1} \mathrm{H}$ NMR using $\mathrm{CH}_{2} \mathrm{Br}_{2}$ as an internal standard. ${ }^{c}$ Yield.

1,2-Bis(4-bromophenyl)diazene $\mathbf{1 2} \mathbf{k} .{ }^{1}$ From the mixture $\mathbf{3} \mathbf{k}+\mathbf{1 2 k}$, $\mathbf{1 2 k}$ was purified by neutral alumina column chromatography using a mixture of ethyl acetate and heptane (1:20) as eluent. Yellow solid (17 mg, 10\%). ${ }^{1} \mathbf{H}$ NMR $\left(400 \mathrm{MHz}, \mathrm{CDCl}_{3}\right) \delta 7.79(\mathrm{~d}, J=8.3 \mathrm{~Hz}, 4 \mathrm{H}), 7.65$ (d, $J=$ $8.3 \mathrm{~Hz}, 4 \mathrm{H}) .{ }^{13} \mathbf{C}\{\mathbf{1 H}\} \mathbf{N M R}\left(101 \mathrm{MHz}, \mathrm{CDCl}_{3}\right) \delta 151.3,132.6,125.9,124.6 . \mathbf{G C}-\mathbf{M S} \mathrm{m} / \mathrm{z}(\%)=$ $340(\mathrm{M}+, 20), 183$ (45), 155 (100), 90 (10), 76 (95), 63 (20), 50 (55). 


\section{5) Reference}

(1) Yan, Z.; Xie, X.; Song, Q.; Ma, F.; Sui, X.; Huo, Z.; Ma, M. Tandem selective reduction of nitroarenes catalyzed by palladium nanoclusters. Green Chem. 2020, 22, 1301. 


\section{6) NMR spectra}

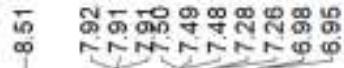<smiles>COc1ccc(/N=C/c2ccccc2)cc1</smiles>
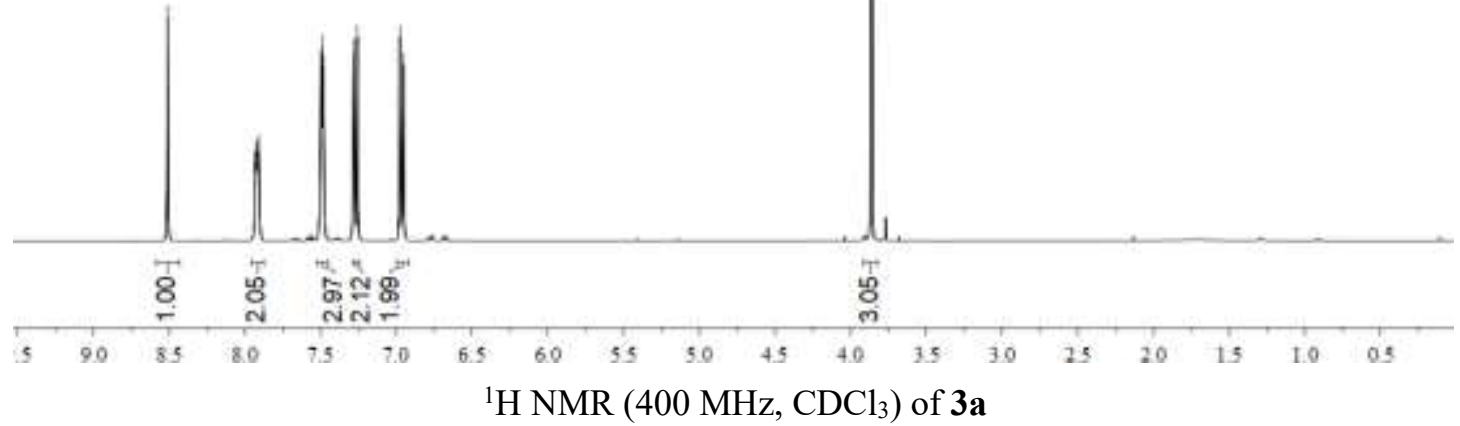

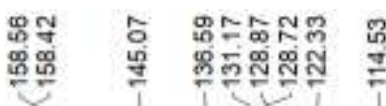

急怘

FFP

త
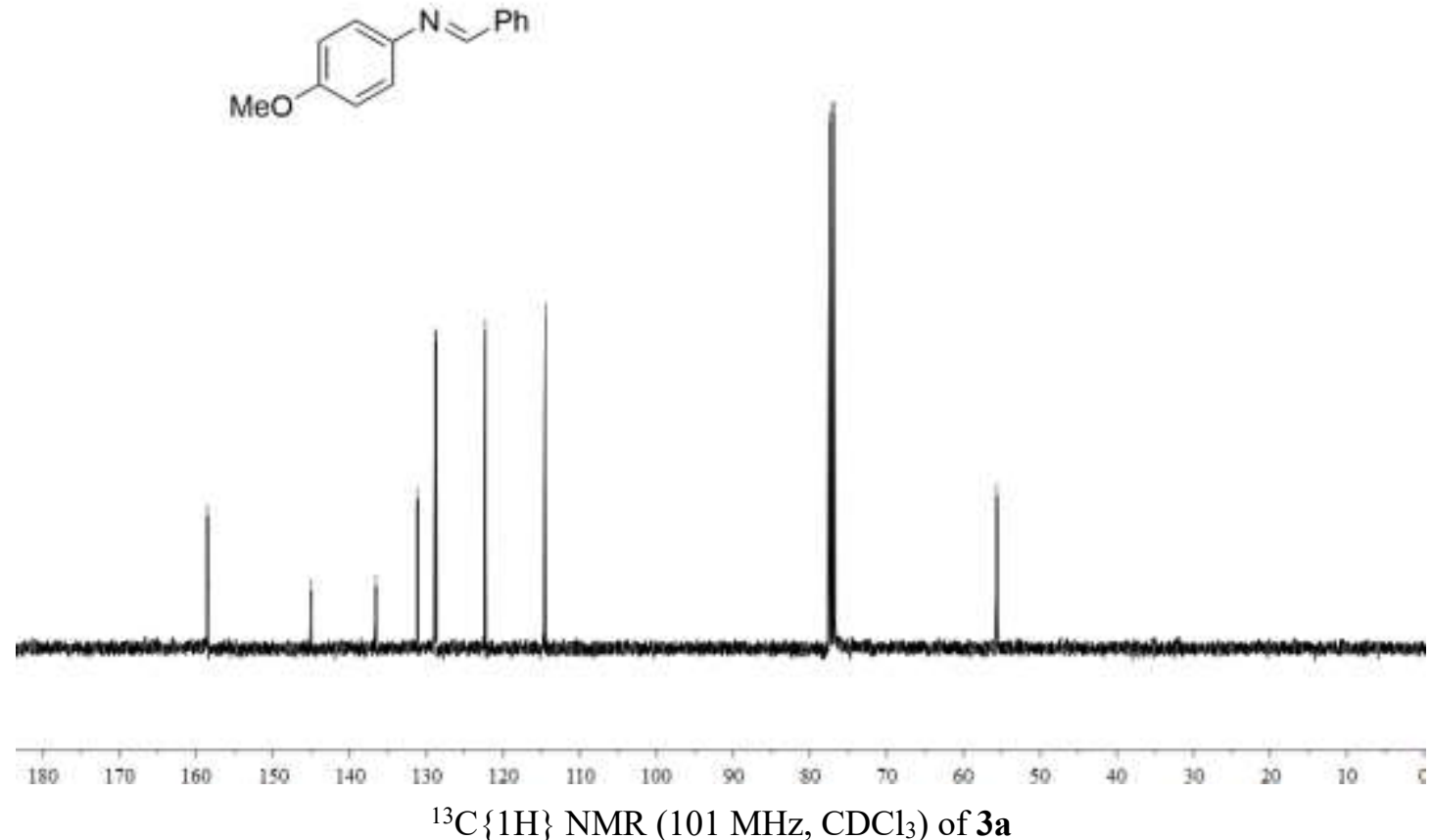

${ }^{13} \mathrm{C}\{1 \mathrm{H}\}$ NMR $\left(101 \mathrm{MHz}, \mathrm{CDCl}_{3}\right)$ of $\mathbf{3 a}$ 

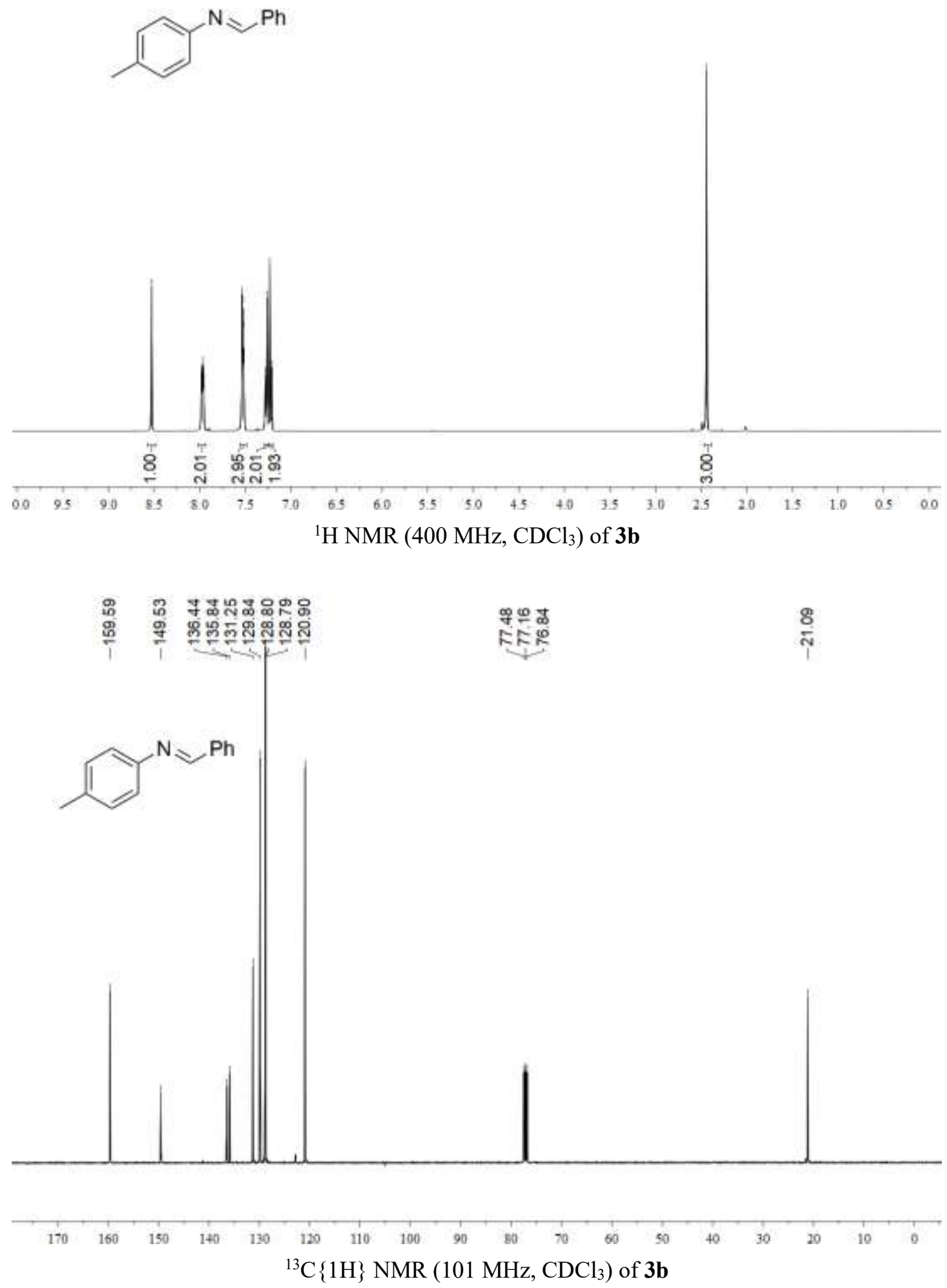


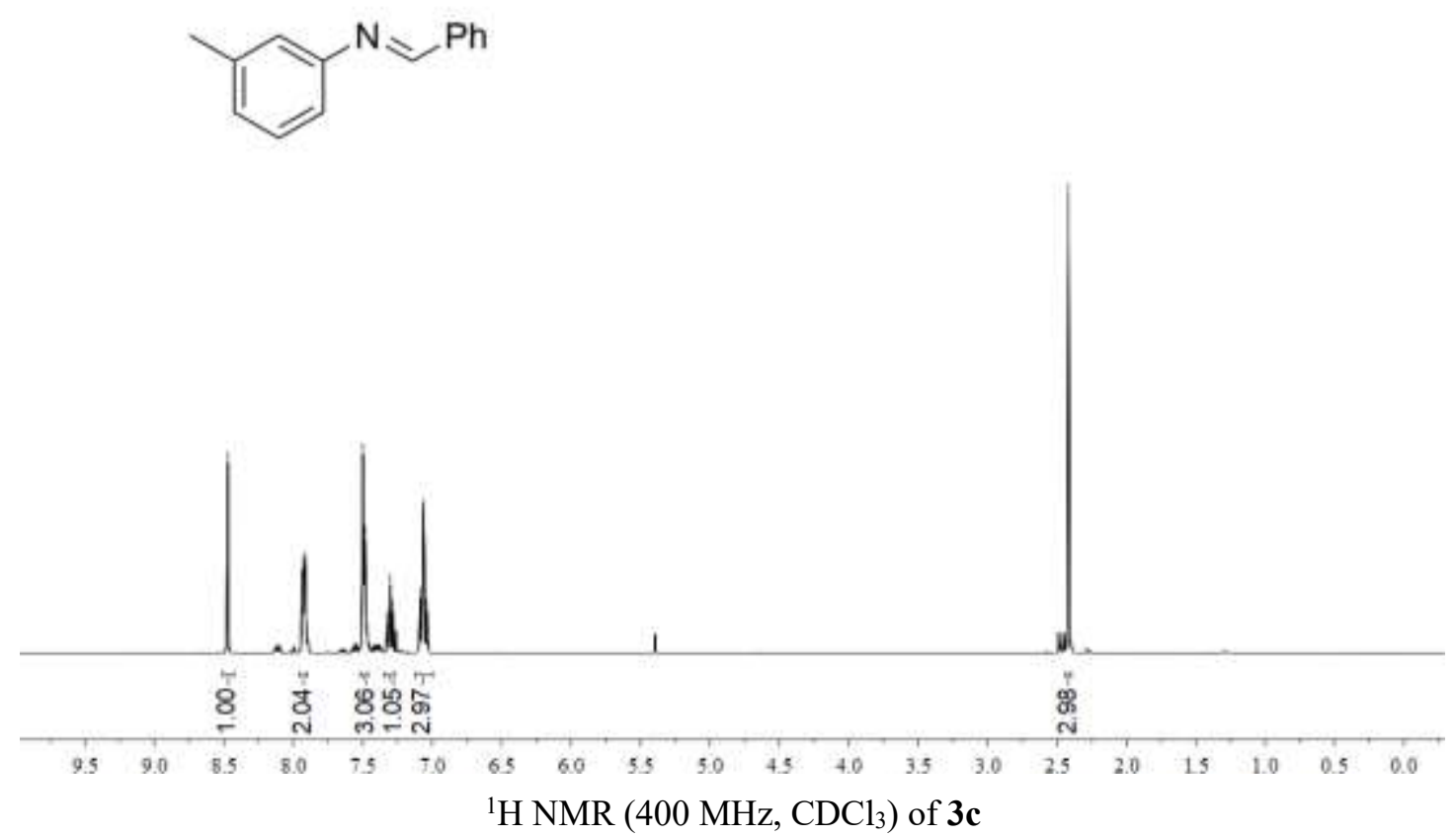

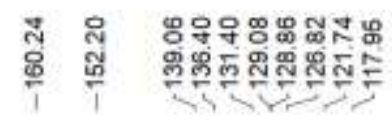

骂鱼声

FFE

$\stackrel{\frac{\pi}{4}}{\frac{7}{1}}$<smiles>Cc1cccc(/N=C/c2ccccc2)c1</smiles>
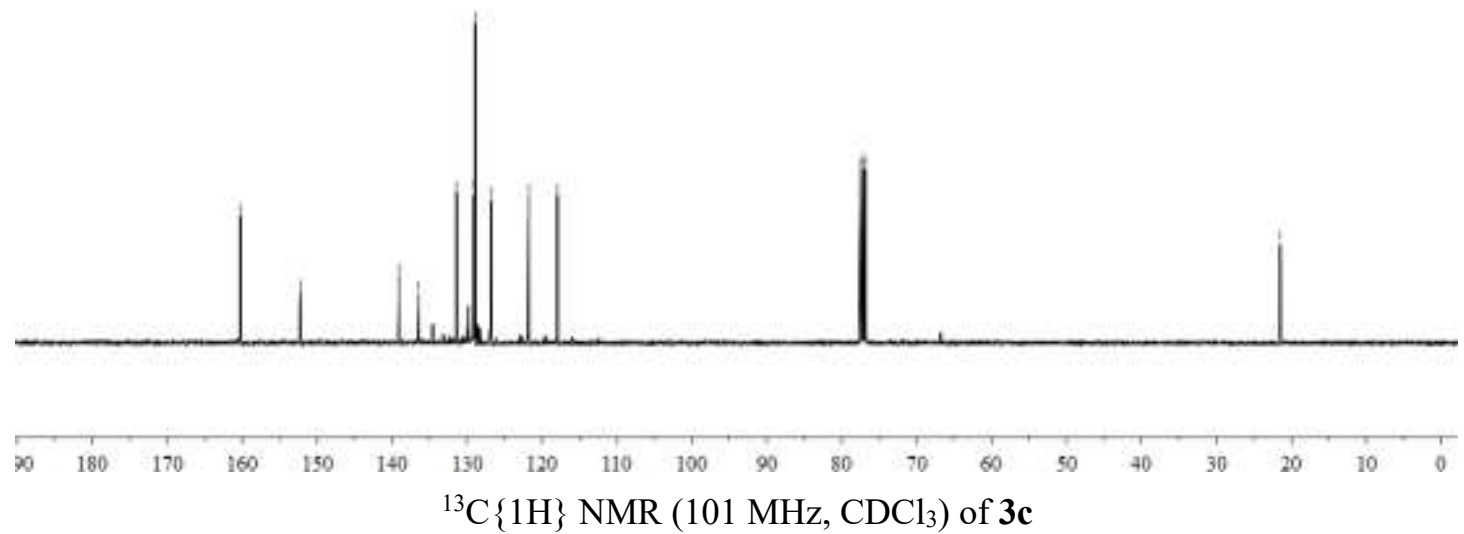

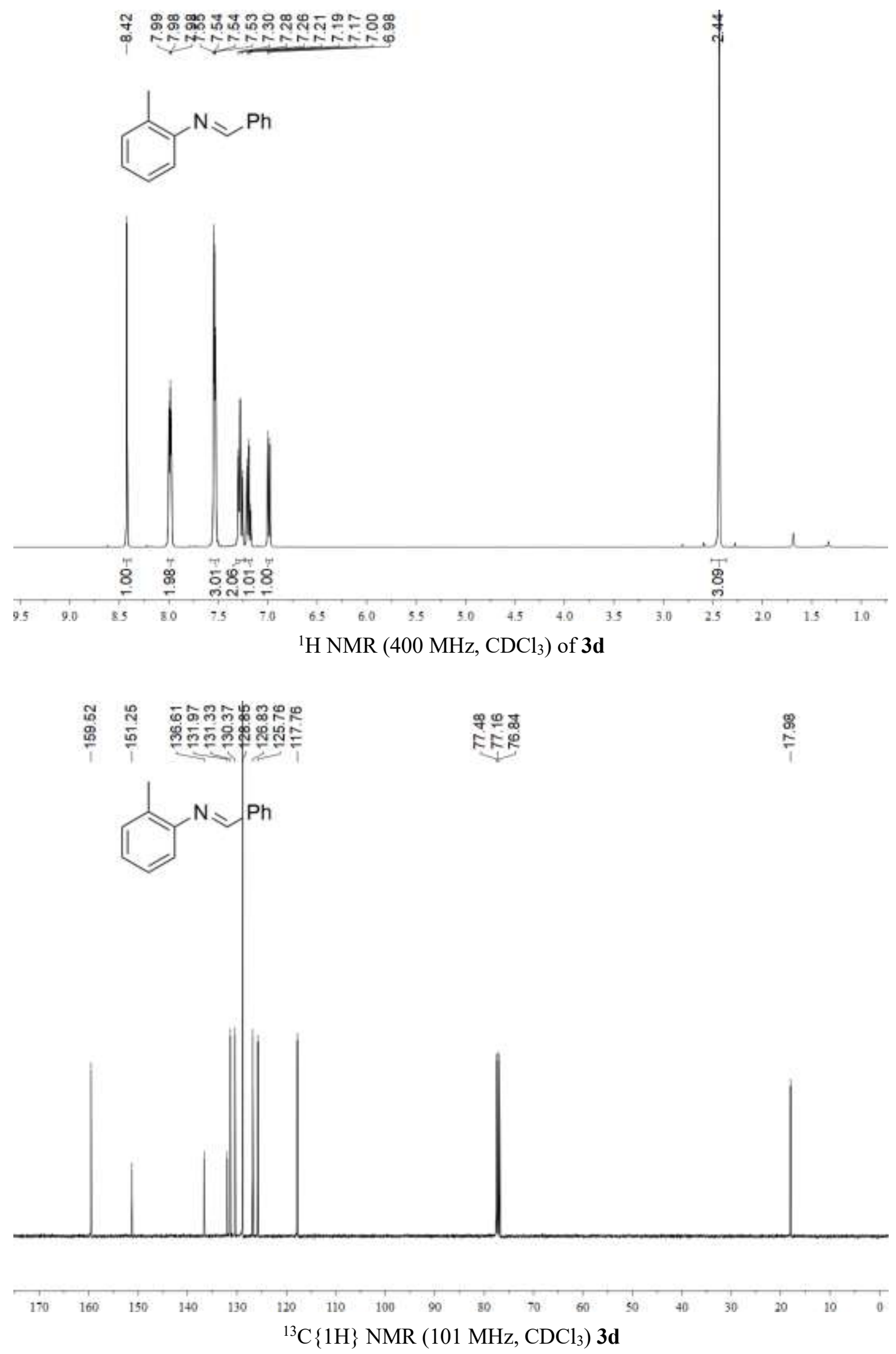
$\curvearrowright \mathrm{N} \approx \mathrm{Ph}$

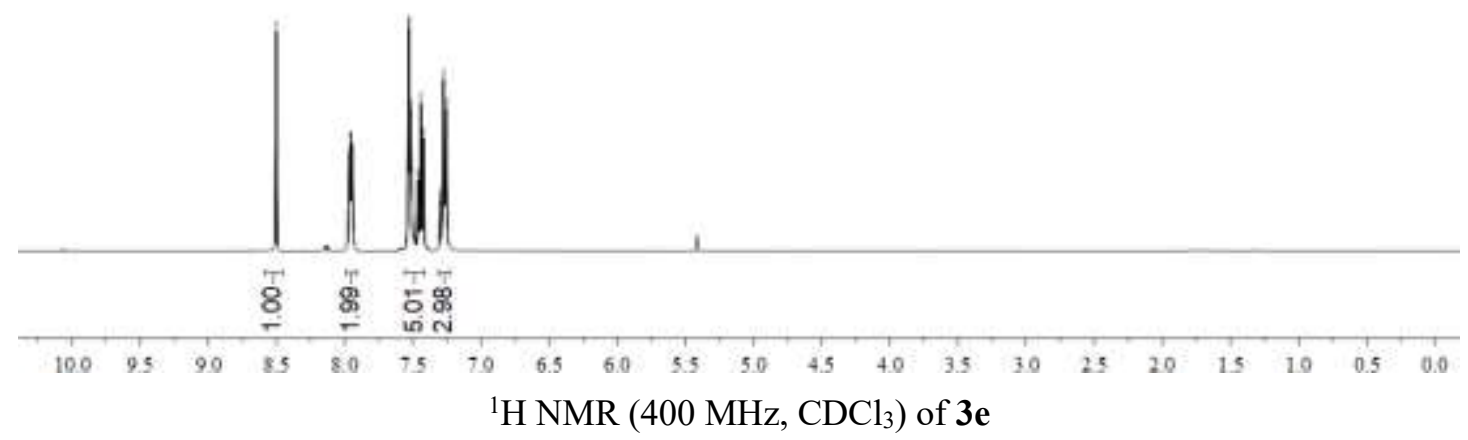

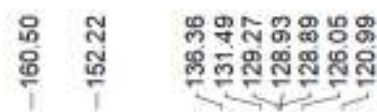

タุツま

ERE<smiles>C(=N/c1ccccc1)\c1ccccc1</smiles>

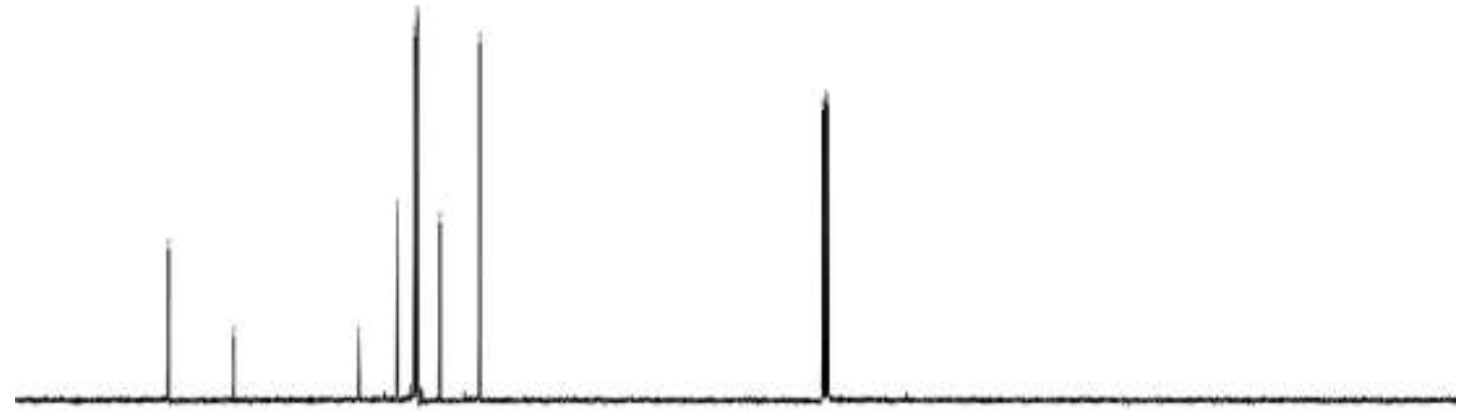

170

130

${ }^{13} \mathrm{C}\{1 \mathrm{H}\} \mathrm{NMR}\left(101 \mathrm{MHz}, \mathrm{CDCl}_{3}\right)$ of $\mathbf{3 e}$ 
<smiles>c1ccc(-c2ccccc2)cc1</smiles>

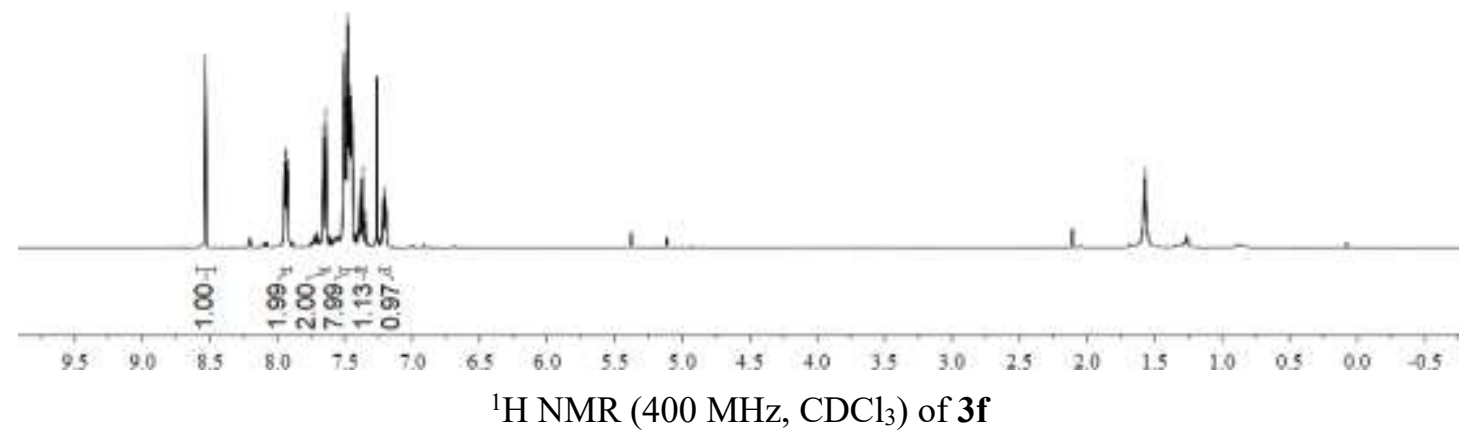

ฌ

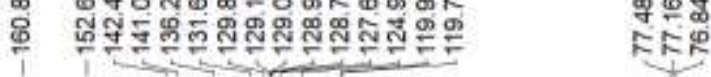

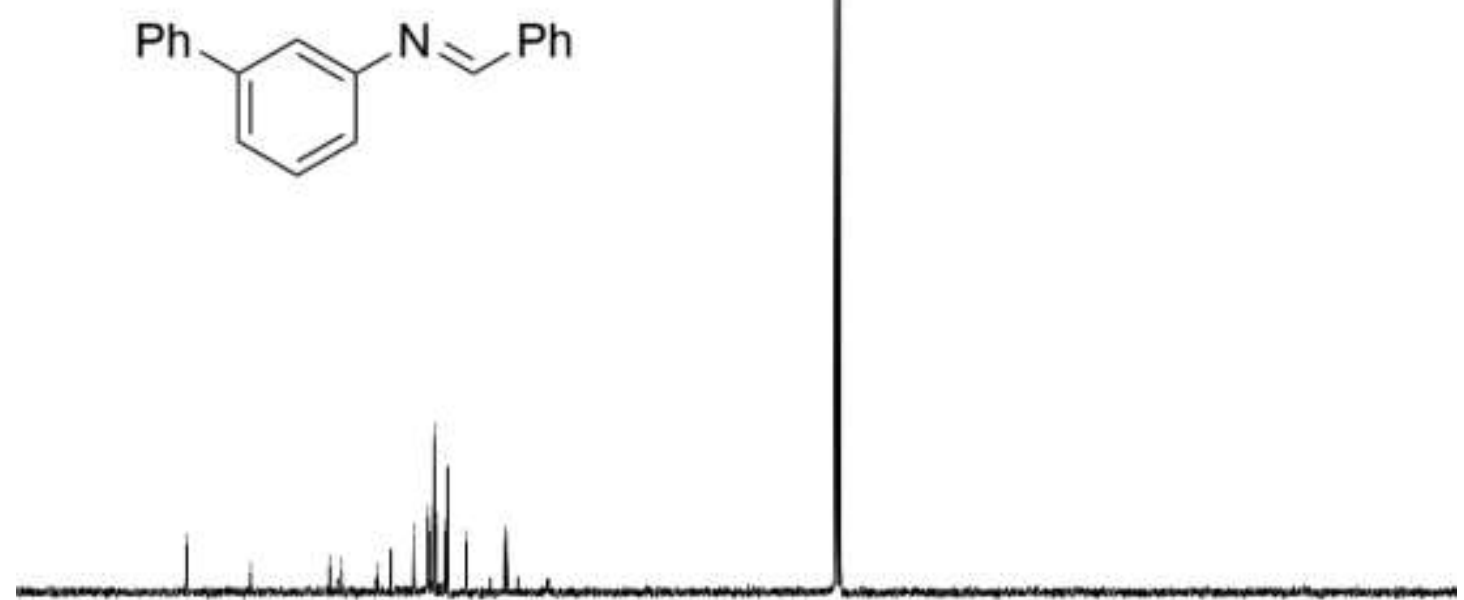

$180 \quad 170 \quad 160 \quad 150 \quad 140 \quad 1$ ${ }^{13} \mathrm{C}\{1 \mathrm{H}\}$ NMR $\left(101 \mathrm{MHz}, \mathrm{CDCl}_{3}\right)$ of $\mathbf{3 f}$ 


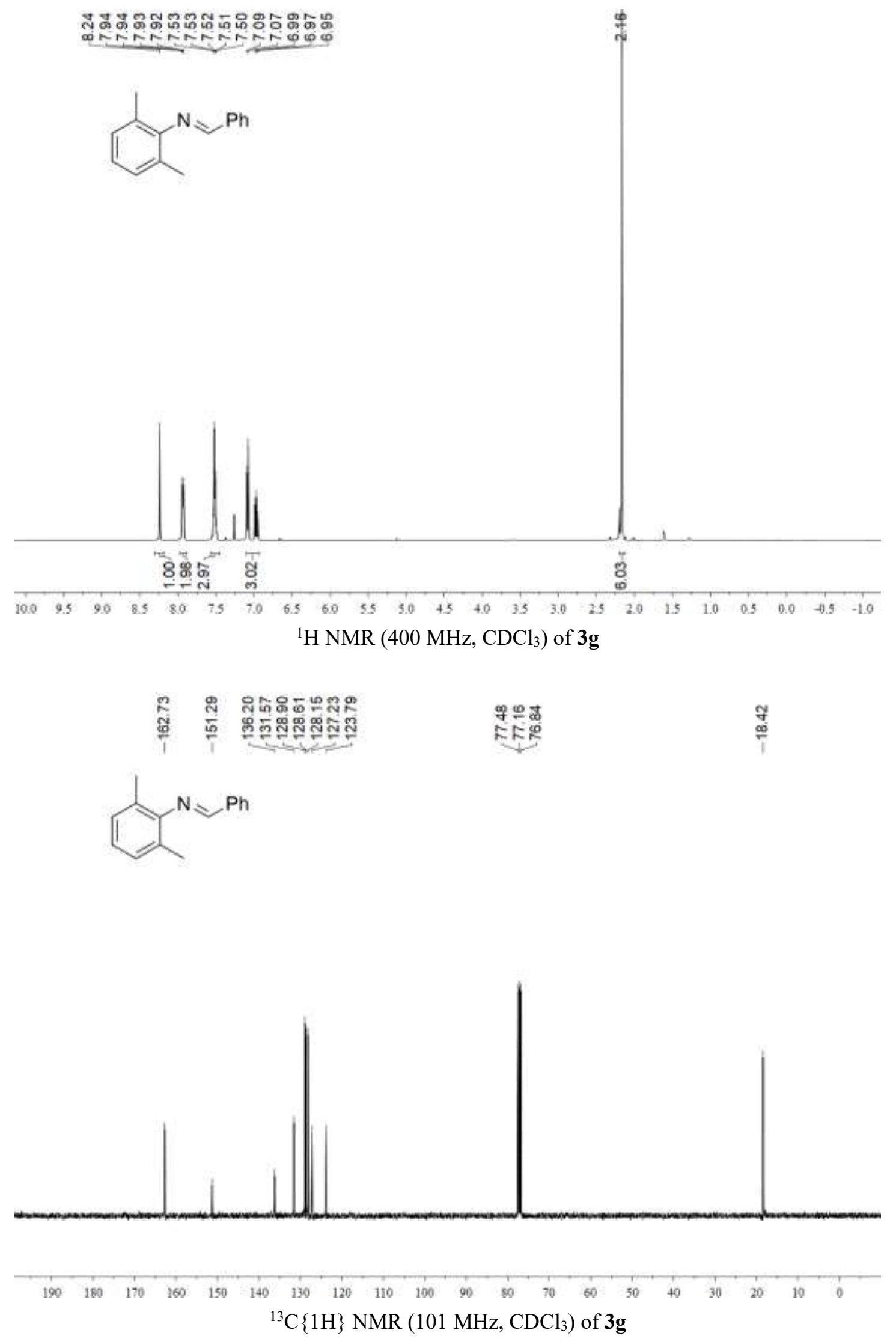




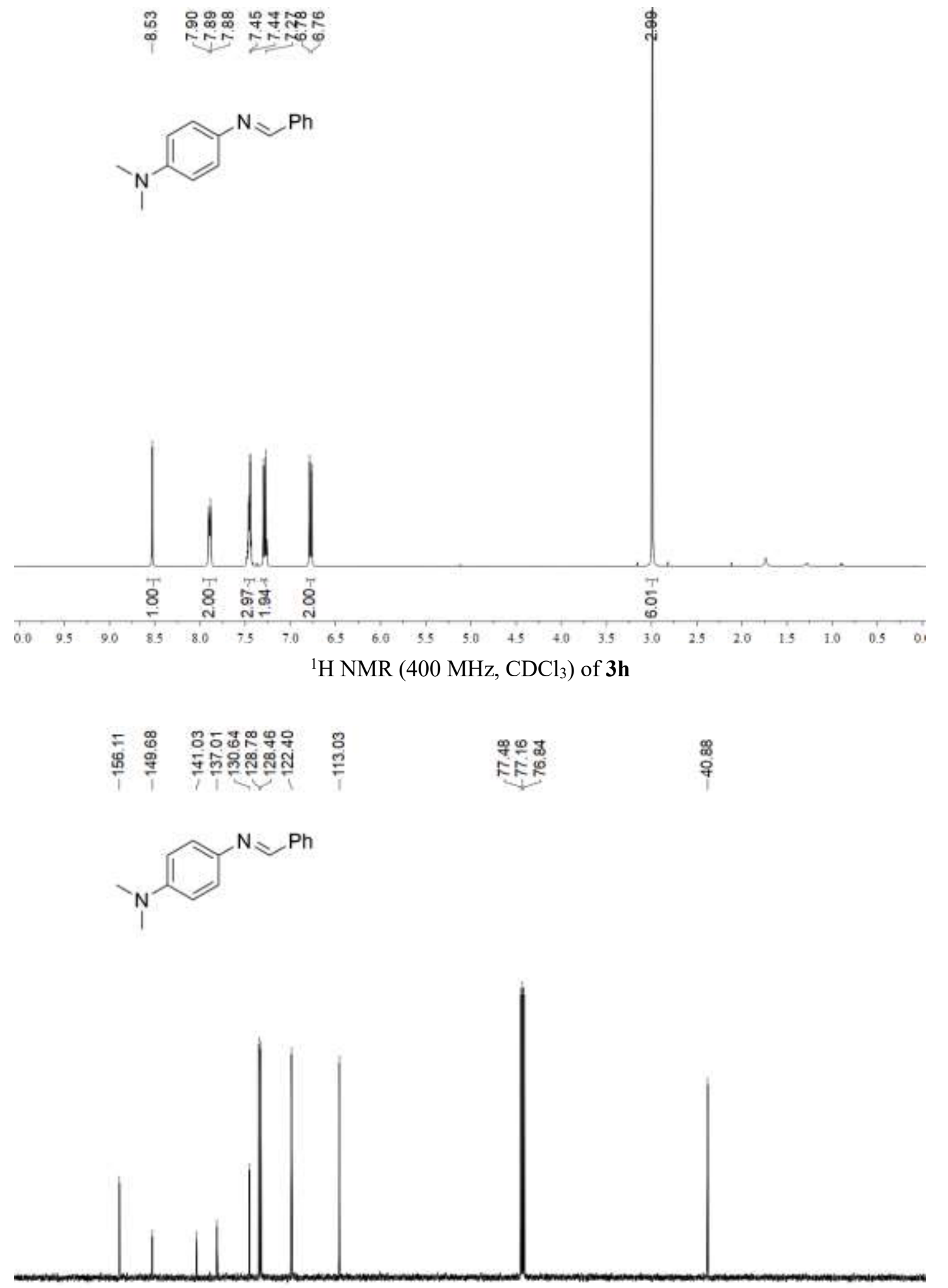

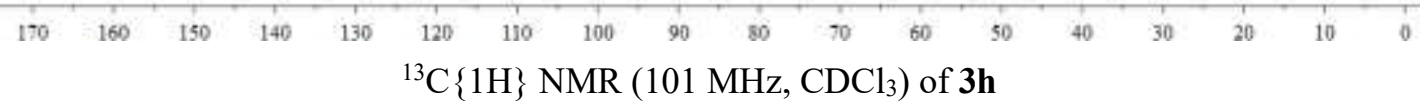


<smiles>Fc1ccc(/N=C/c2ccccc2)cc1</smiles>

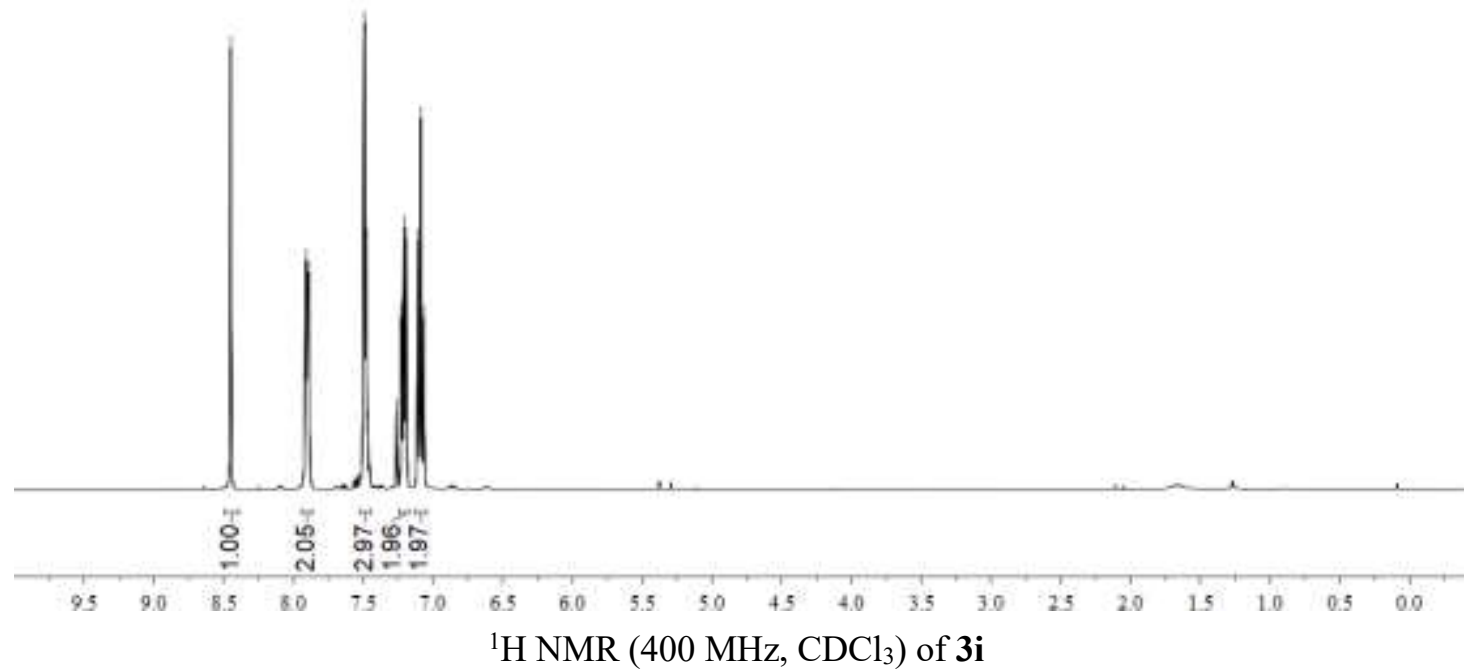

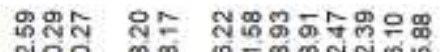

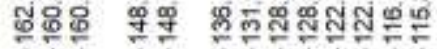

gृㅀ

T -7 -

FFi<smiles>Fc1ccc(/N=C/c2ccccc2)cc1</smiles>

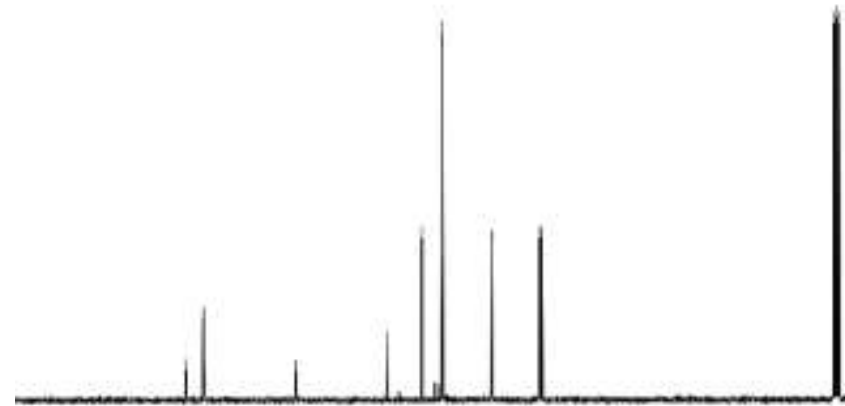

1

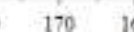

$150 \quad 140 \quad 130$

${ }^{13} \mathrm{C}\{1 \mathrm{H}\}$ NMR $\left(101 \mathrm{MHz}, \mathrm{CDCl}_{3}\right)$ of $\mathbf{3 i}$ 


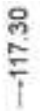<smiles>Fc1ccc(/N=C/c2ccccc2)cc1</smiles>

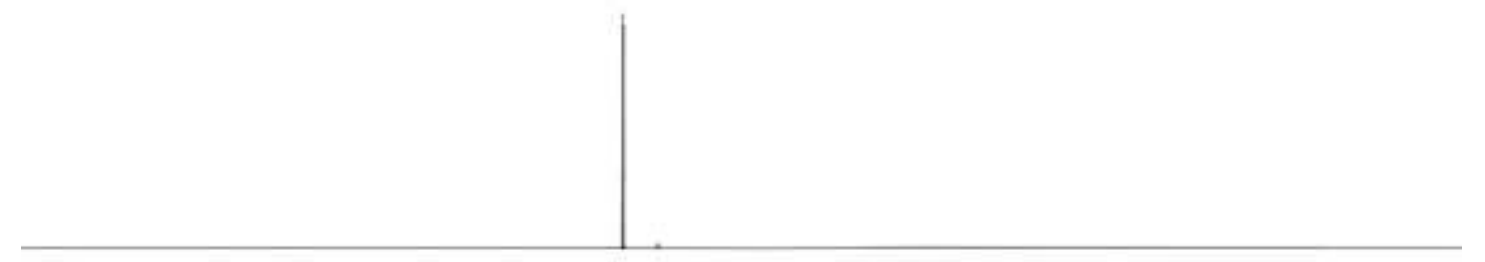

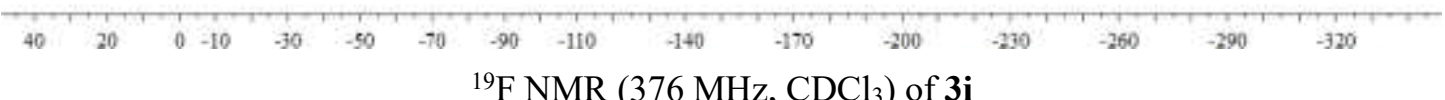

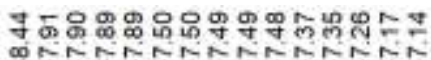

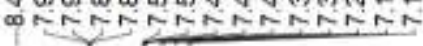<smiles>Clc1ccc(/N=C/c2ccccc2)cc1</smiles>

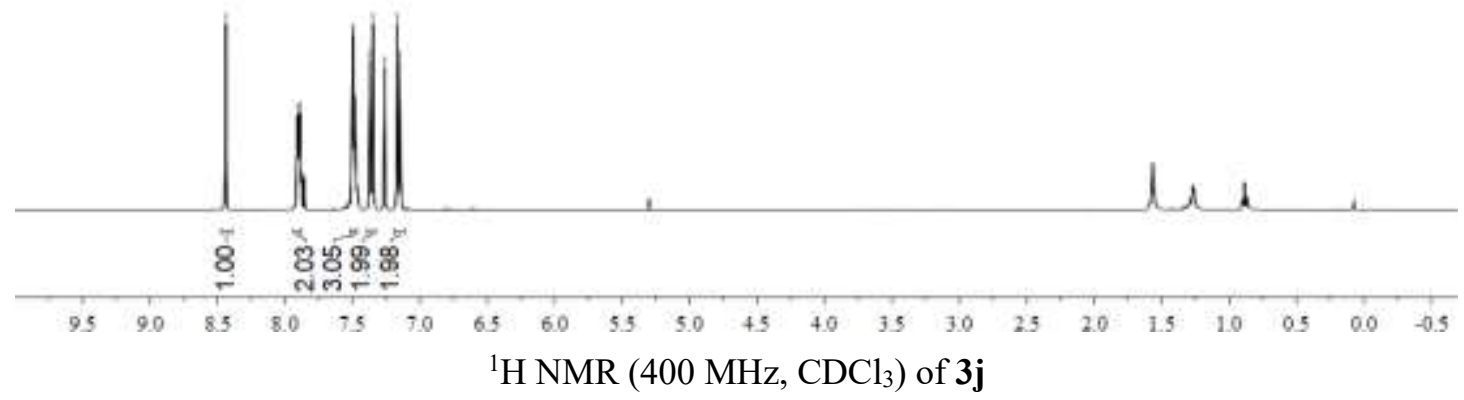



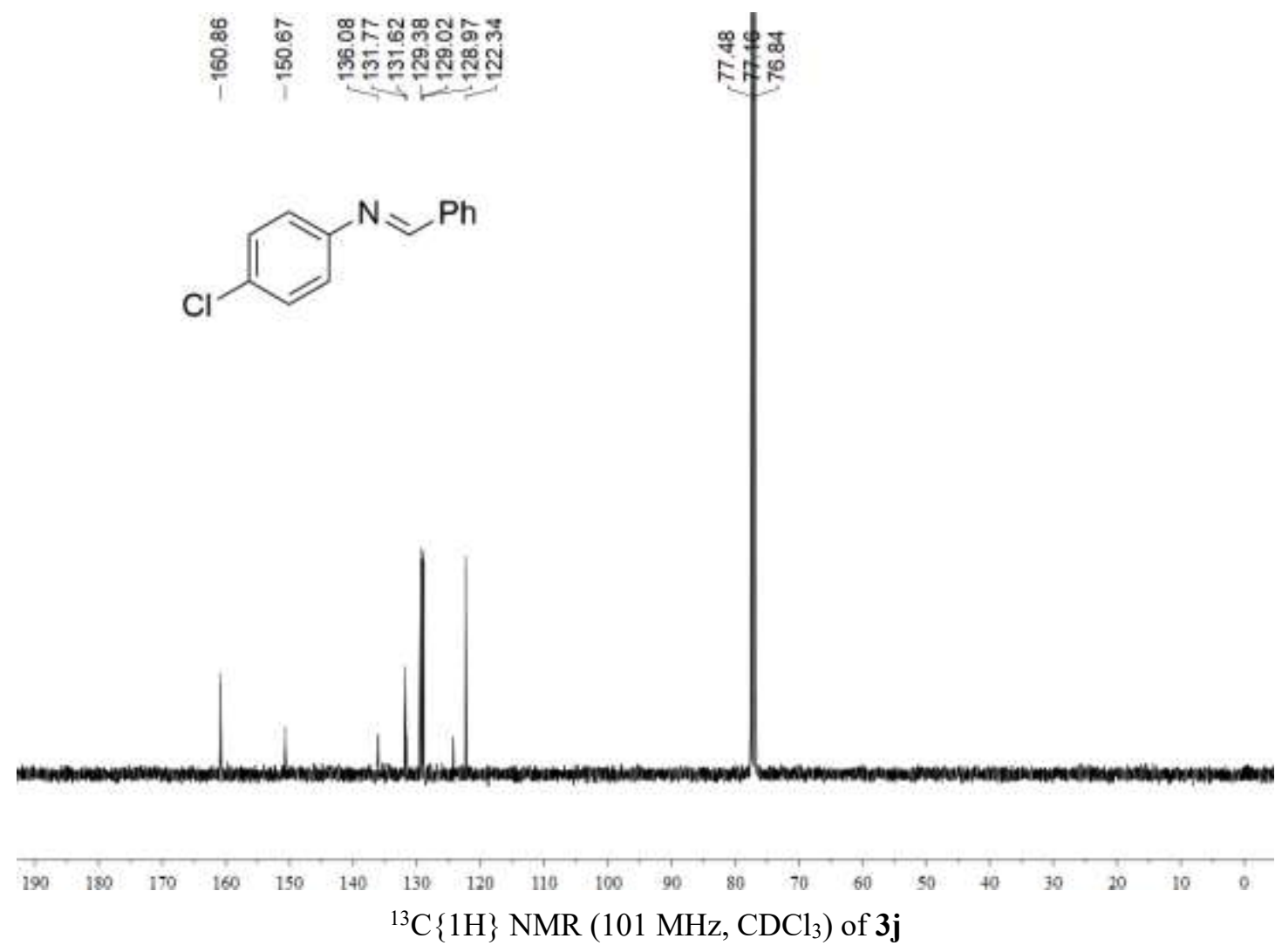

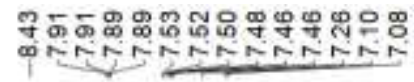<smiles>Brc1ccc(/N=C/c2ccccc2)cc1</smiles>

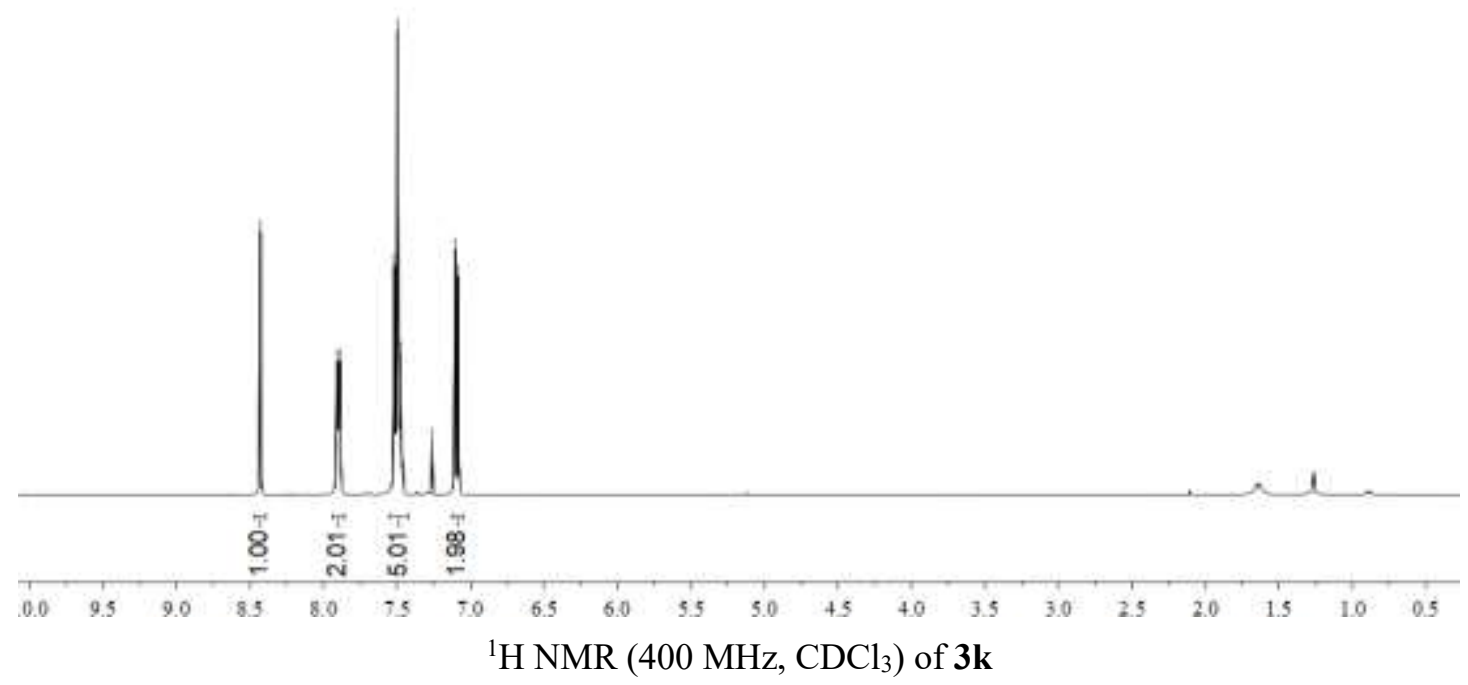


<smiles>Brc1ccc(/N=C/c2ccccc2)cc1</smiles>
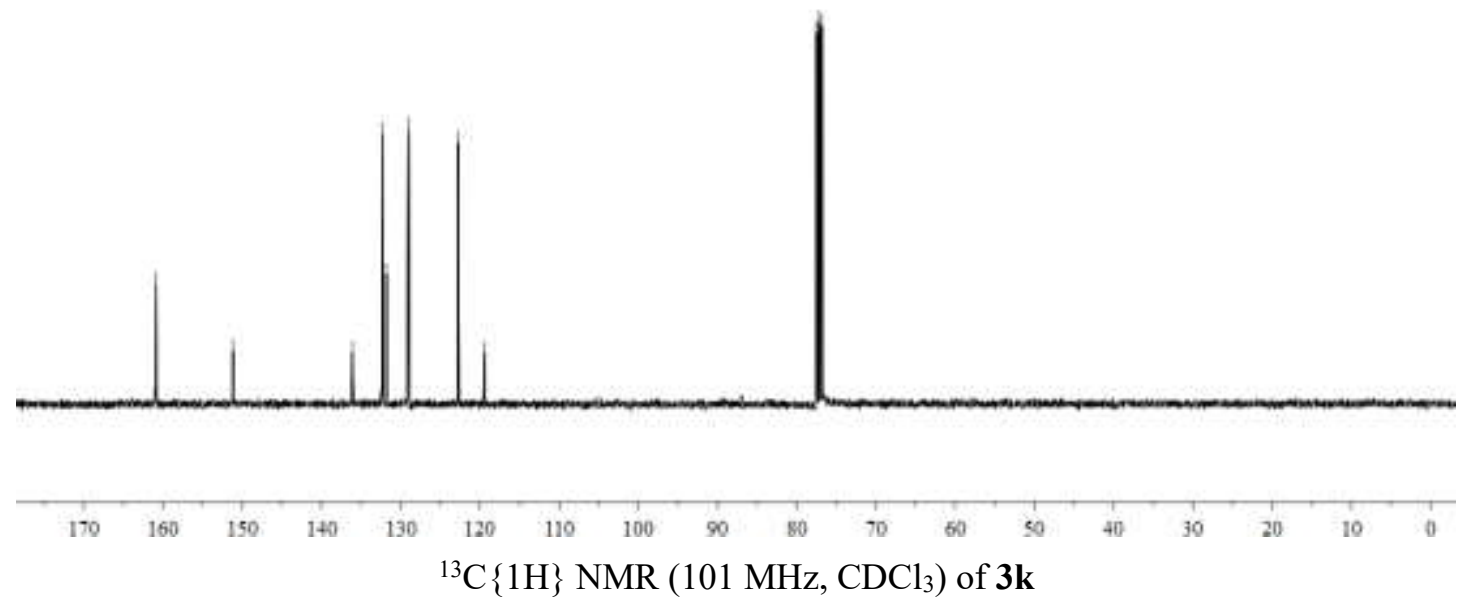

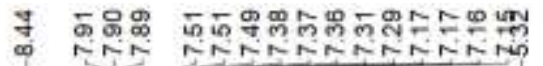

Br $\rightleftharpoons \mathrm{N} \approx P$

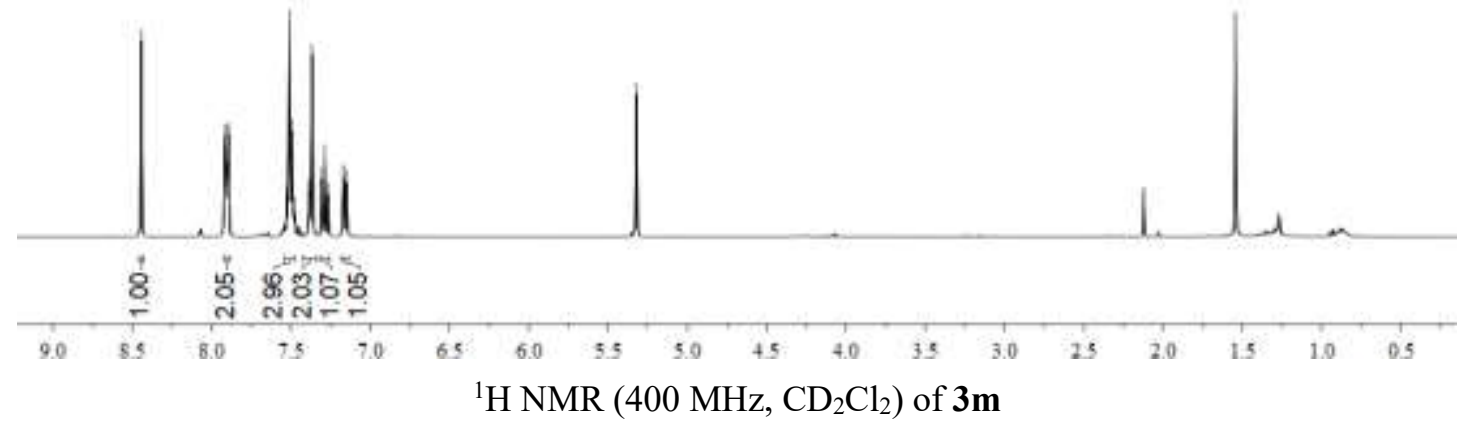




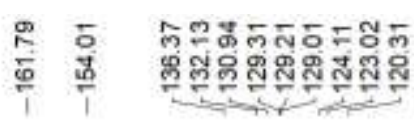

$9=\$$ 的里

Br $\mathrm{N} \approx \mathrm{Ph}$
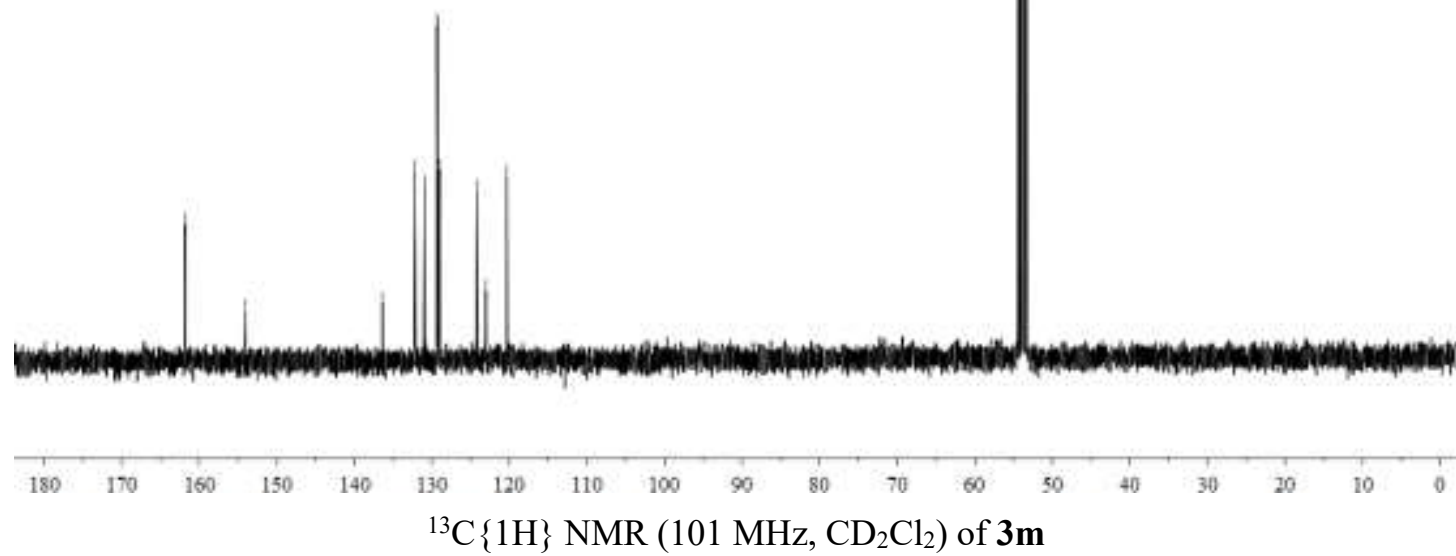

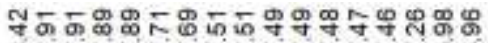

DNATNRANRNANNAOO<smiles>Ic1ccc(/N=C/c2ccccc2)cc1</smiles>

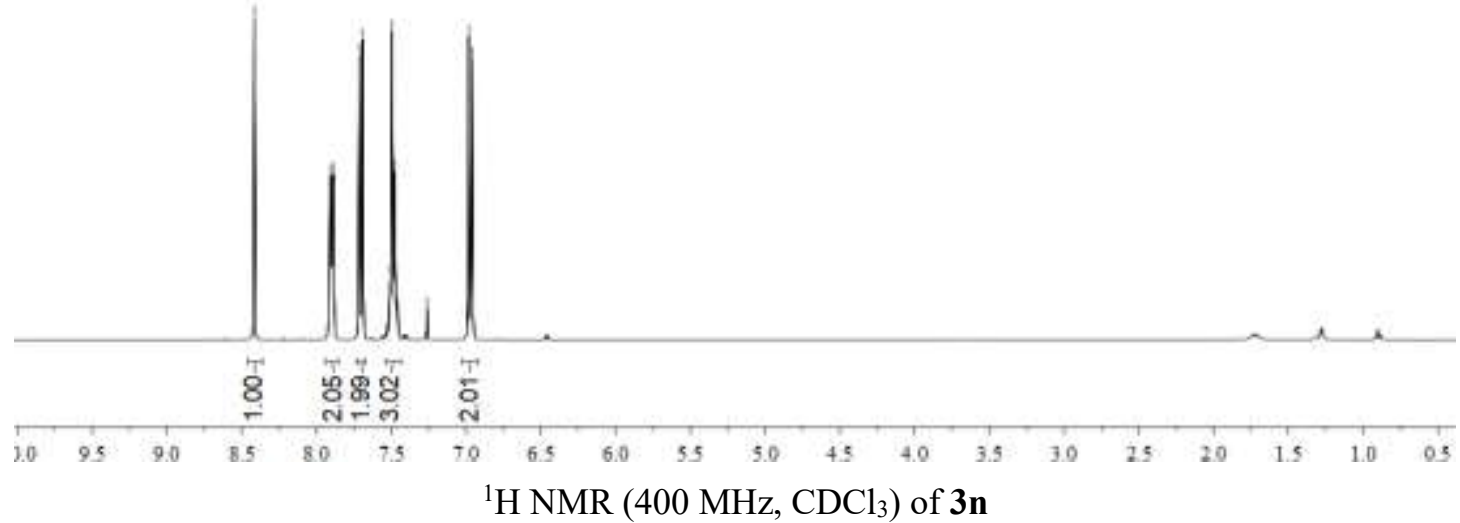




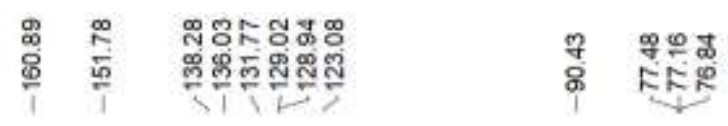<smiles>Ic1ccc(/N=C/c2ccccc2)cc1</smiles>
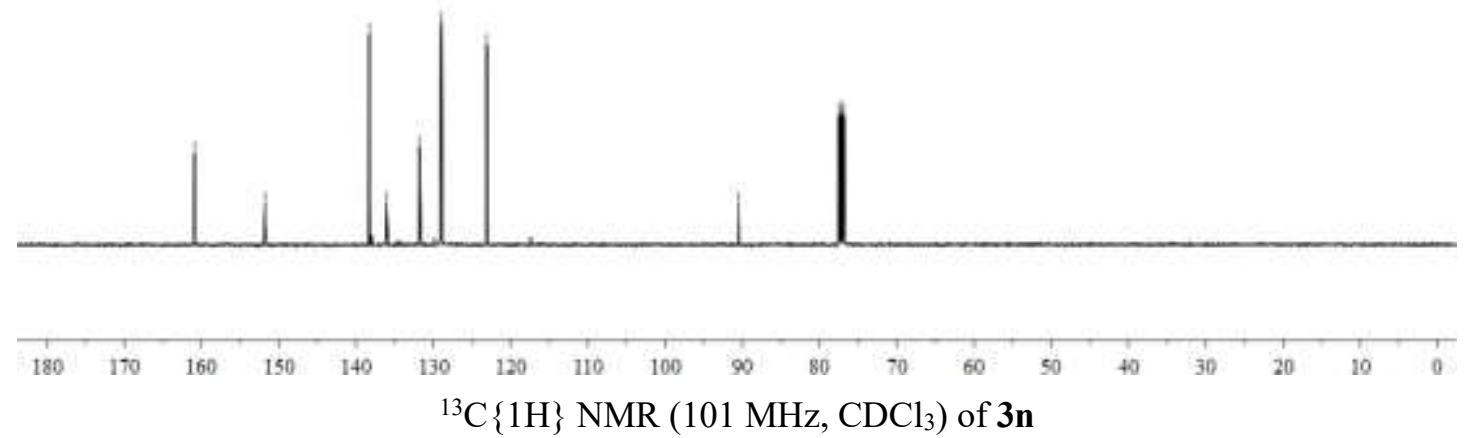

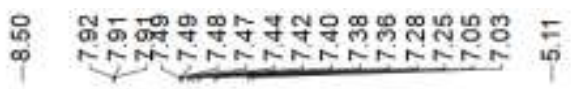<smiles>C(=Nc1ccc(OCc2ccccc2)cc1)c1ccccc1</smiles>

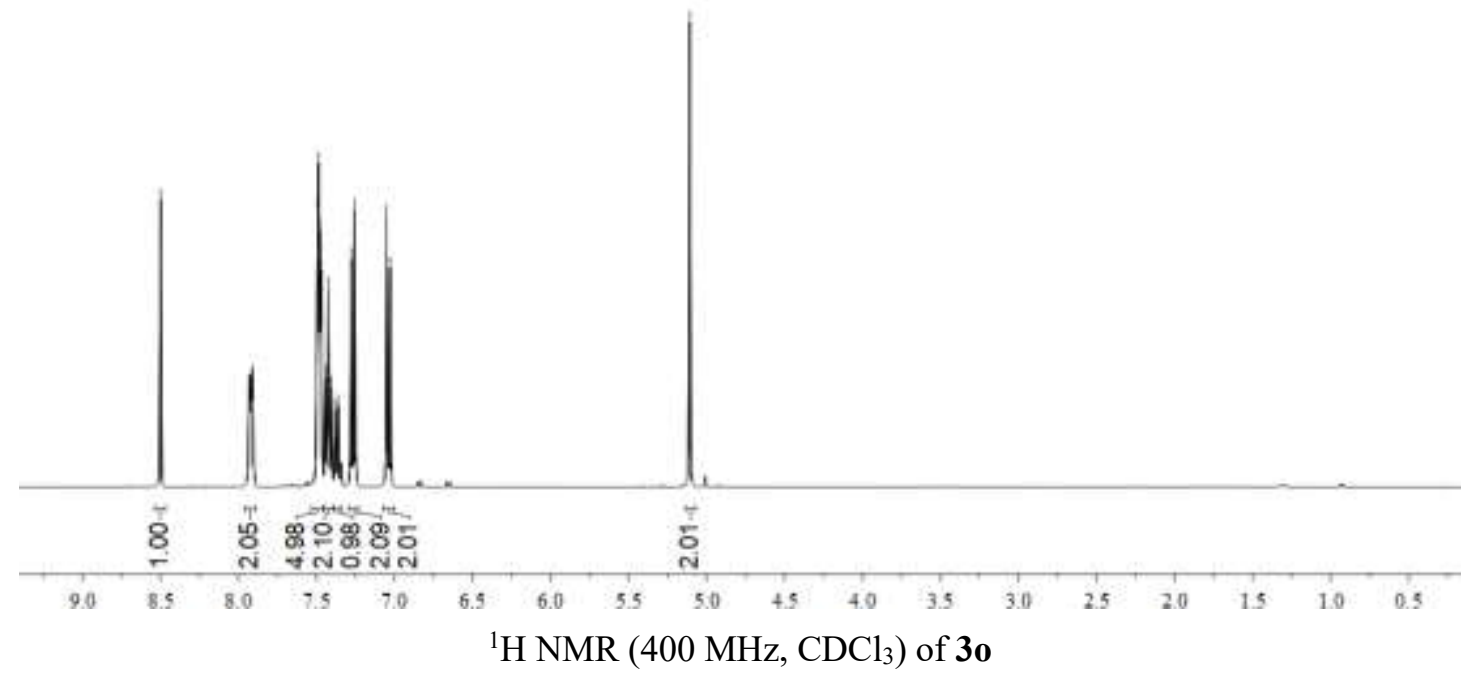



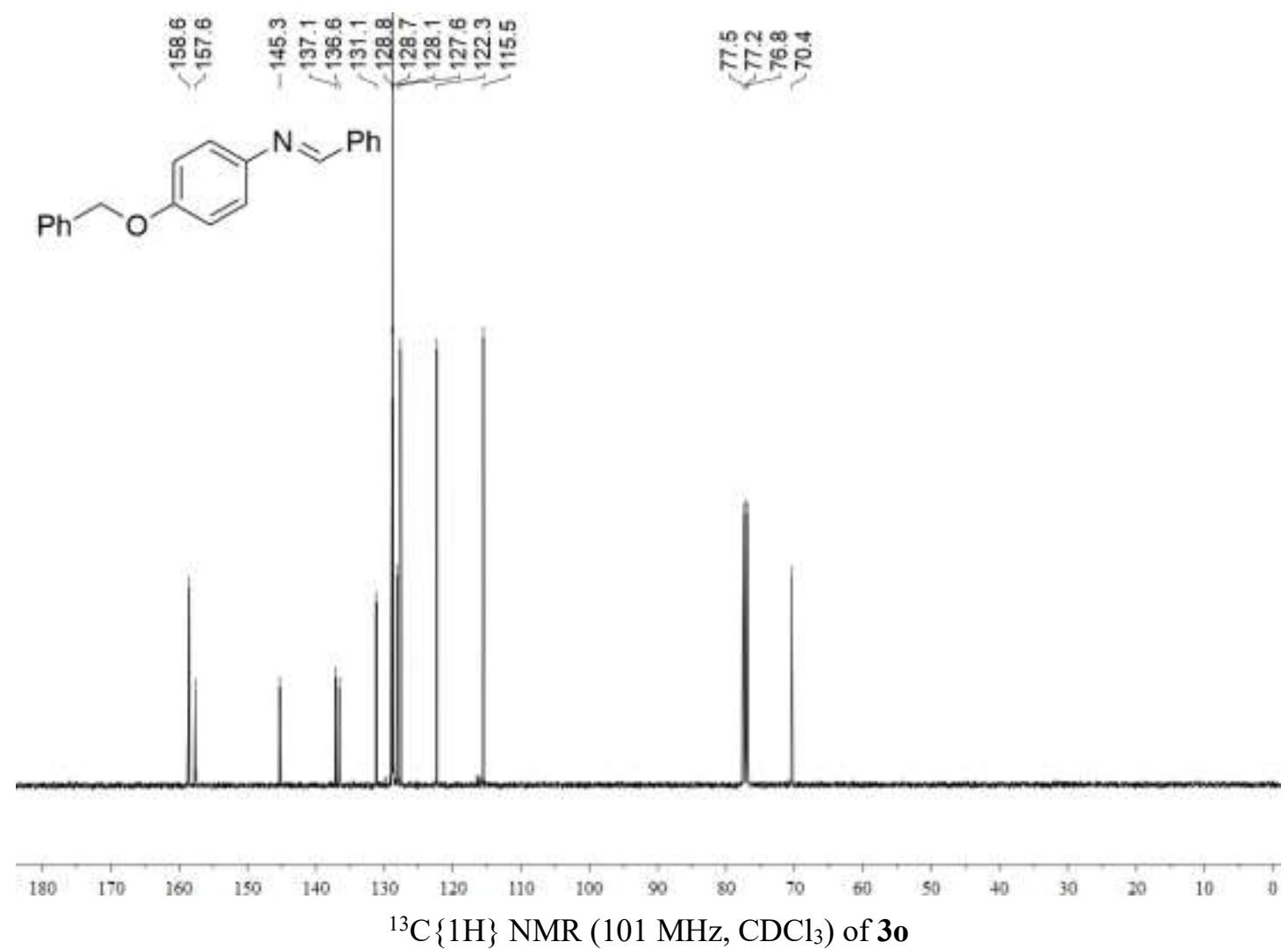

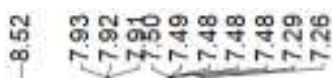

${ }_{\mathrm{Ph}} \approx_{\mathrm{N}} \approx \mathrm{Ph}$

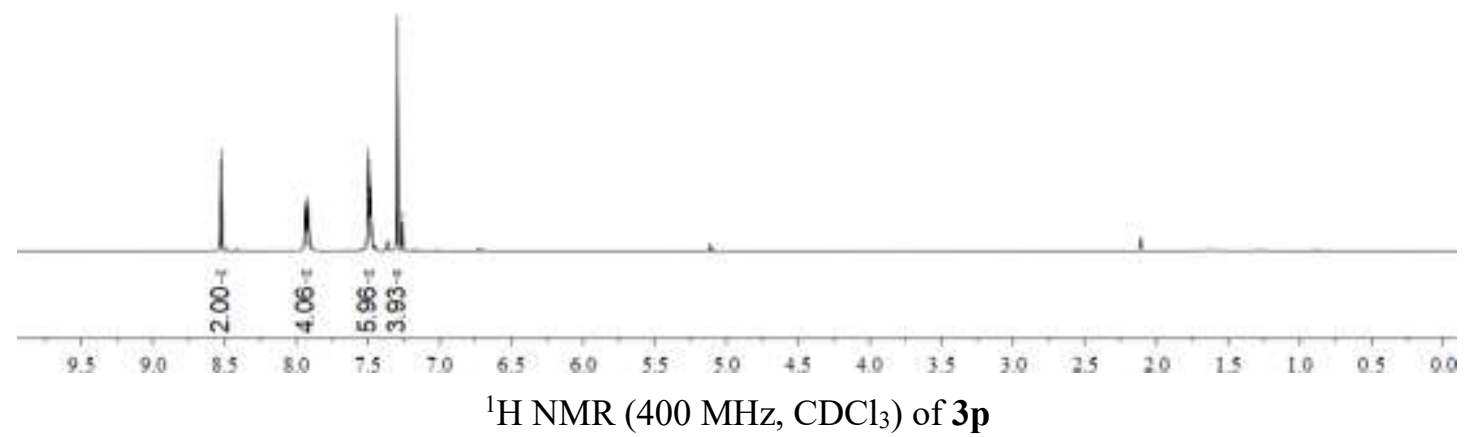


<smiles>C(=N/c1ccc(/N=C/c2ccccc2)cc1)\c1ccccc1</smiles>
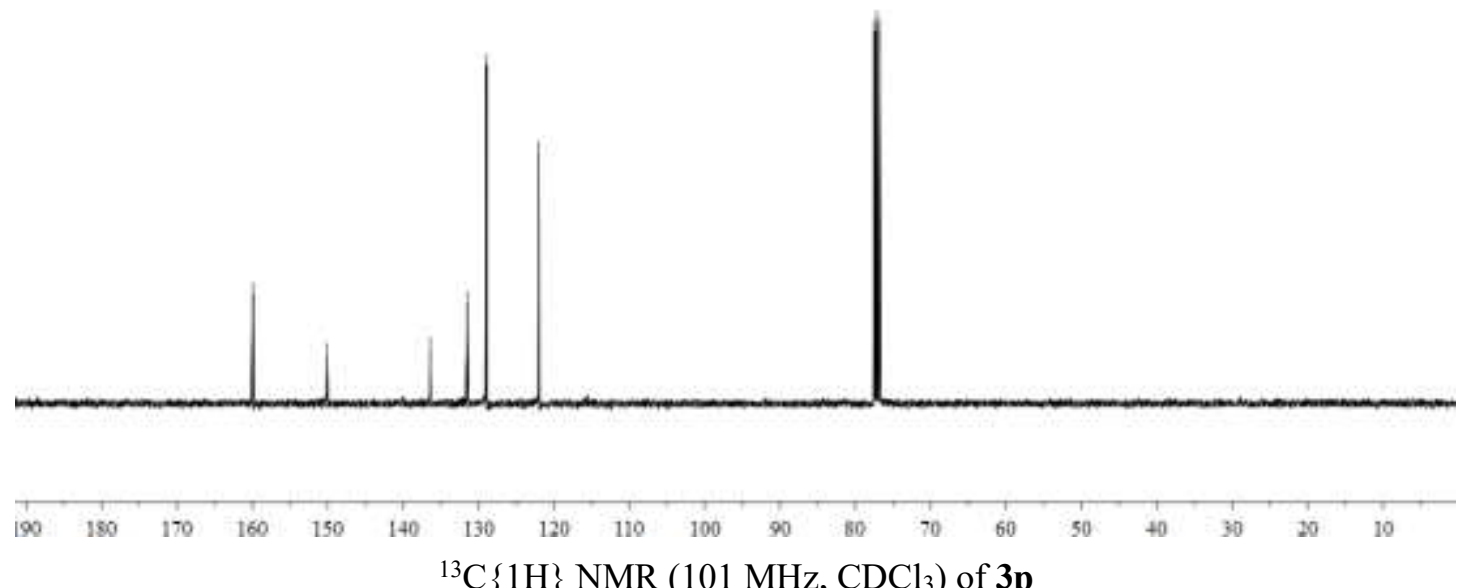

${ }^{13} \mathrm{C}\{1 \mathrm{H}\} \mathrm{NMR}\left(101 \mathrm{MHz}, \mathrm{CDCl}_{3}\right)$ of $\mathbf{3 p}$

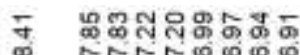

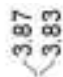<smiles>COc1ccc(/C=N/c2ccc(OC)cc2)cc1</smiles>

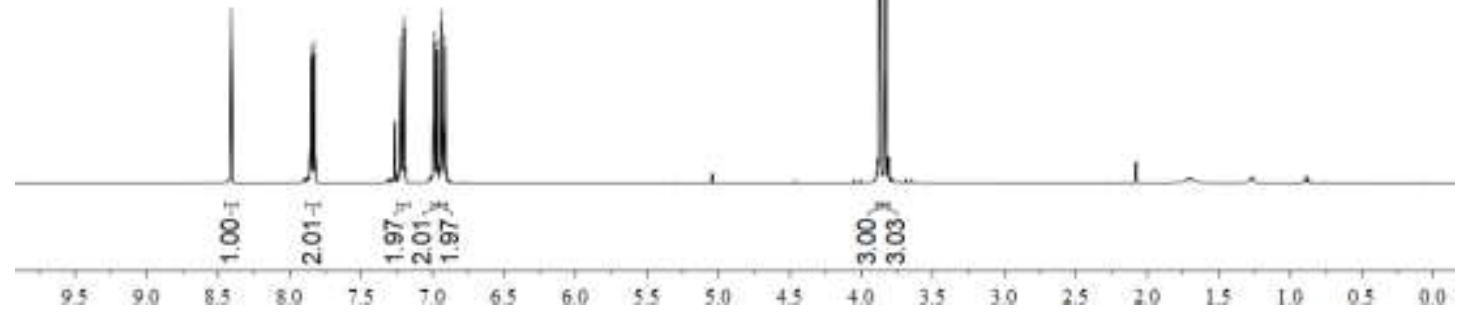

${ }^{1} \mathrm{H}$ NMR $\left(400 \mathrm{MHz}, \mathrm{CDCl}_{3}\right)$ of $\mathbf{3 q}$ 
<smiles>COc1ccc(/C=N/c2ccc(OC)cc2)cc1</smiles>

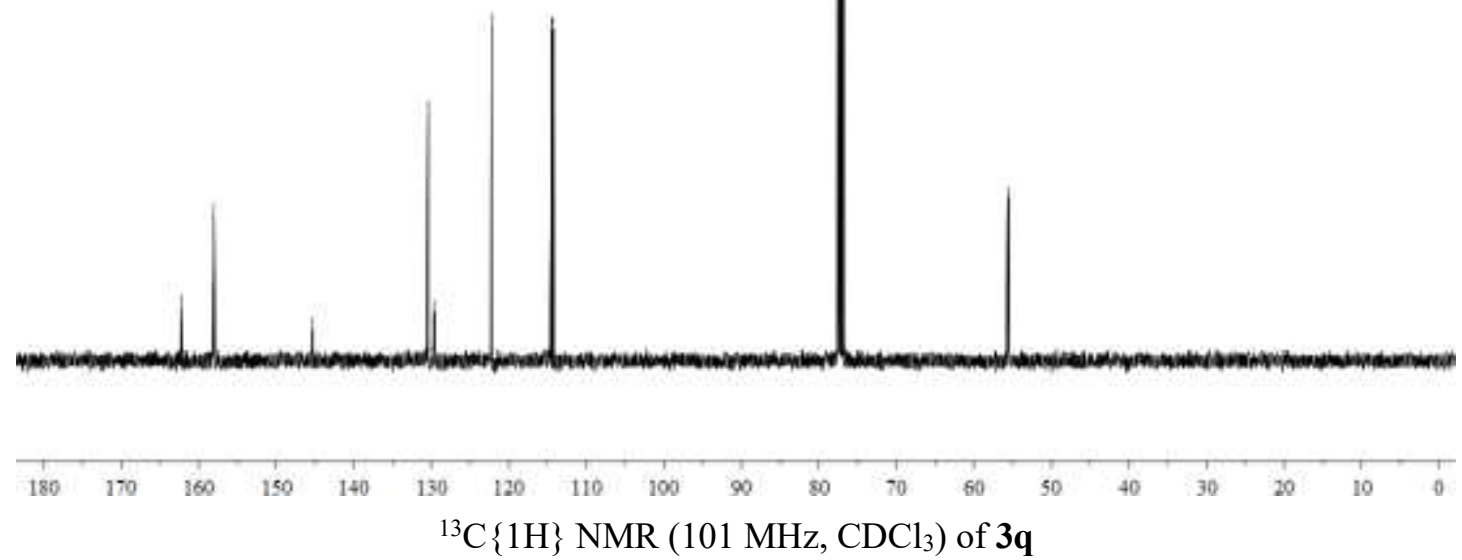

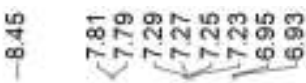

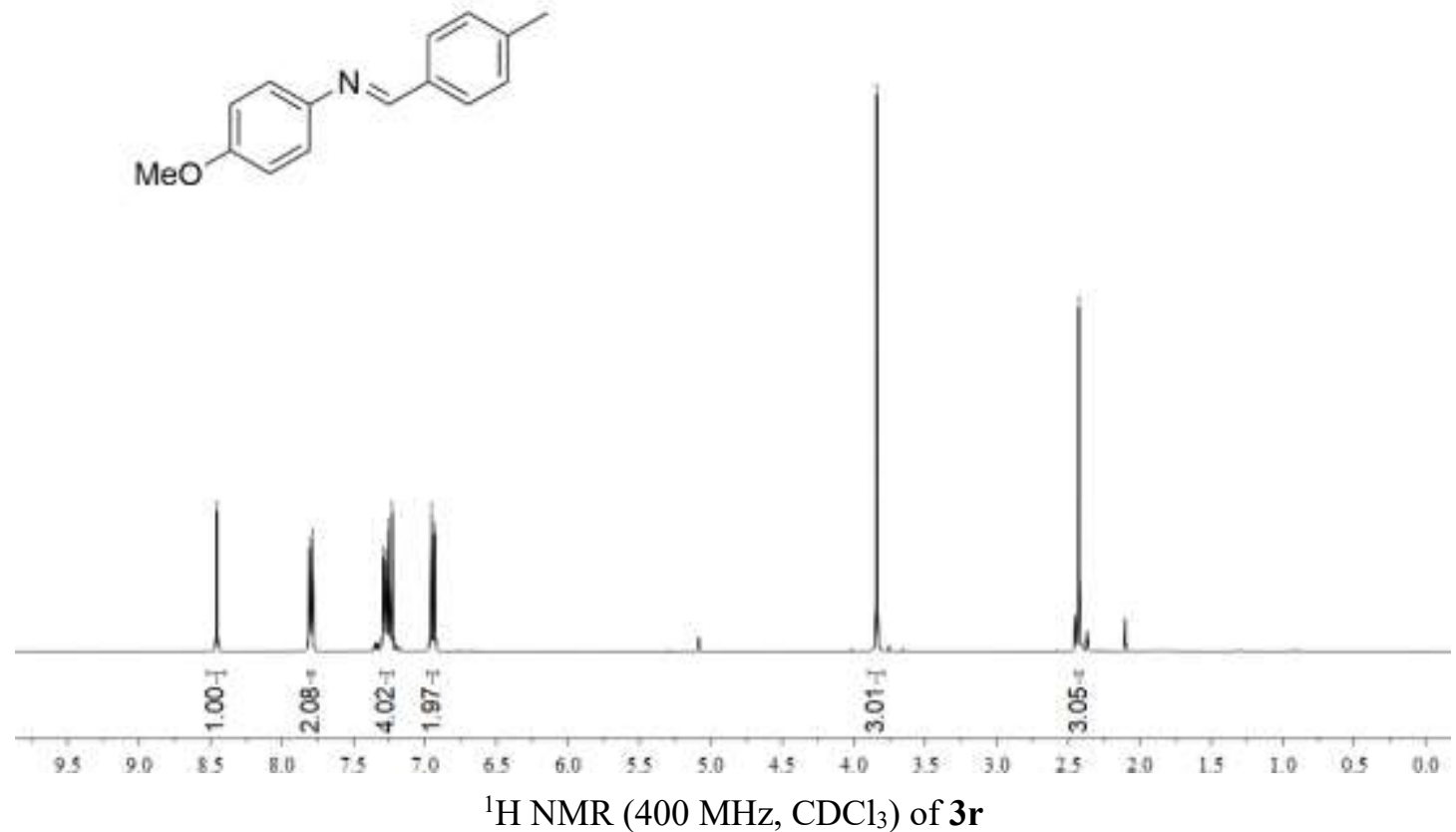




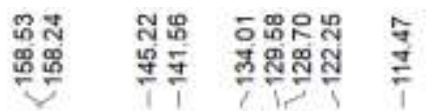<smiles>COc1ccc(/N=C/c2ccc(C)cc2)cc1</smiles>
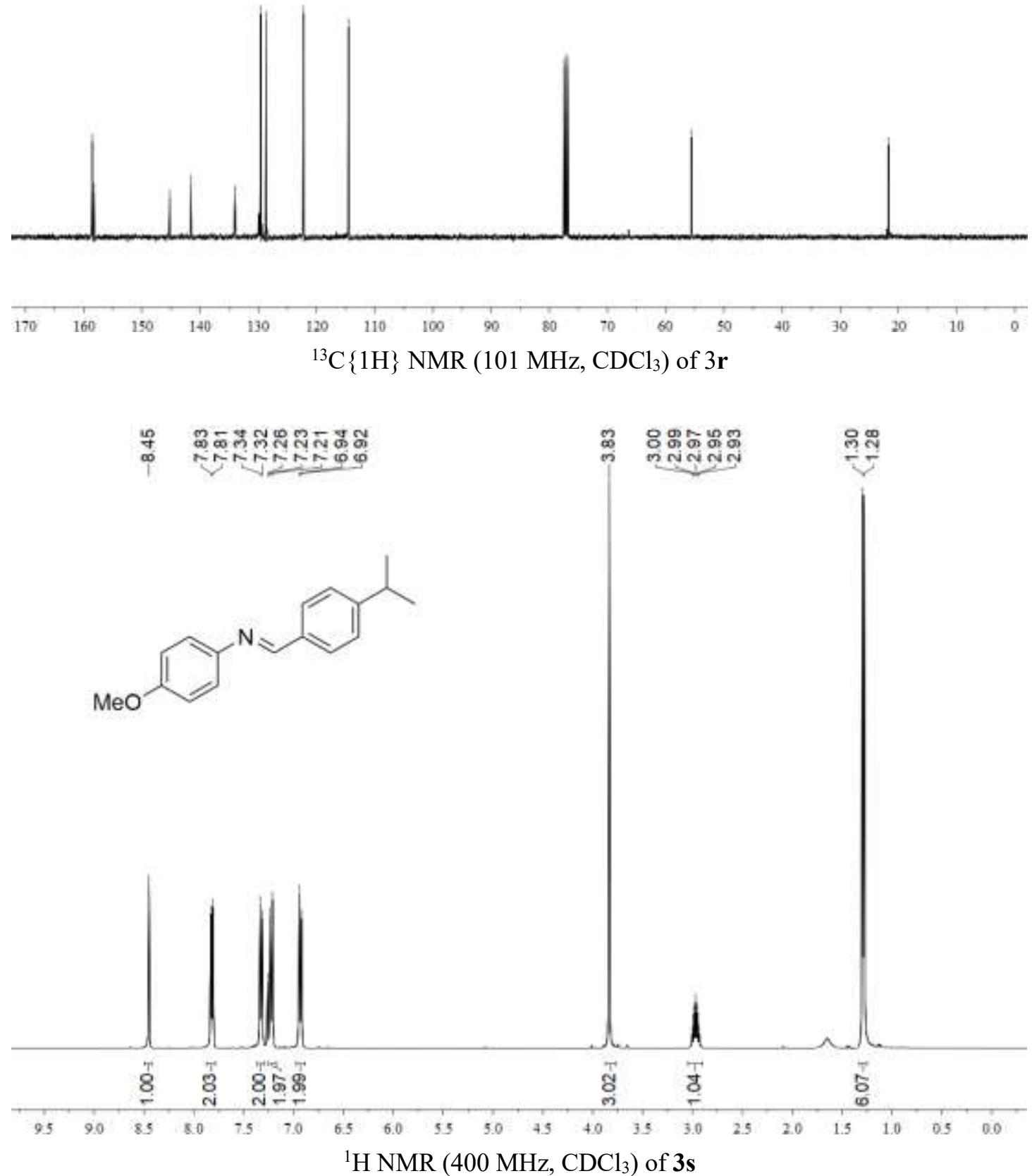
<smiles>COc1ccc(/N=C/c2ccc(C(C)C)cc2)cc1</smiles>
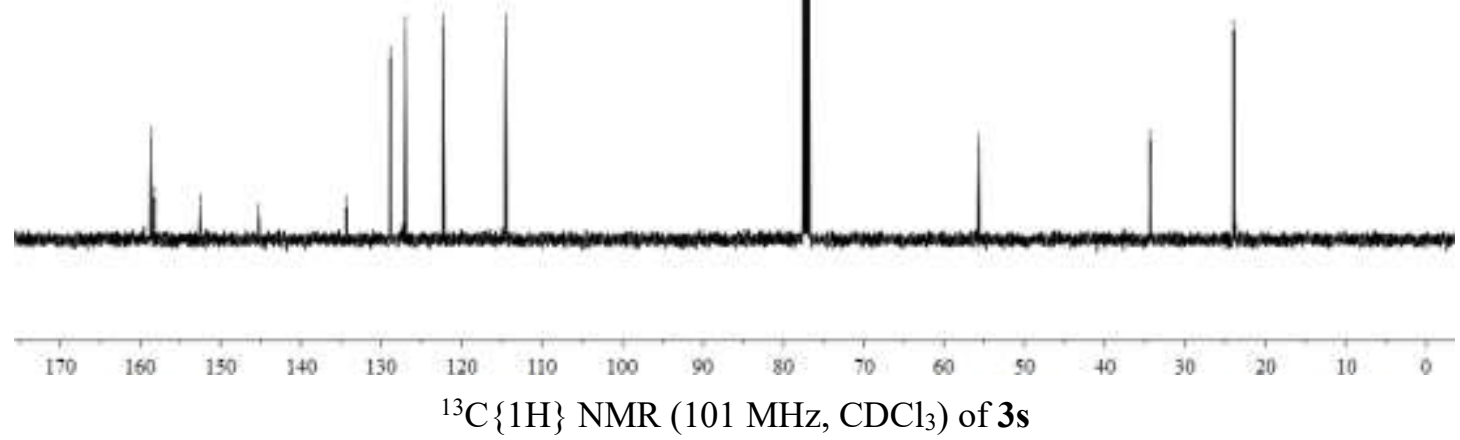

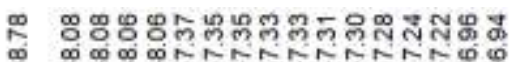

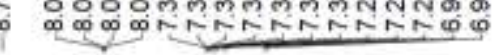<smiles>COc1ccc(/N=C/c2ccccc2C)cc1</smiles>

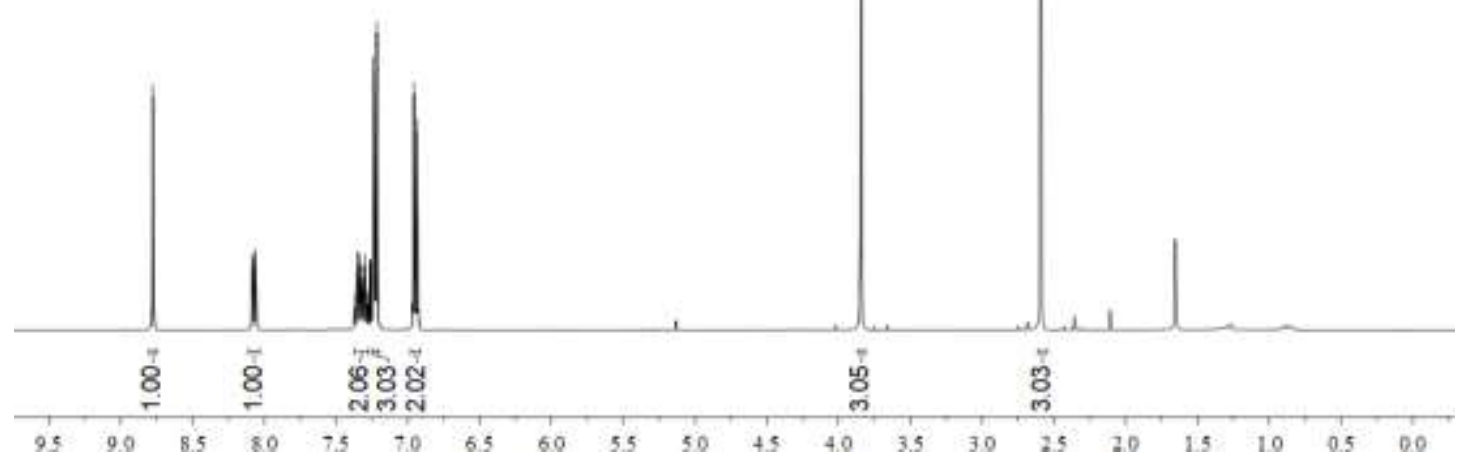

${ }^{1} \mathrm{H}$ NMR (400 MHz, $\left.\mathrm{CDCl}_{3}\right)$ of $\mathbf{3 t}$ 


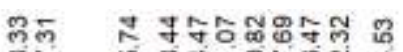

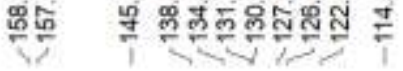

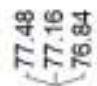

8
岁

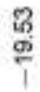<smiles>COc1ccc(/N=C/c2ccccc2C)cc1</smiles>
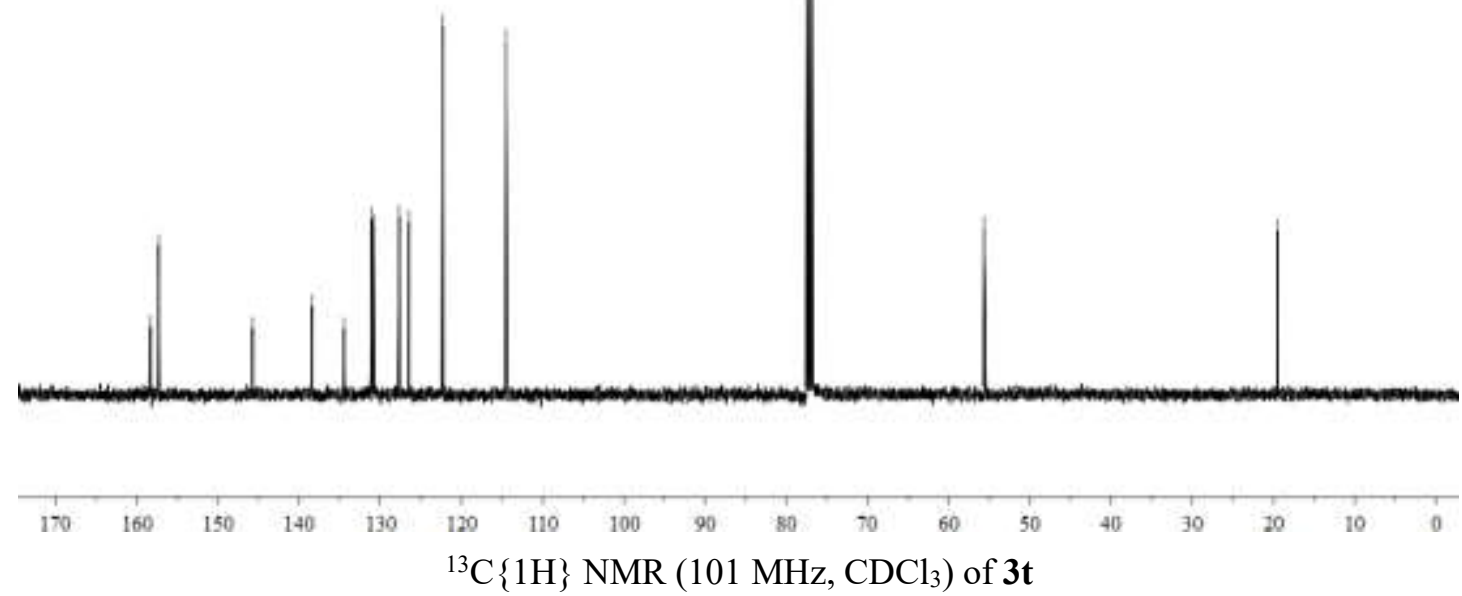

ป

$\infty \quad N-N=N=06$<smiles>COc1ccc(/N=C/c2ccc(F)cc2)cc1</smiles>

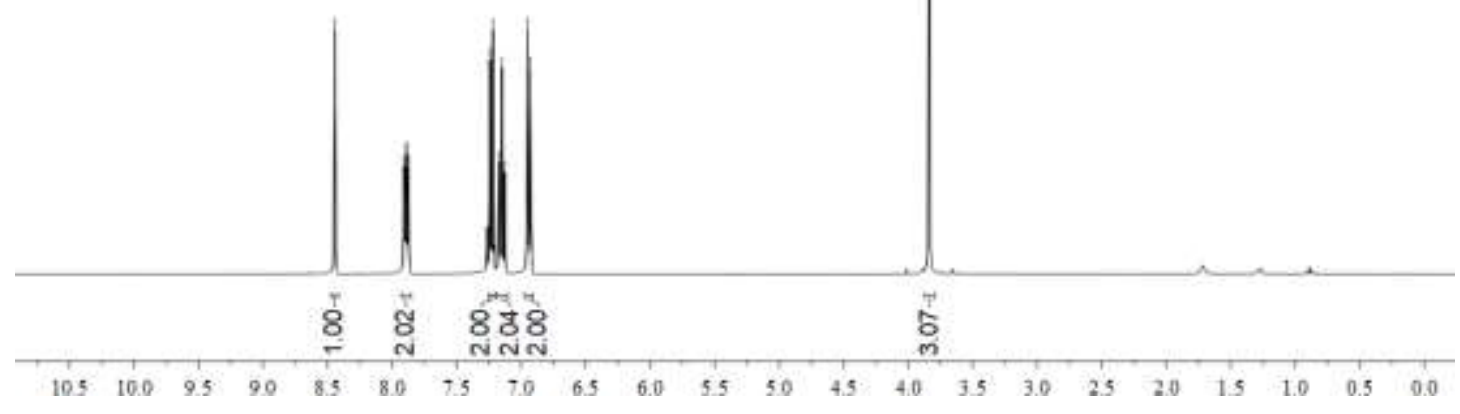

${ }^{1} \mathrm{H}$ NMR $\left(400 \mathrm{MHz}, \mathrm{CDCl}_{3}\right)$ of $\mathbf{3 u}$ 

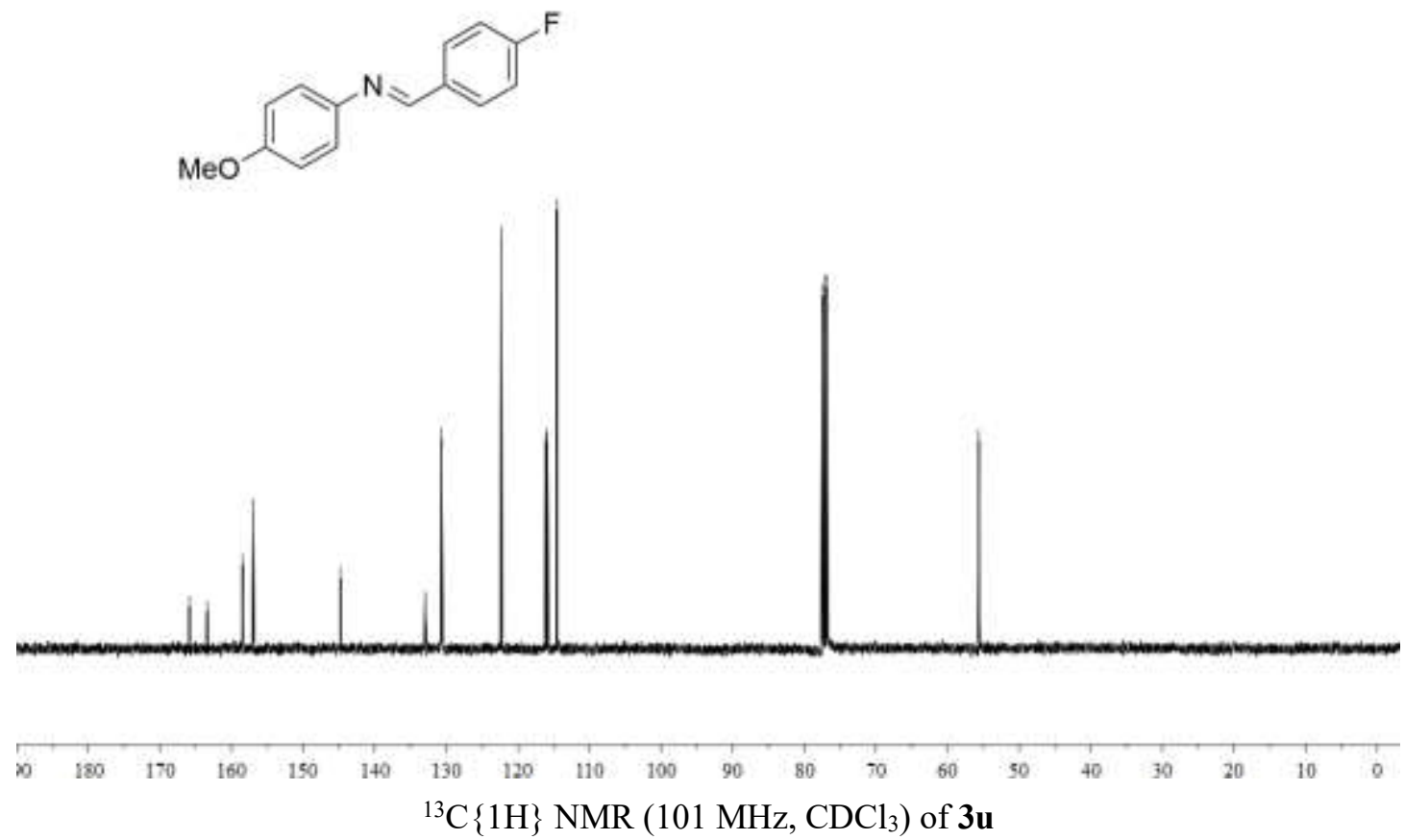

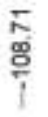

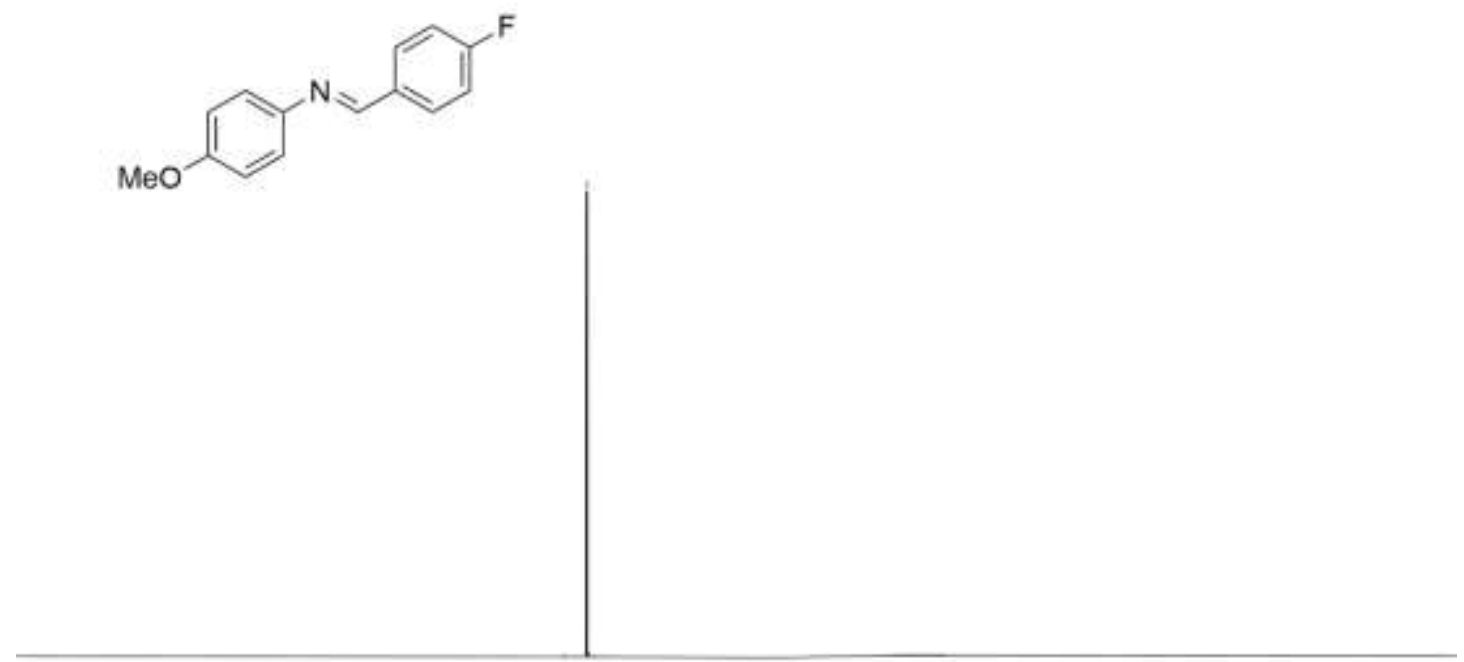

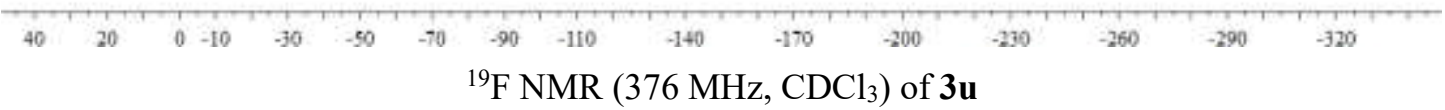




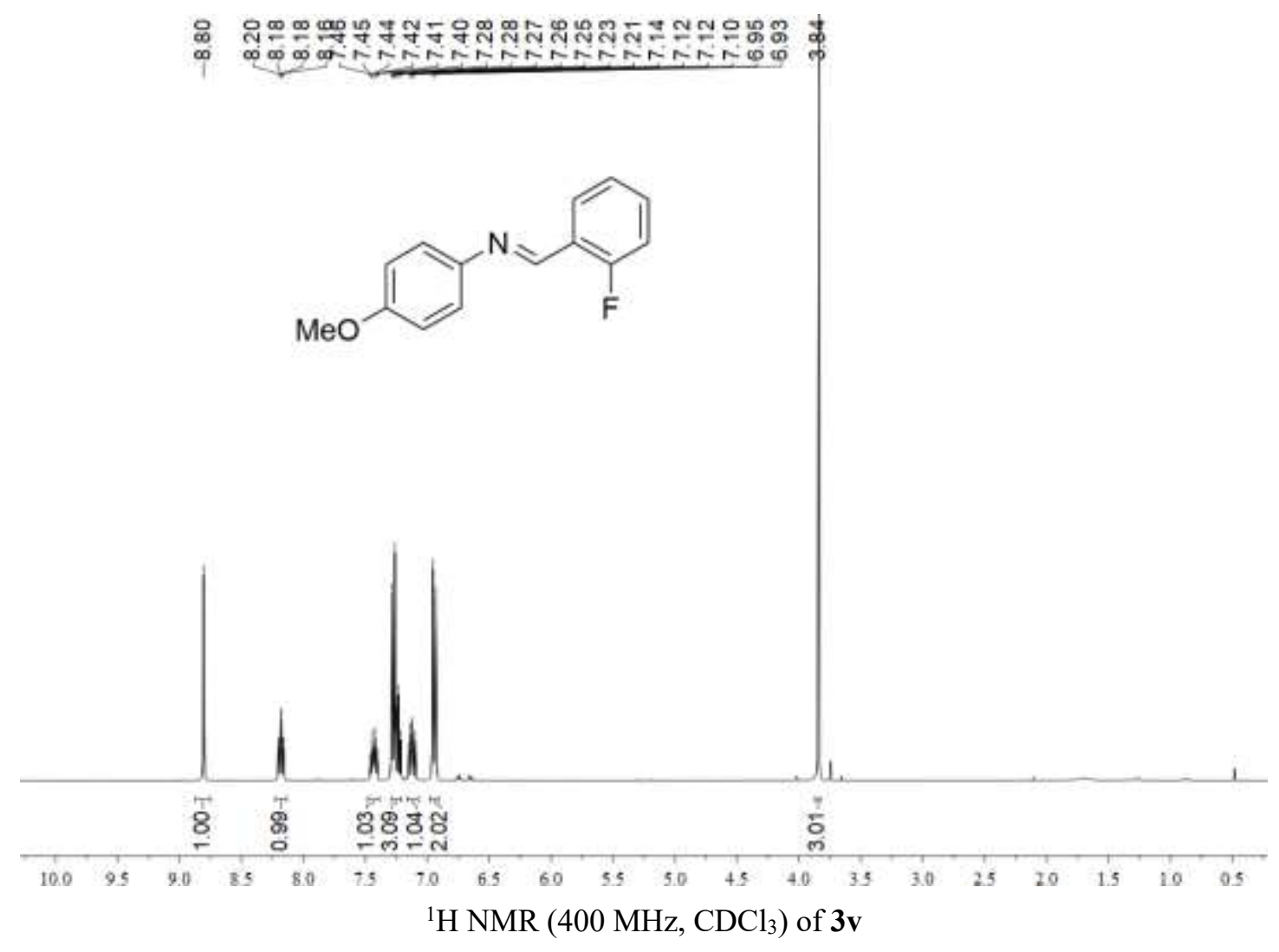

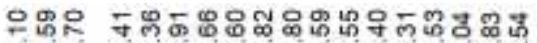

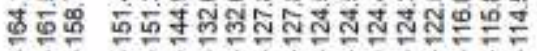

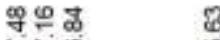

FE⿱<smiles>COc1ccc(/N=C/c2ccccc2F)cc1</smiles>

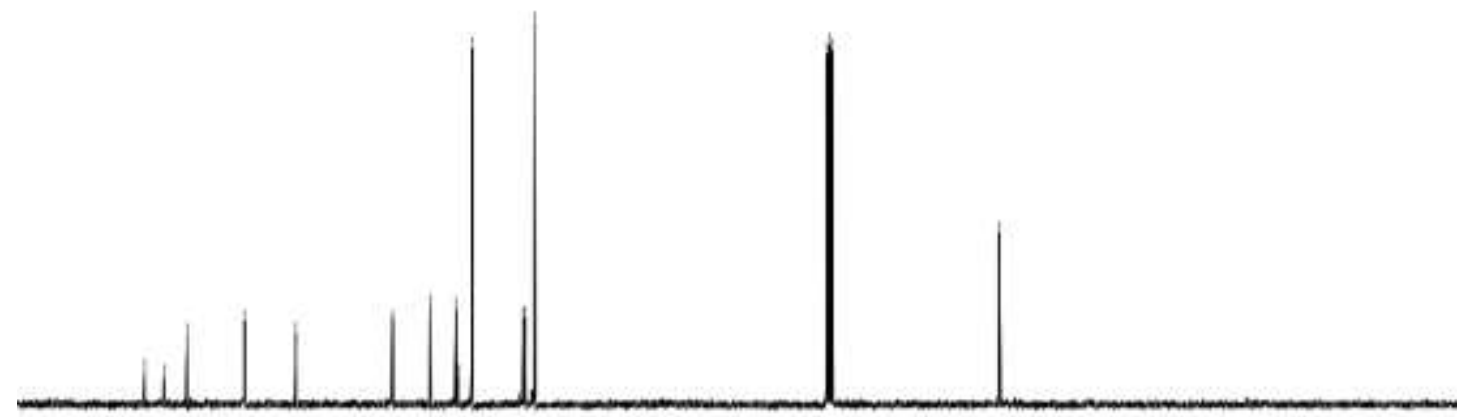

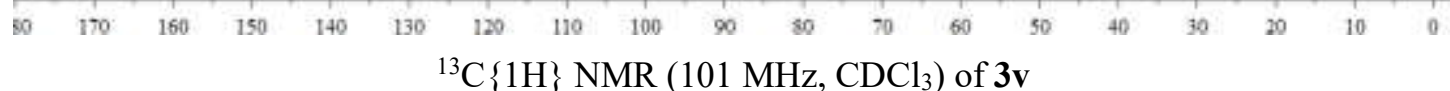



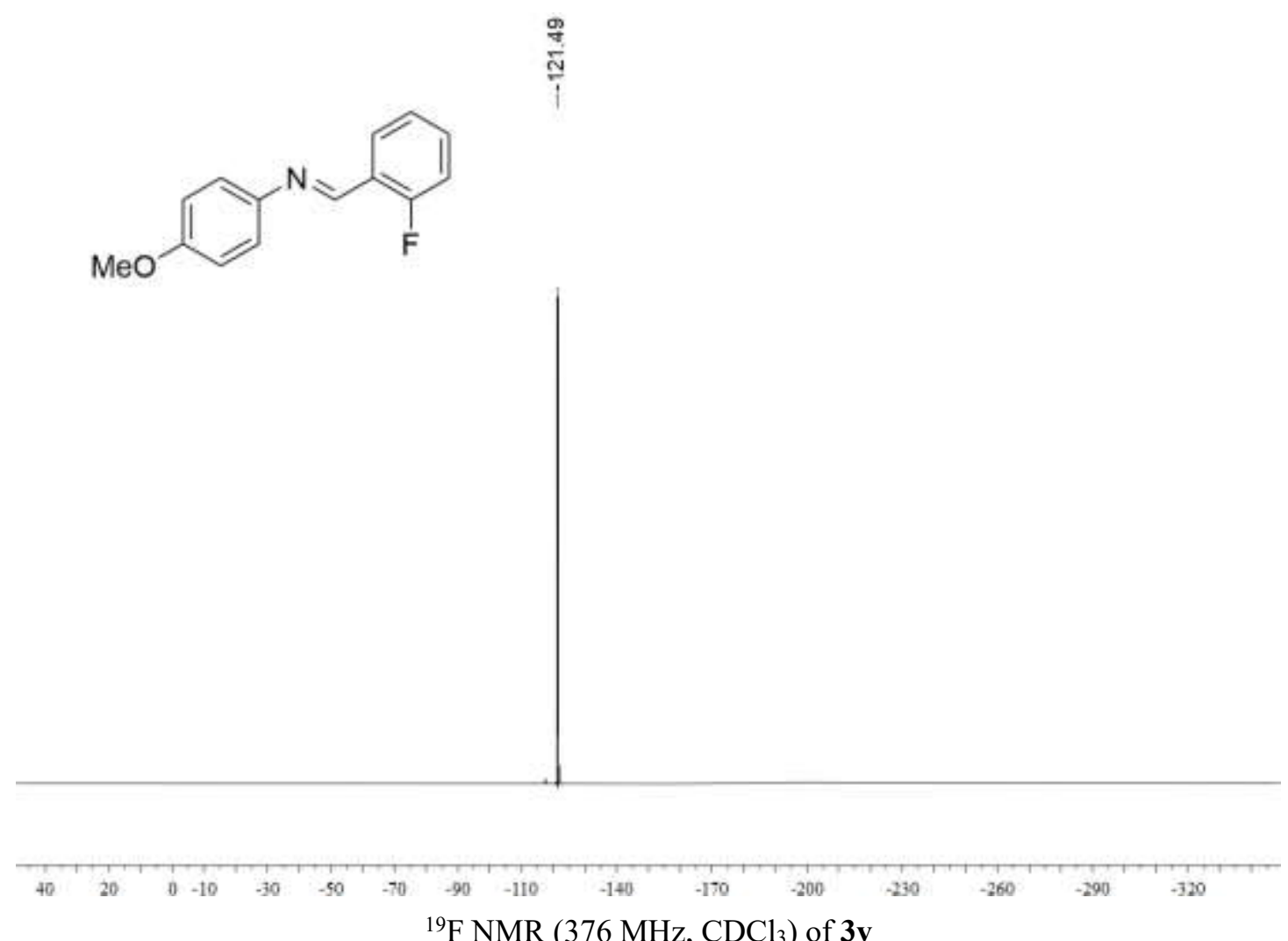

${ }^{19} \mathrm{~F}$ NMR $\left(376 \mathrm{MHz}, \mathrm{CDCl}_{3}\right.$ ) of $\mathbf{3 v}$

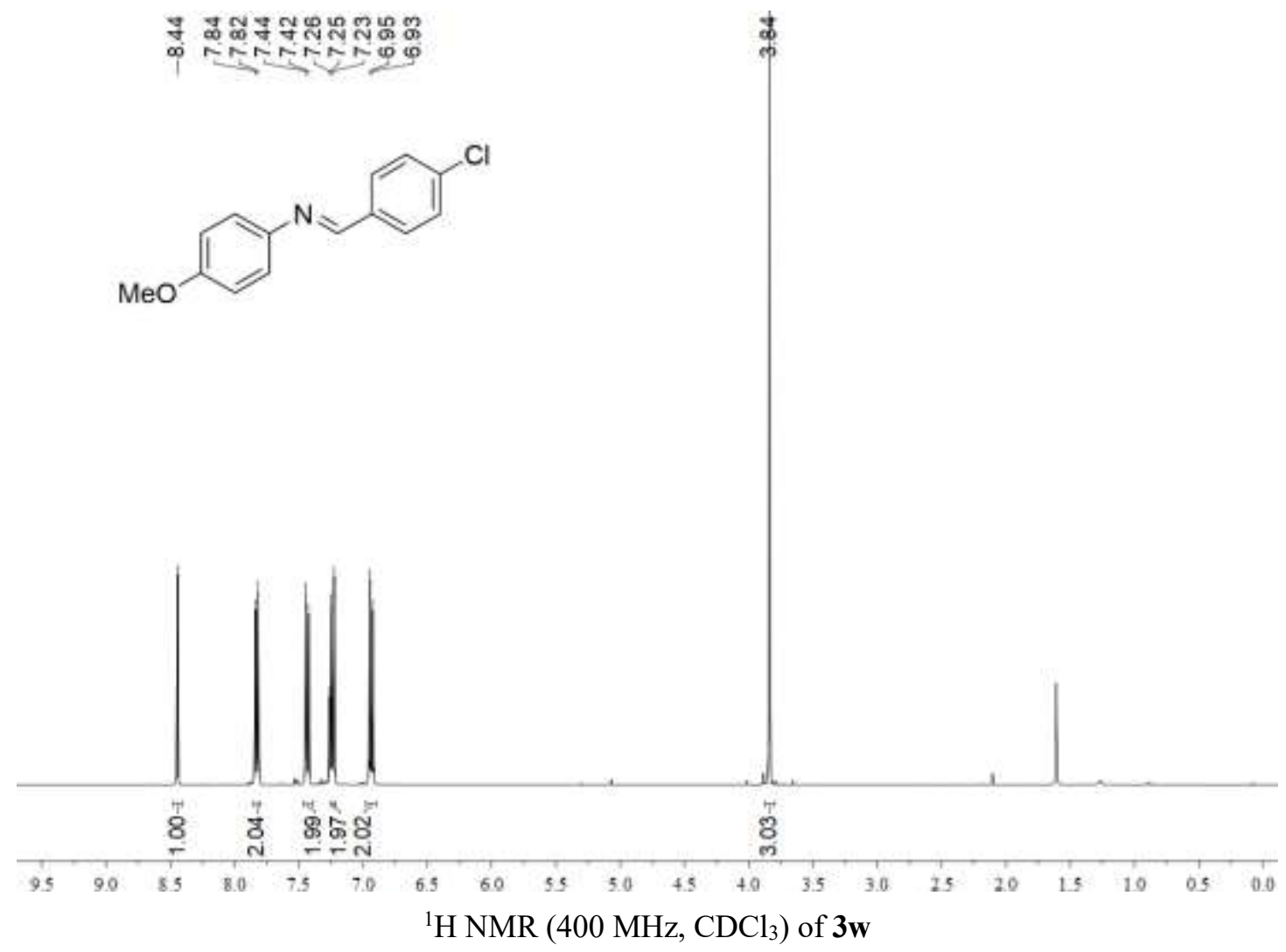



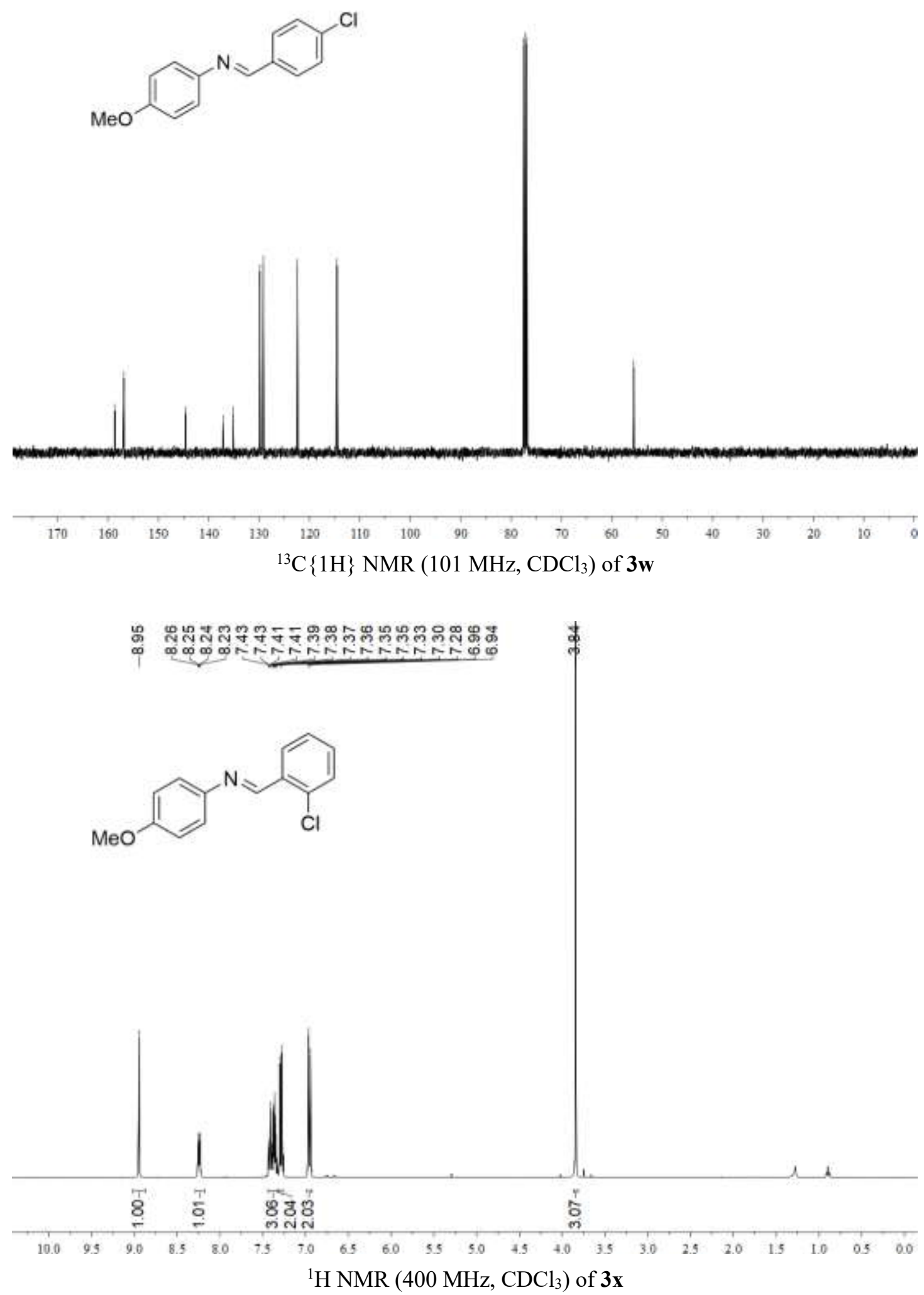
<smiles>COc1ccc(/N=C/c2ccccc2Cl)cc1</smiles>
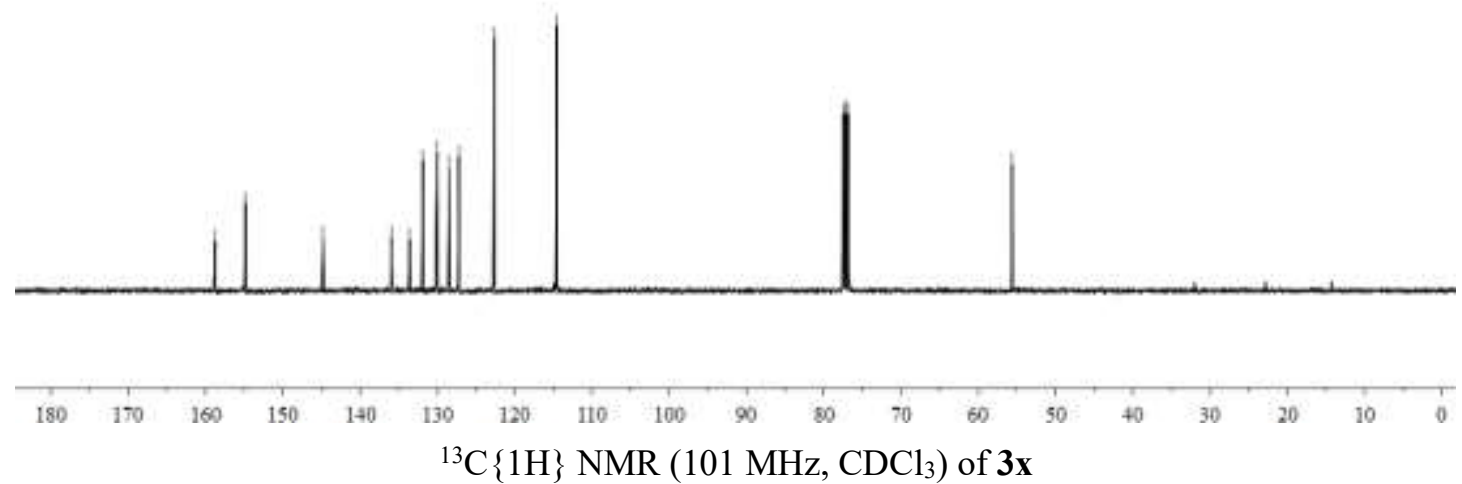

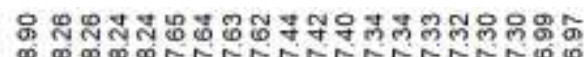

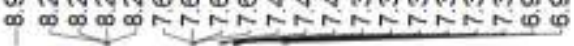<smiles>COc1ccc(/N=C/c2ccccc2Br)cc1</smiles>

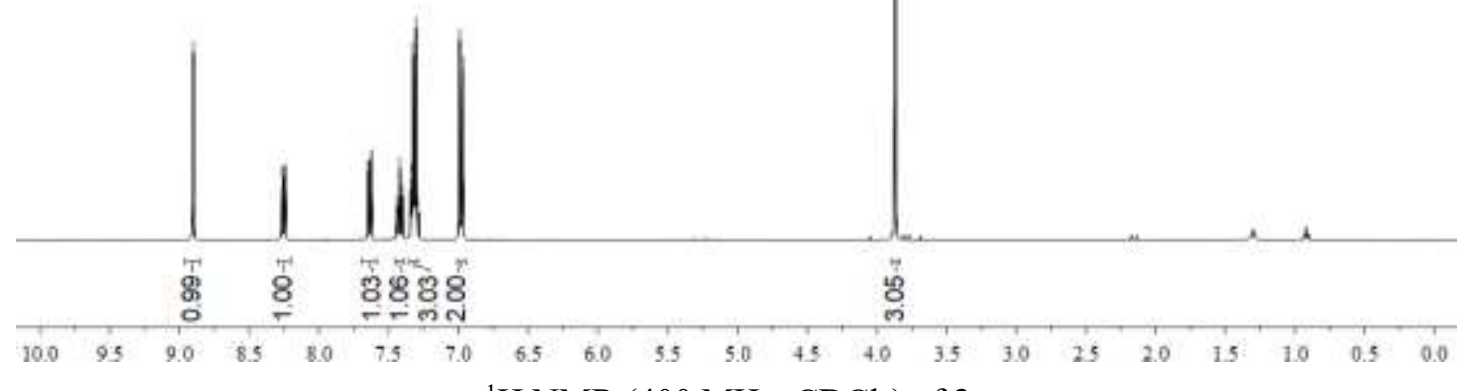

${ }^{1} \mathrm{H}$ NMR (400 MHz, $\left.\mathrm{CDCl}_{3}\right)$ of $\mathbf{3 y}$ 
<smiles>COc1ccc(/N=C/c2ccccc2Br)cc1</smiles>
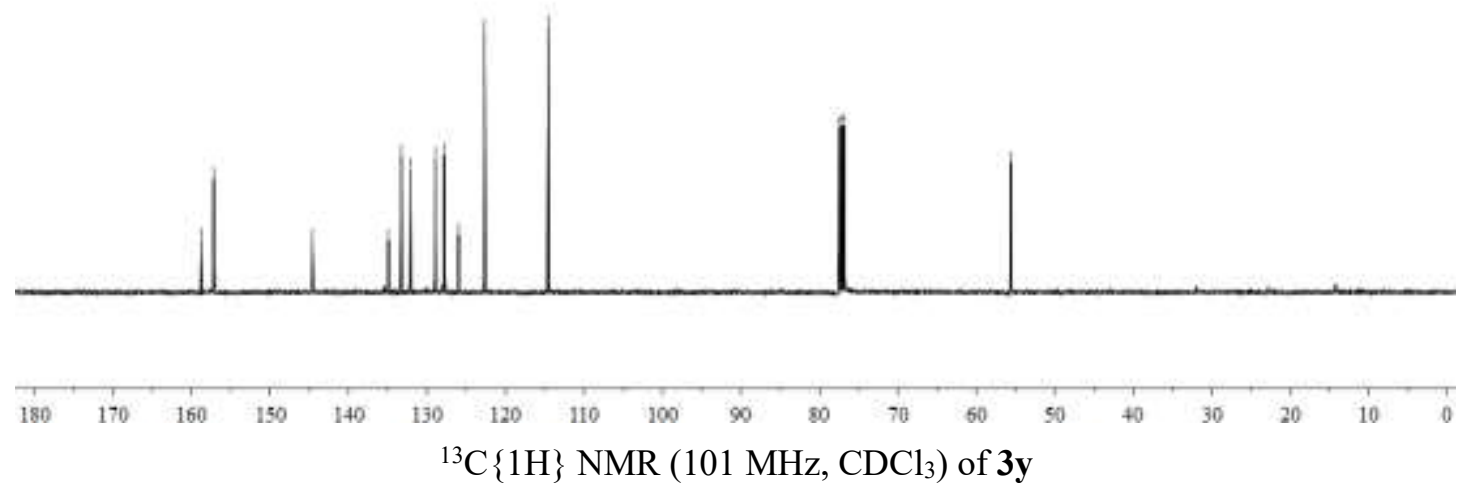

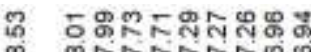

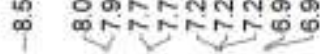<smiles>COc1ccc(/N=C/c2ccc(C(F)(F)F)cc2)cc1</smiles>
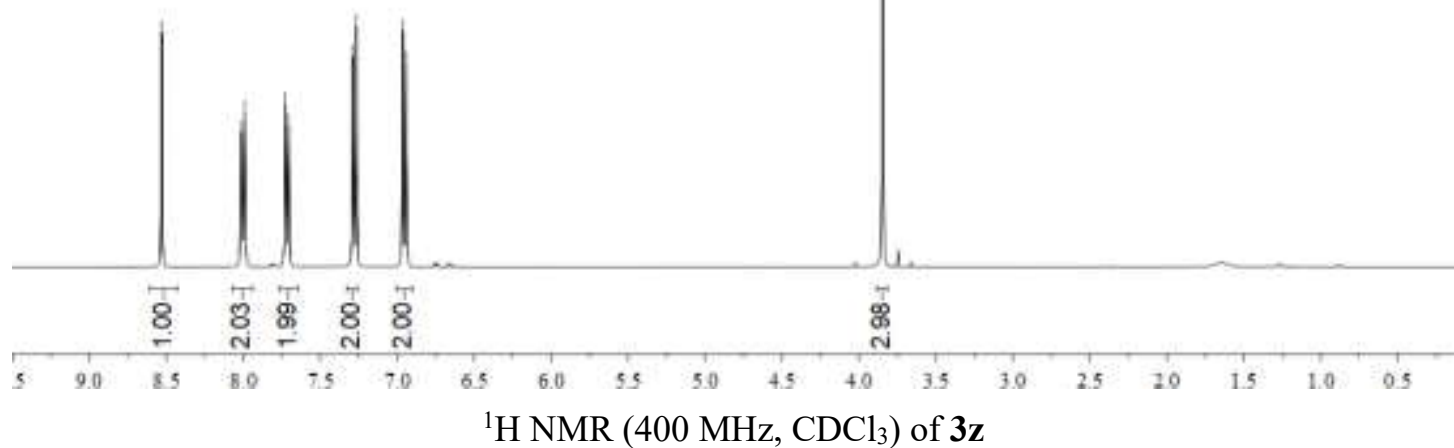

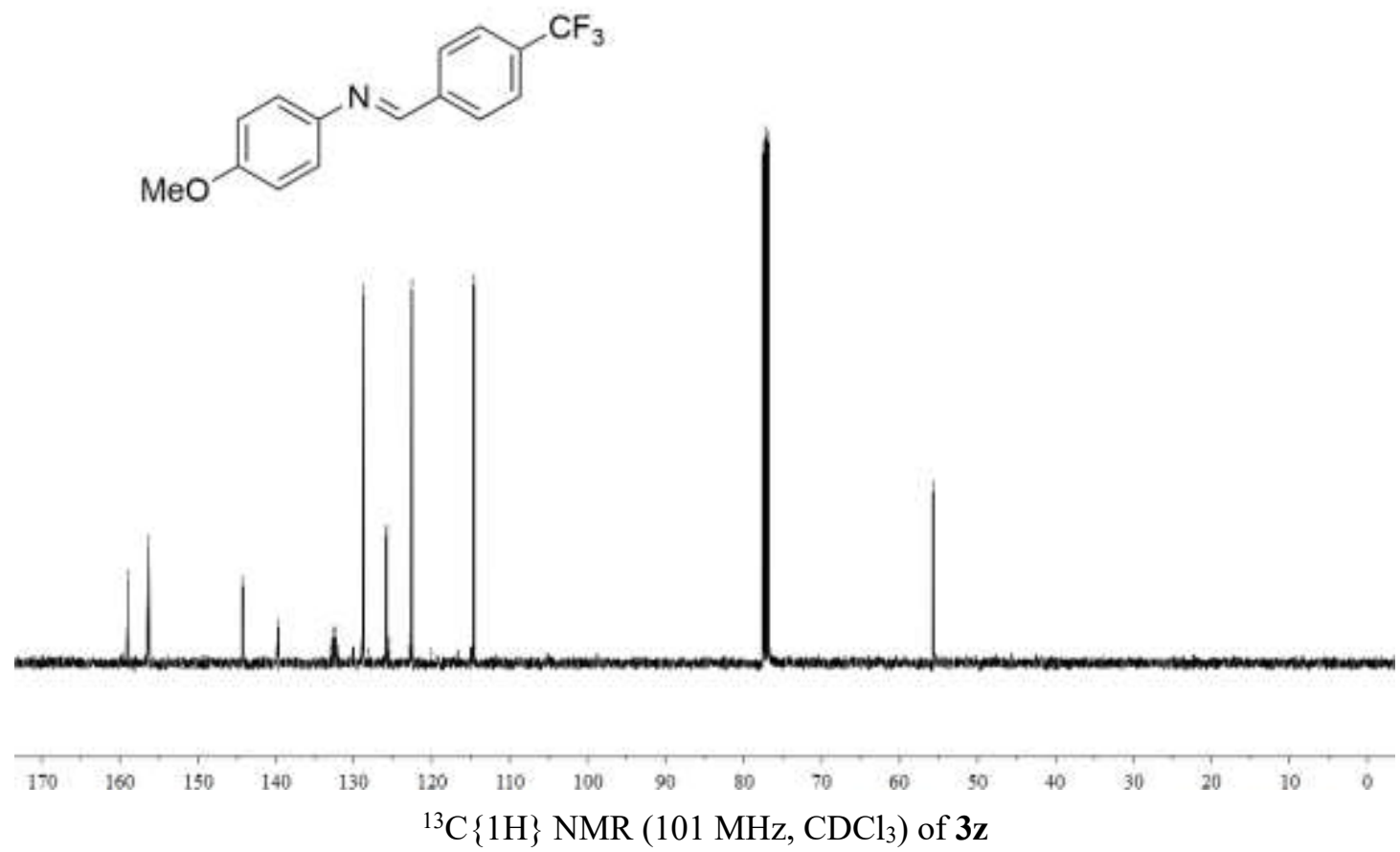

ญ<smiles>COc1ccc(/N=C/c2ccc(C(F)(F)F)cc2)cc1</smiles>

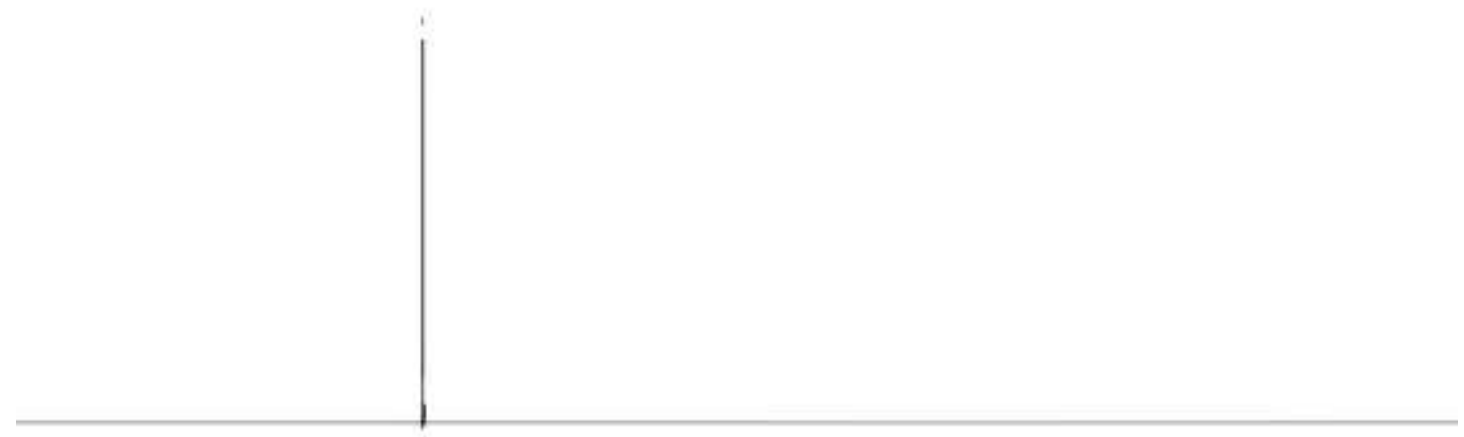

$\begin{array}{llll}20 & 10 & 0 & -20\end{array}$

${ }^{19} \mathrm{~F}$ NMR (376 MHz, $\mathrm{CDCl}_{3}$ ) of $\mathbf{3 z}$ 


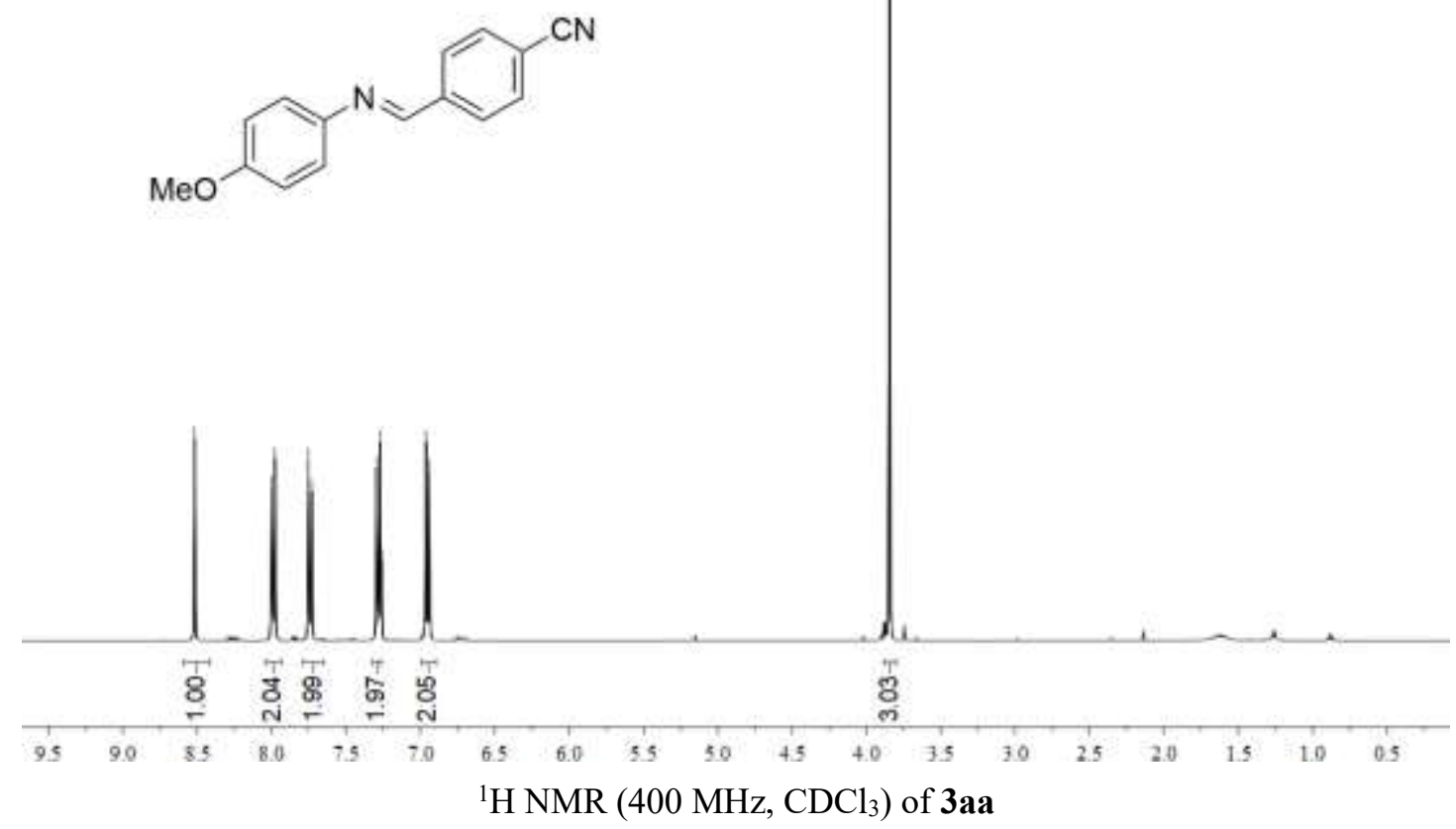

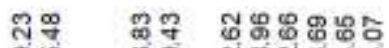

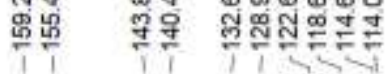

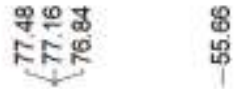<smiles>COc1ccc(/N=C/c2ccc(C#N)cc2)cc1</smiles>

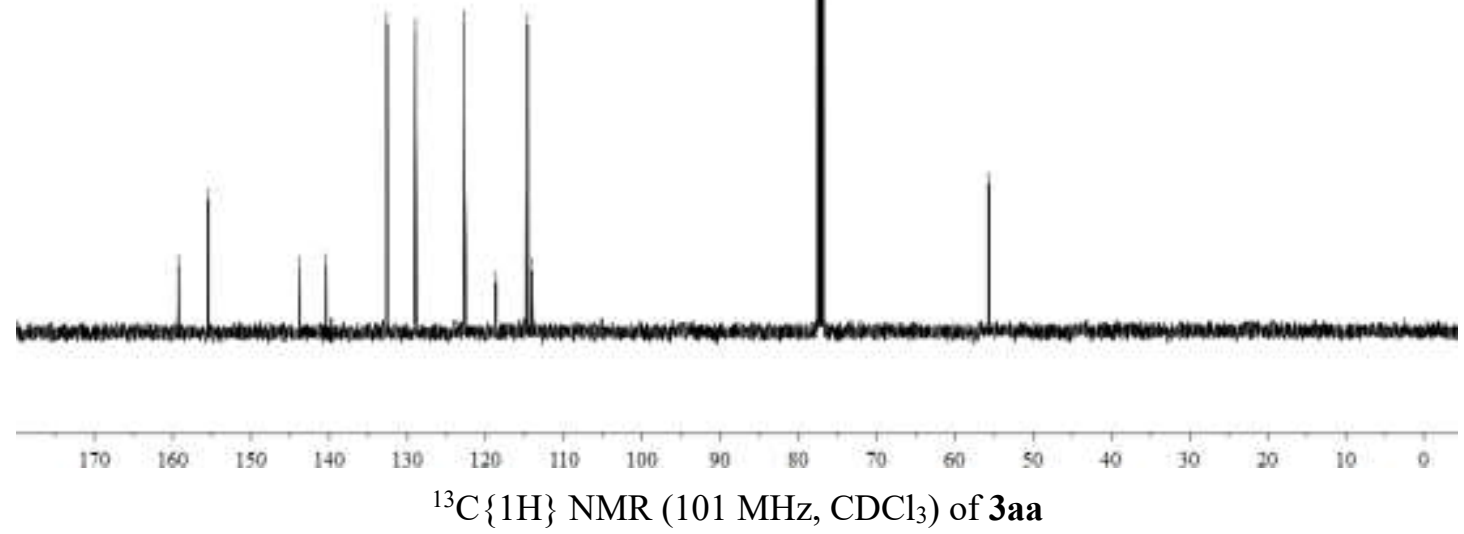




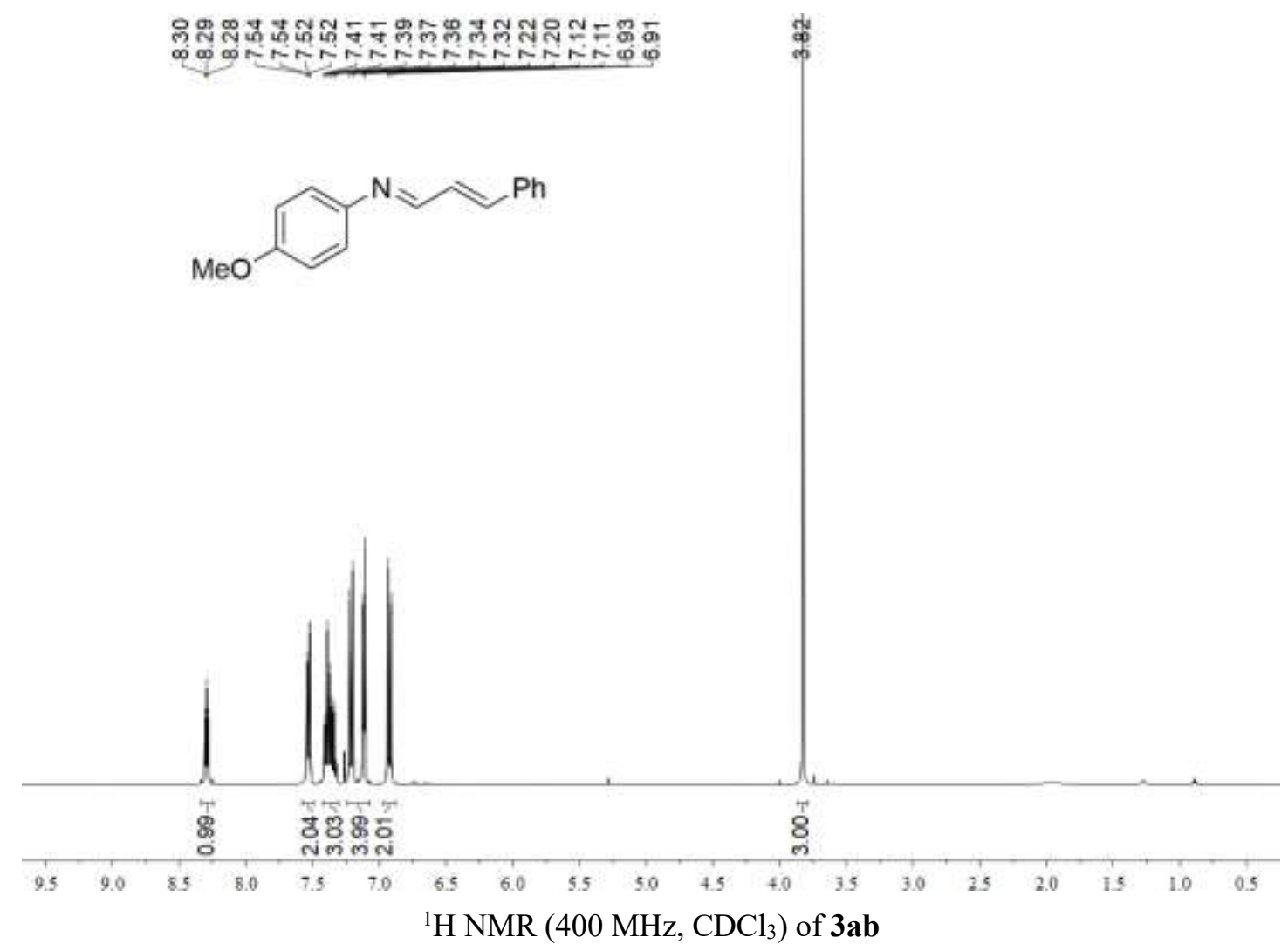

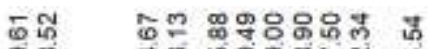

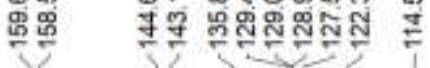

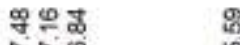

FE～点<smiles>COc1ccc(/N=C/C=C/c2ccccc2)cc1</smiles>

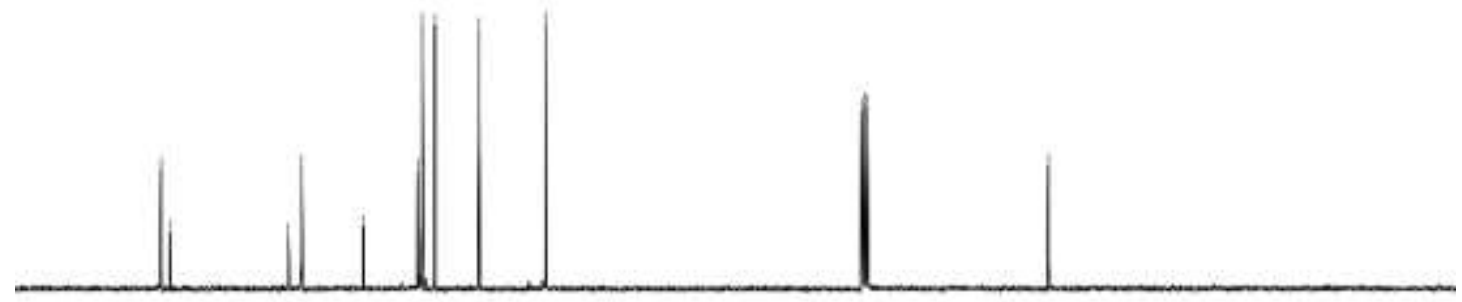

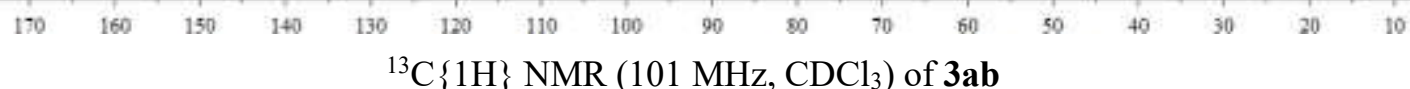



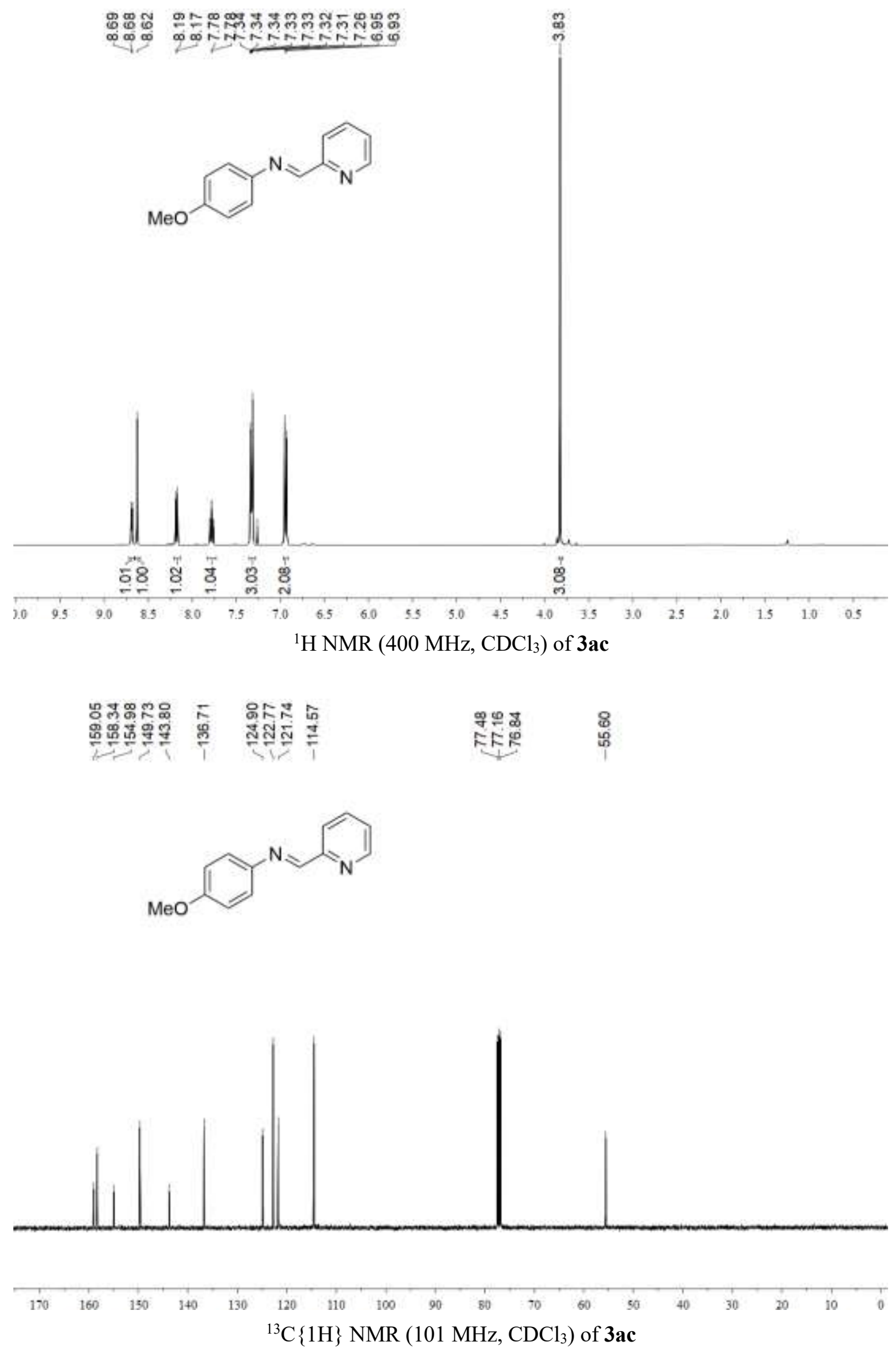

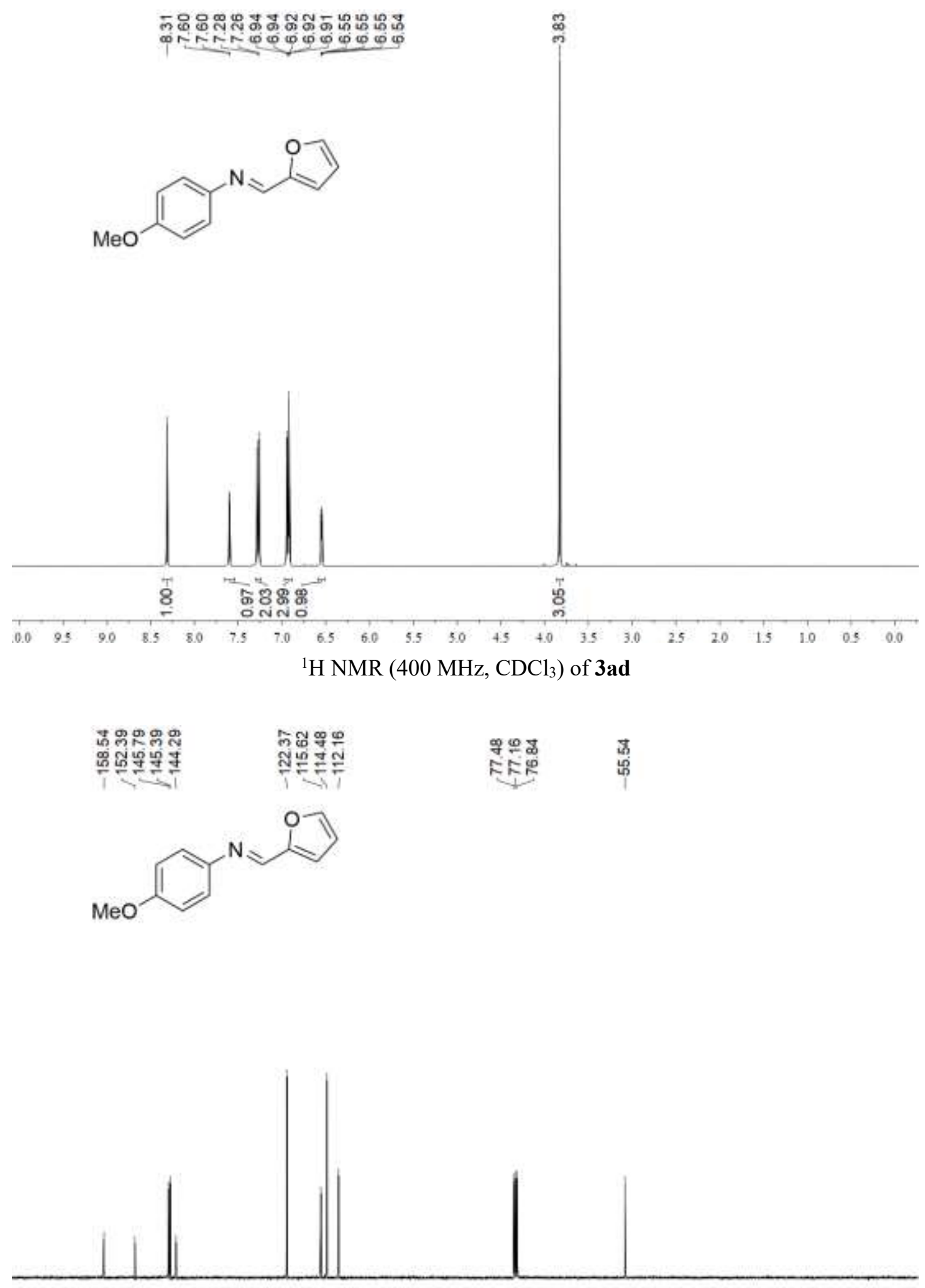

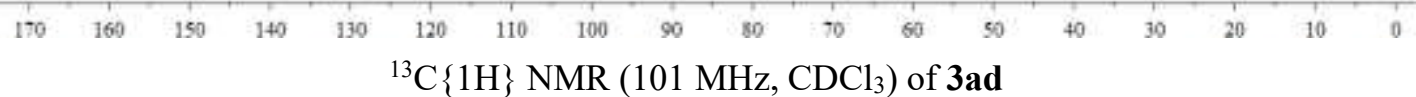


品 品界早

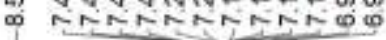

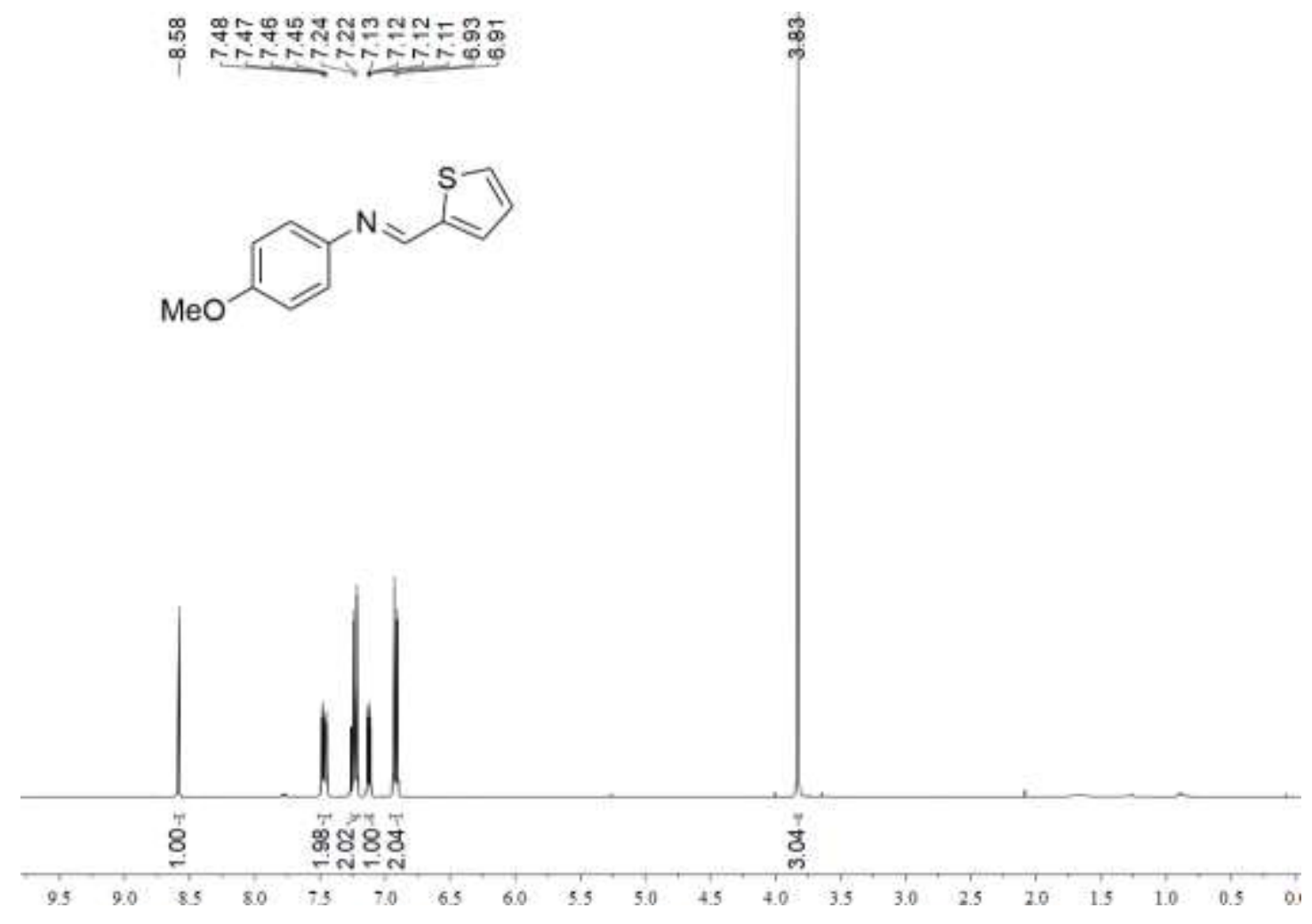

${ }^{1} \mathrm{H}$ NMR (400 MHz, $\mathrm{CDCl}_{3}$ ) of $\mathbf{3 a e}$

\begin{tabular}{|c|c|c|c|}
\hline 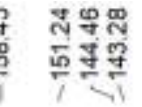 & 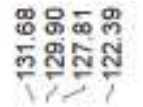 & 品 & 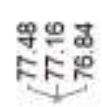 \\
\hline
\end{tabular}<smiles>COc1ccc(/N=C/c2cccs2)cc1</smiles>

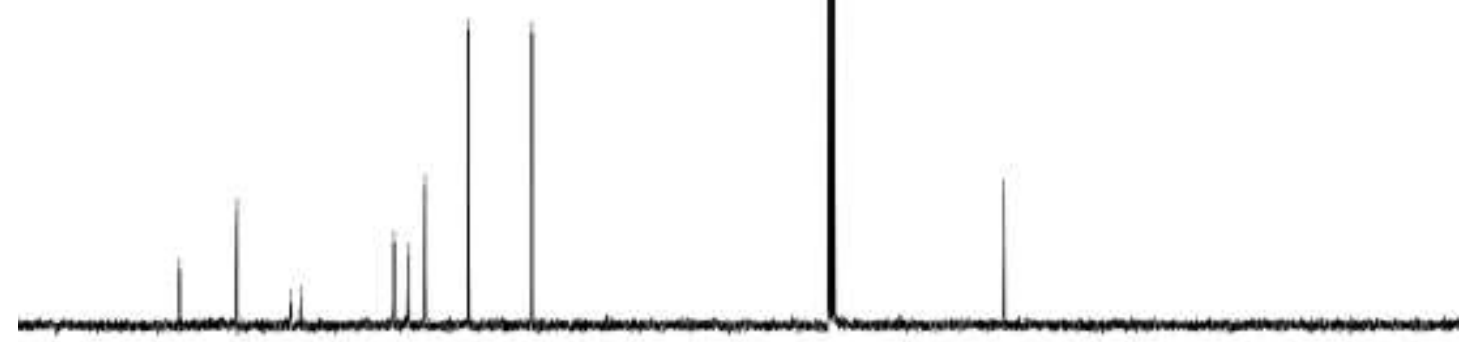

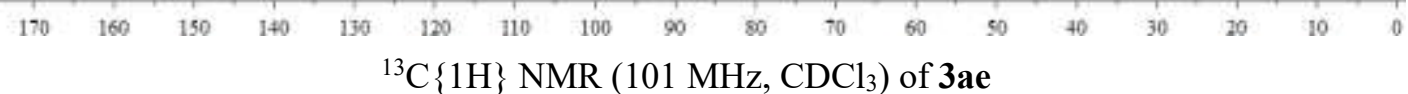



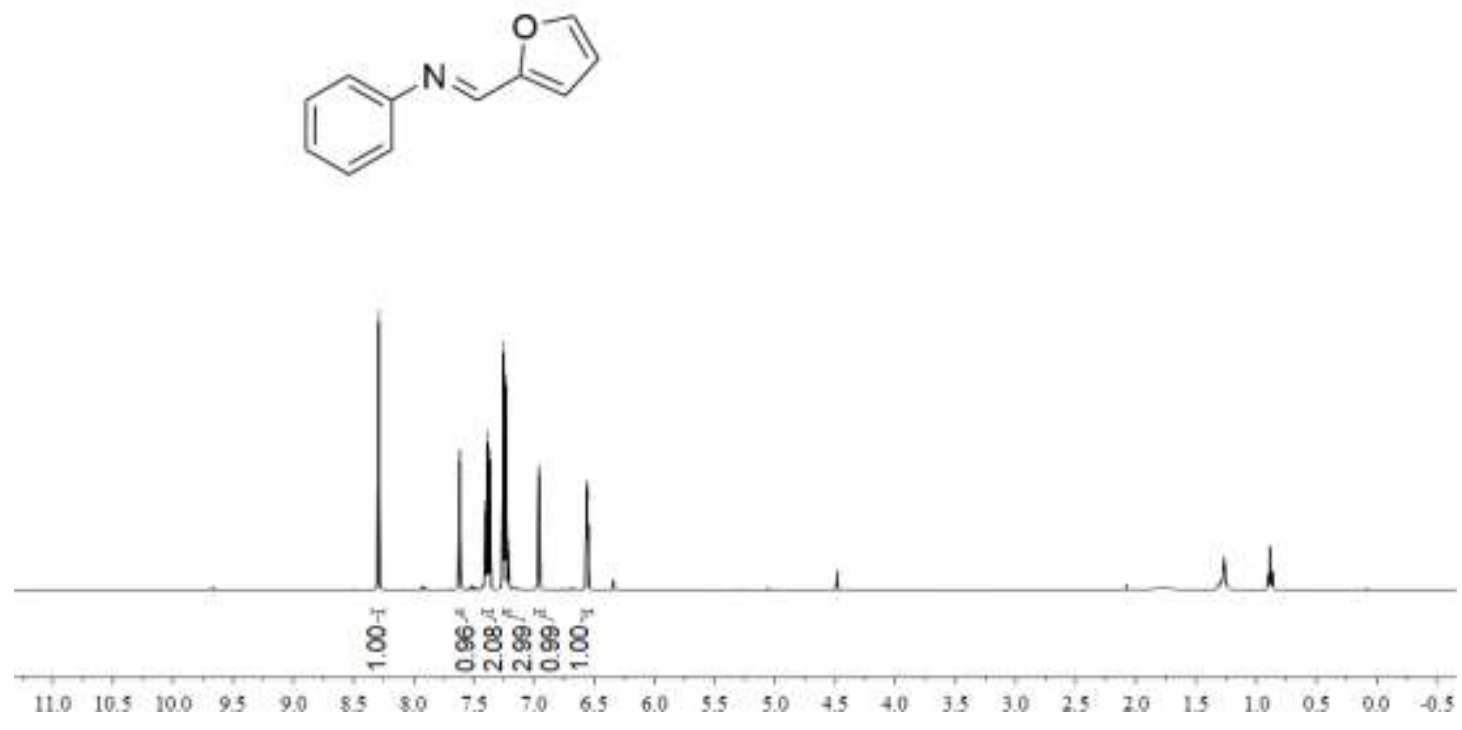

${ }^{1} \mathrm{H}$ NMR (400 MHz, $\mathrm{CDCl}_{3}$ ) of $\mathbf{3 a f}$

\begin{tabular}{|c|c|}
\hline 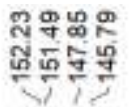 & 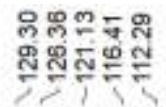 \\
\hline
\end{tabular}<smiles>C(=N/c1ccccc1)\c1ccco1</smiles>

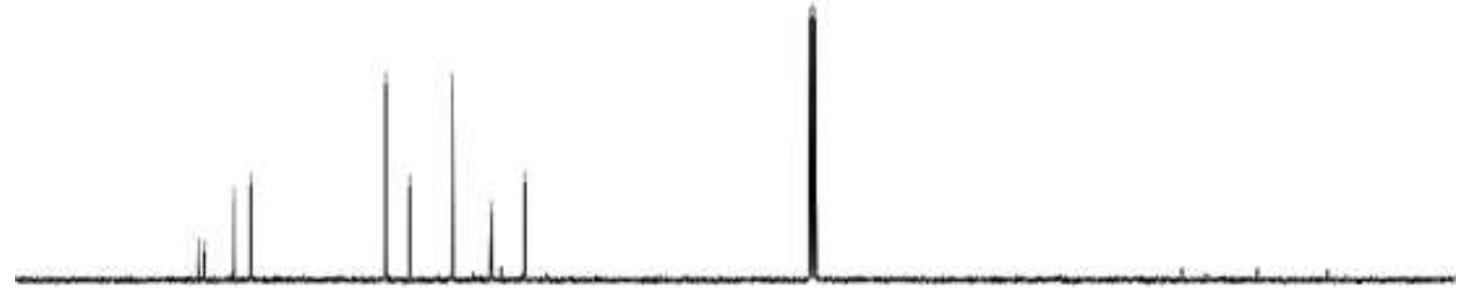

\begin{tabular}{|c|c|c|c|c|c|c|c|c|c|c|c|c|c|c|c|c|}
\hline & 160 & 150 & 140 & 130 & 120 & 110 & 100 & 90 & 50 & 70 & 60 & 50 & +0 & 30 & 20 & 10 \\
\hline
\end{tabular}


<smiles>C(=N/c1ccccc1)\c1cccs1</smiles>

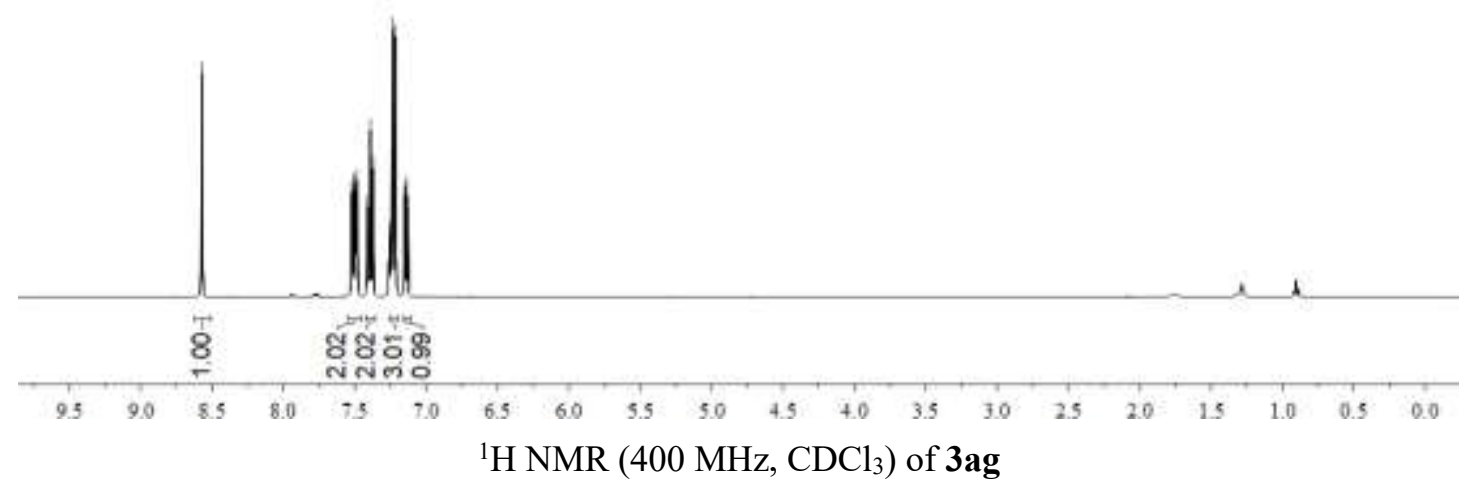

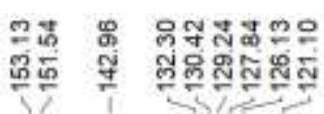

ํㅜㅇㅛ

FF⿱<smiles>C(=N/c1ccccc1)\c1cccs1</smiles>

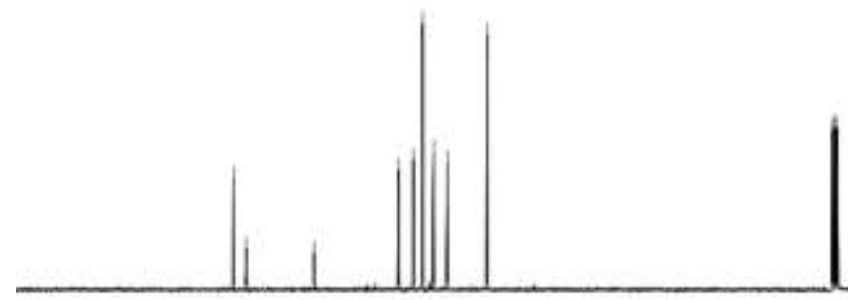

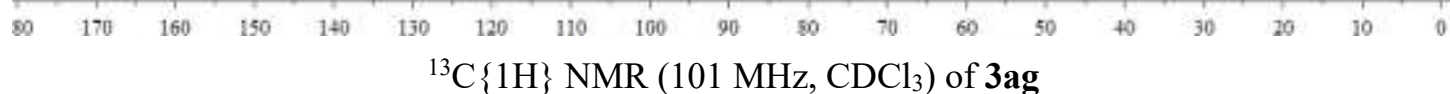


<smiles>C(=N/c1ccc(OCc2ccccc2)cc1)\c1ccco1</smiles>

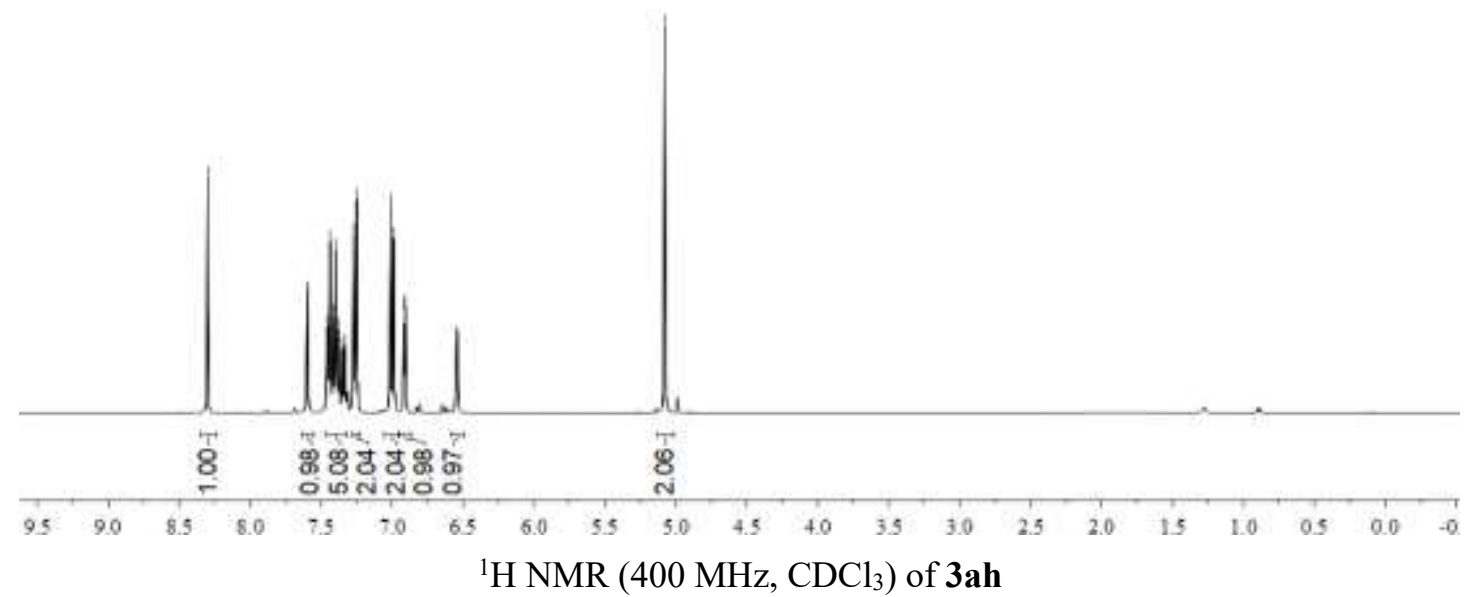

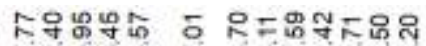

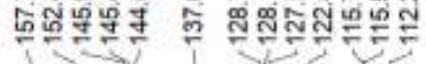

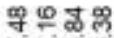

FFER<smiles>C(=N/c1ccc(OCc2ccccc2)cc1)\c1ccco1</smiles>

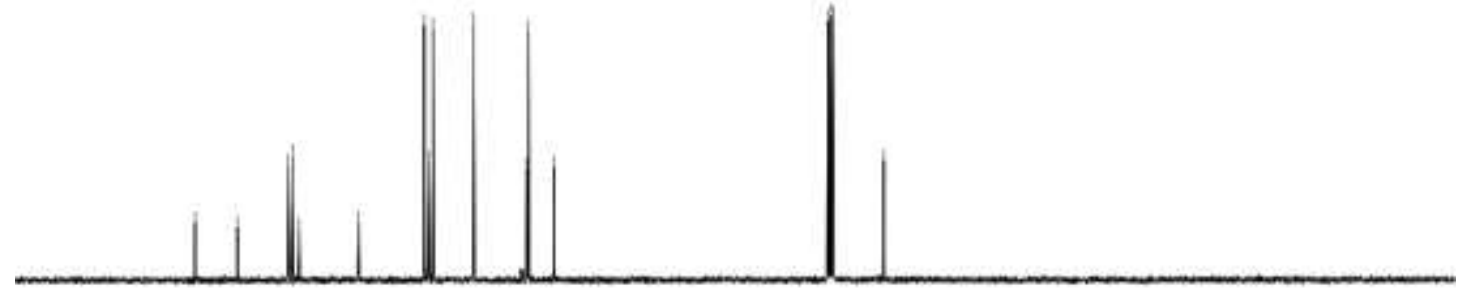

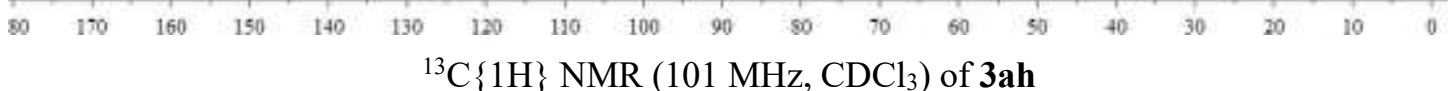


<smiles>C(=N/c1ccc(OCc2ccccc2)cc1)\c1cccs1</smiles>

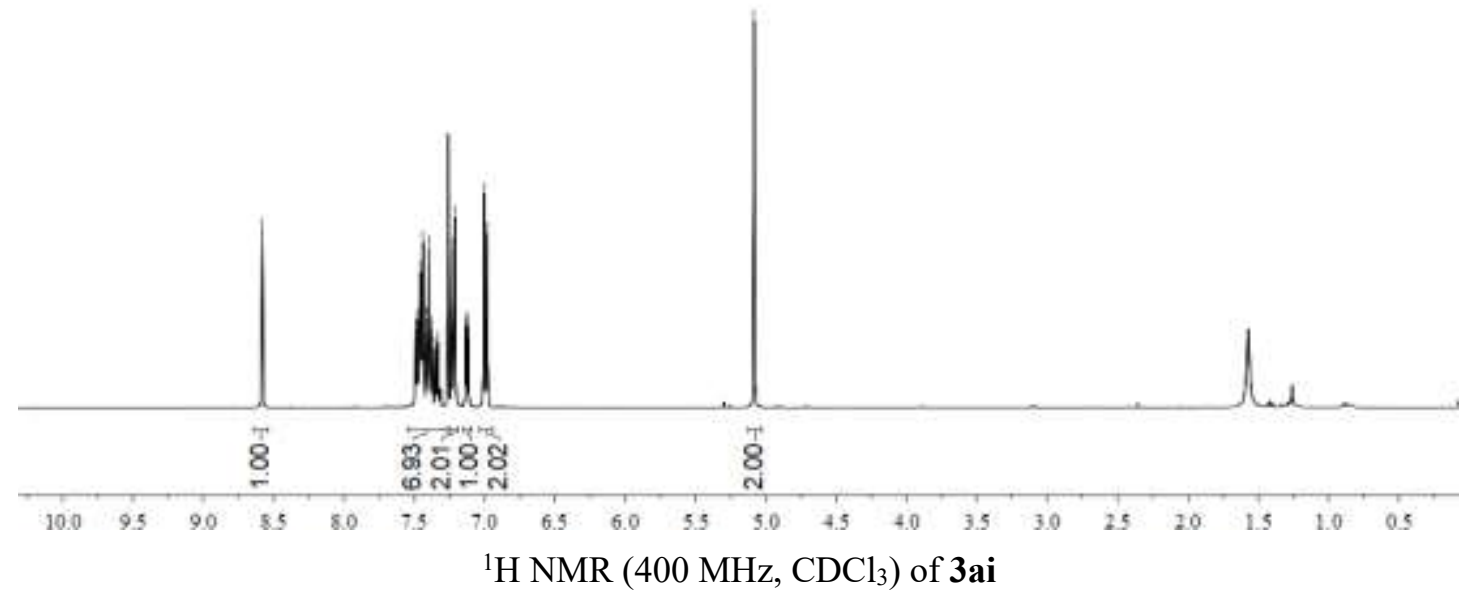

뭏ㅇㅇㅛ

FRER<smiles>C(=N/c1ccc(OCc2ccccc2)cc1)\c1cccs1</smiles>
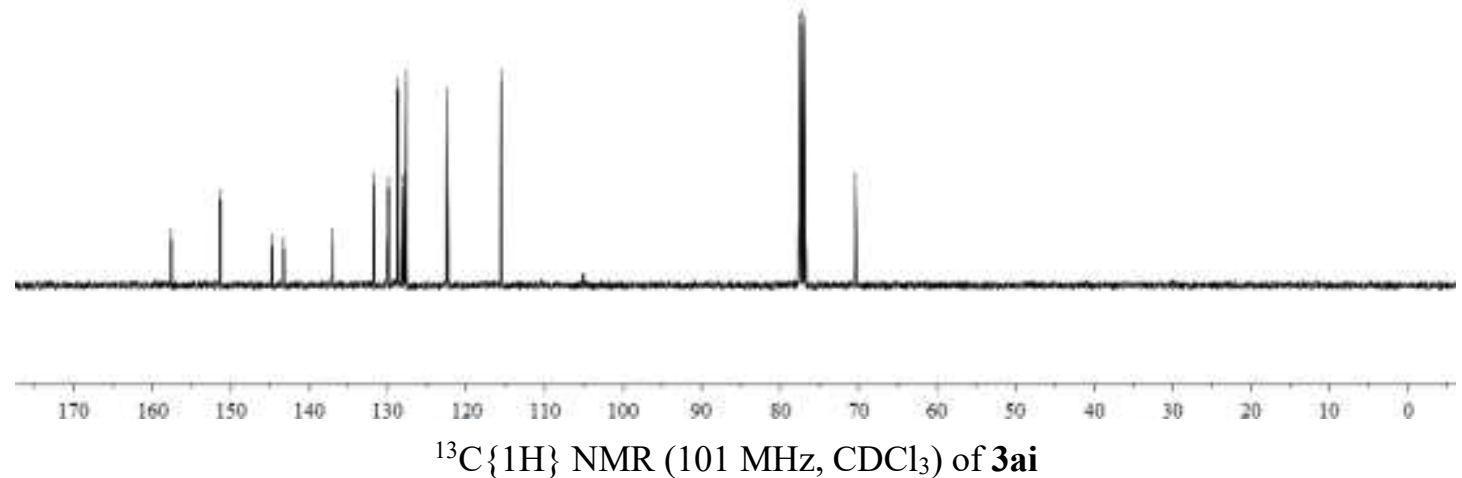
<smiles>c1ccc(-c2nc3ccccc3[nH]2)cc1</smiles>

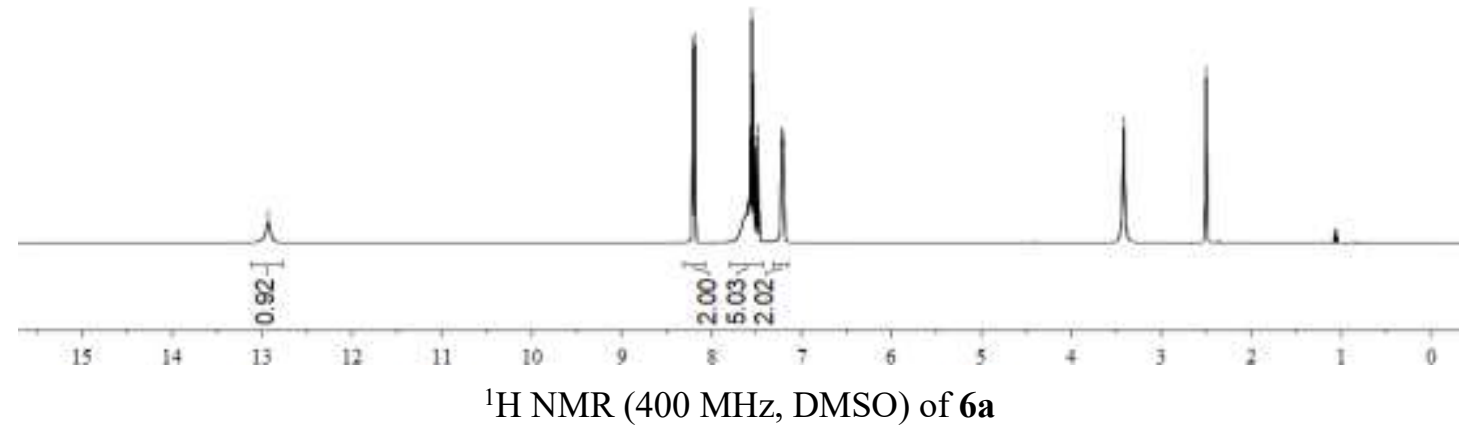

ำ

เ

느ㅁㅠㅜㅇ드음ㅇ

ㅁำ<smiles>c1ccc(-c2nc3ccccc3[nH]2)cc1</smiles>

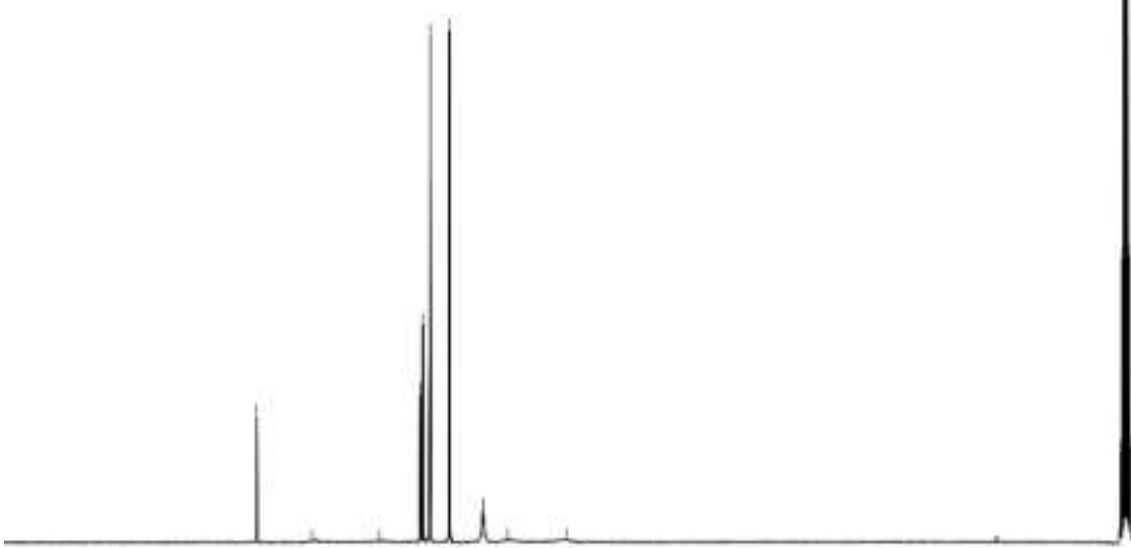

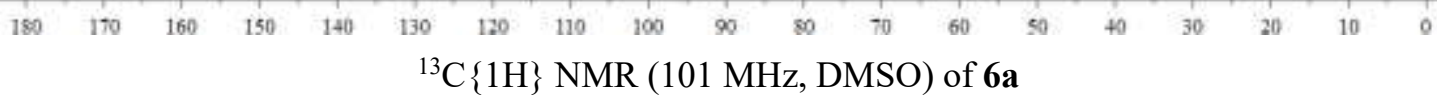




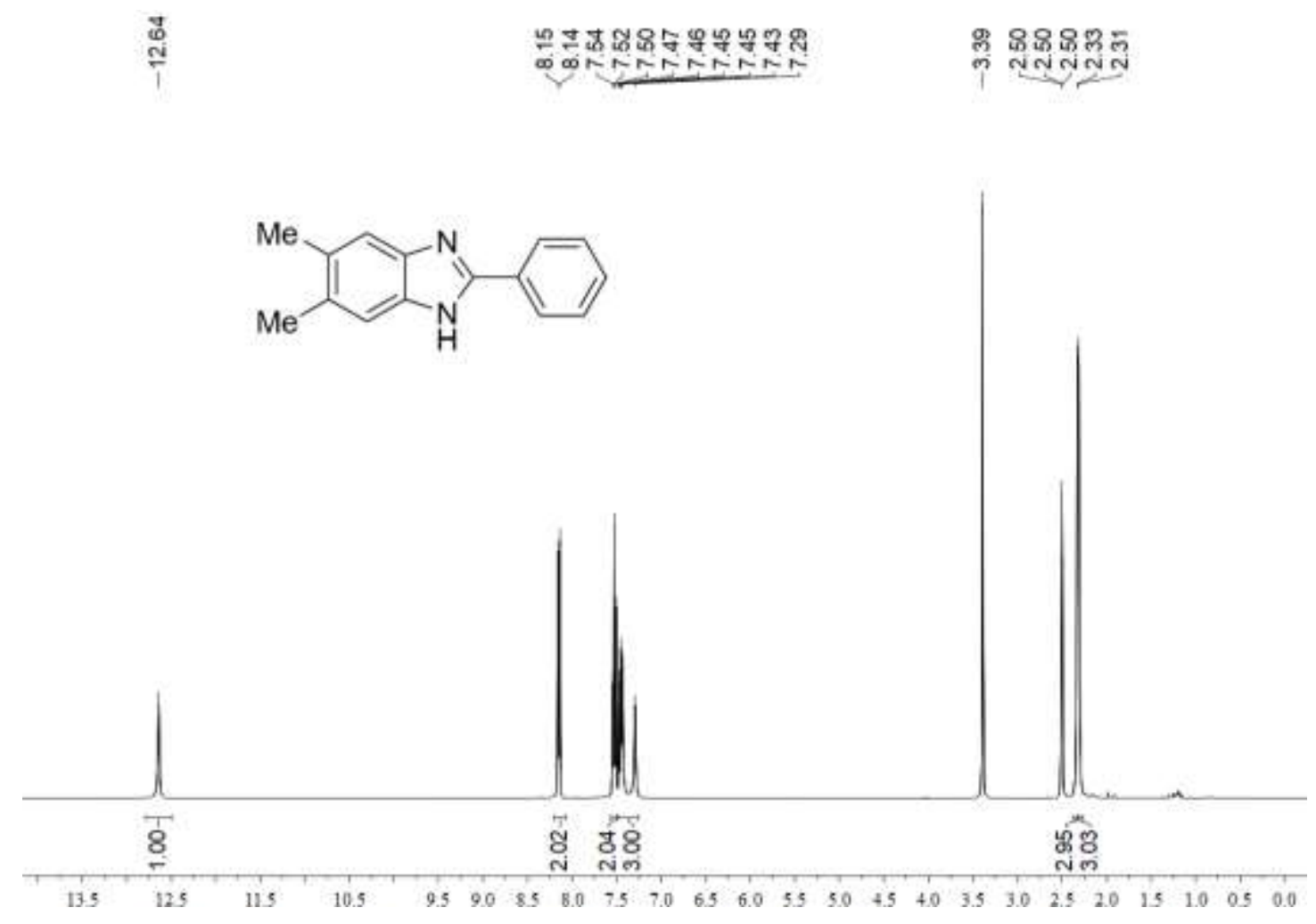

${ }^{1} \mathrm{H}$ NMR (400 MHz, DMSO) of $\mathbf{6 b}$

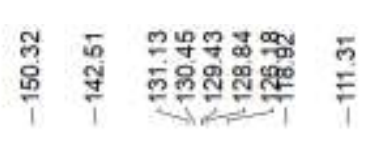
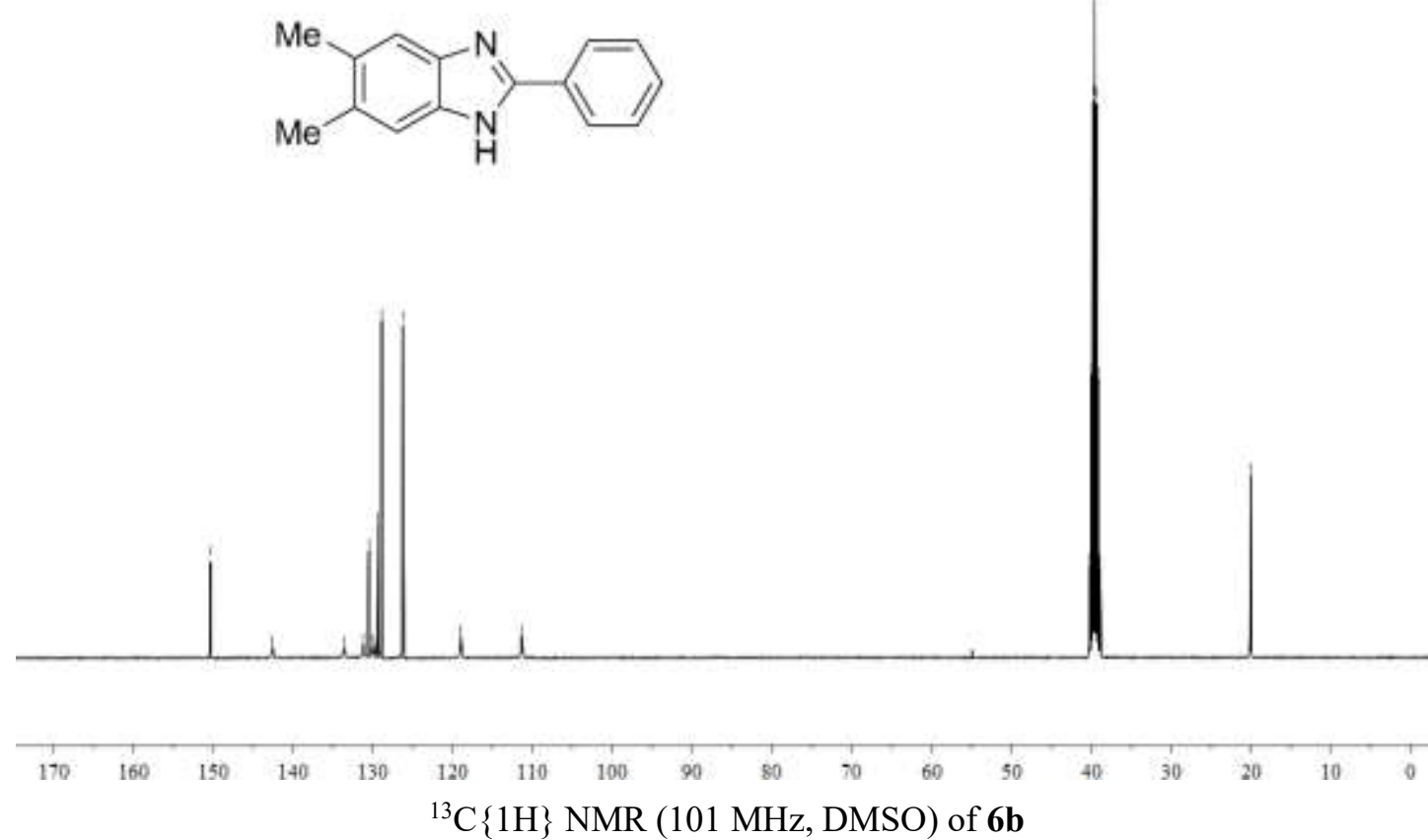


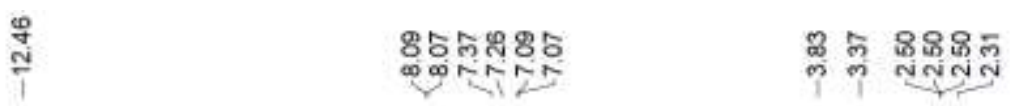

Me

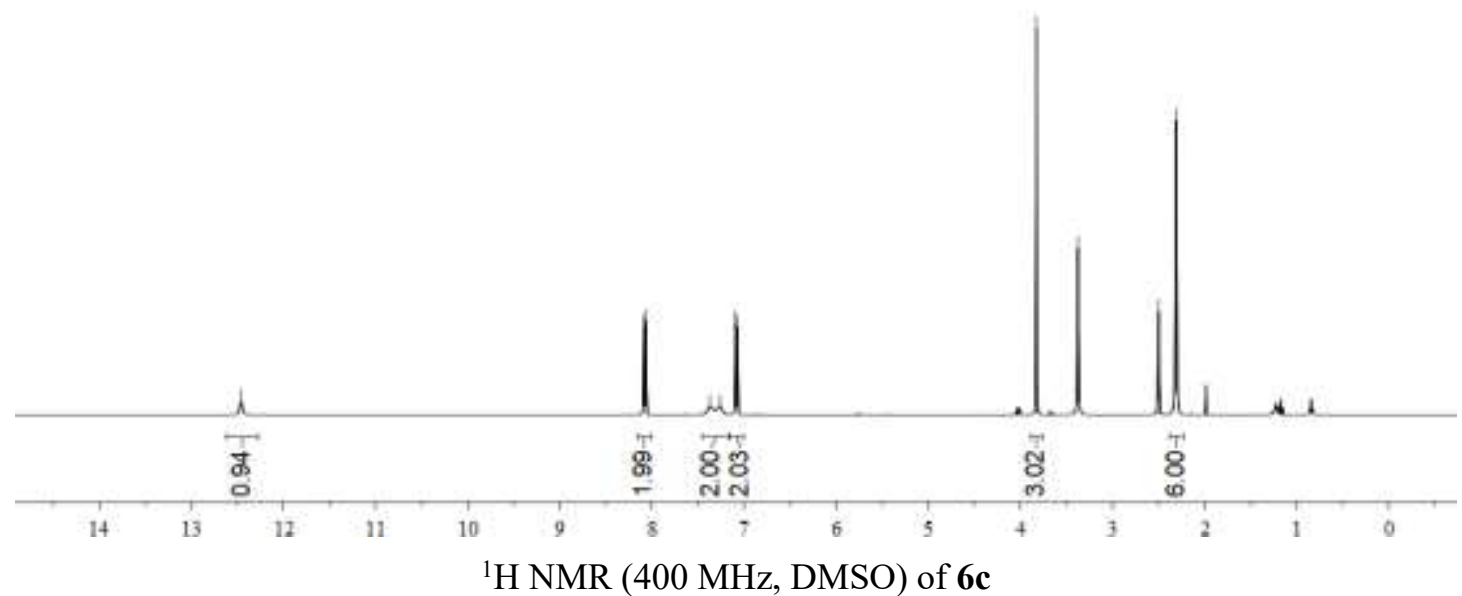

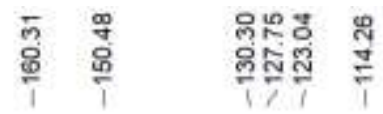

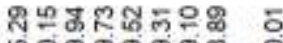

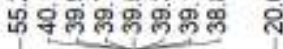<smiles>COc1ccc(-c2nc3cc(C)c(C)cc3[nH]2)cc1</smiles>

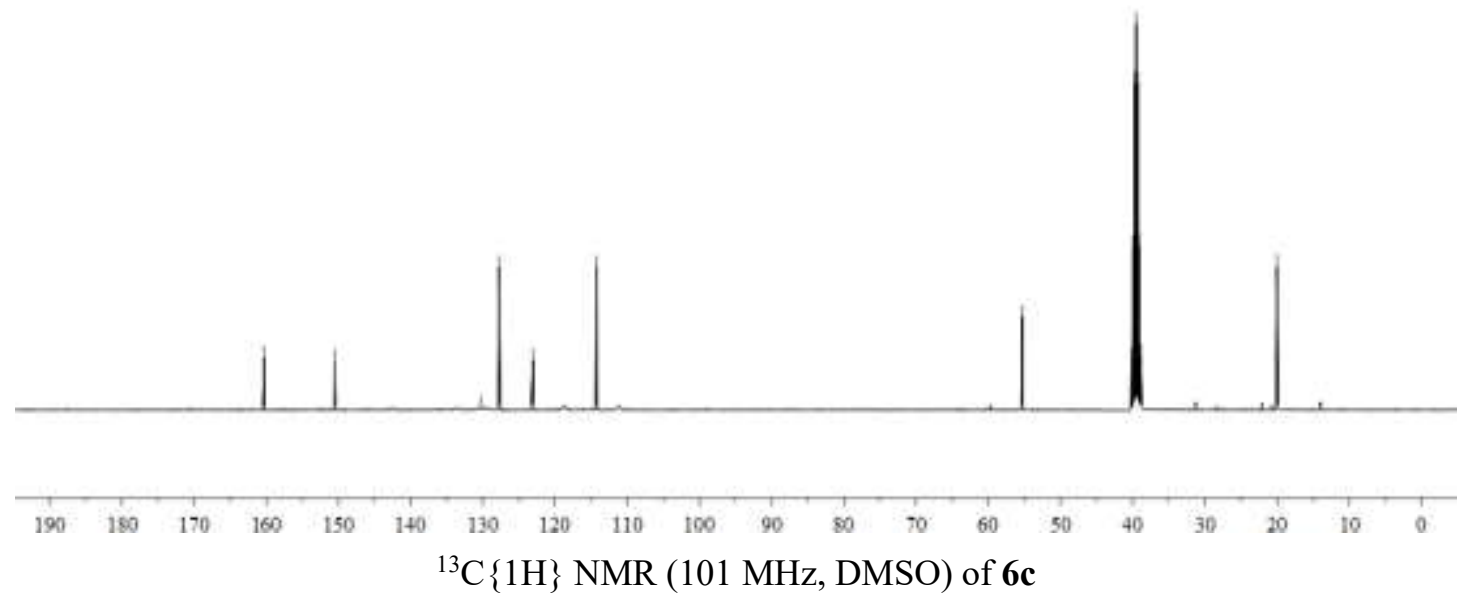


<smiles>c1ccc(-c2cnc3ccccc3n2)cc1</smiles>

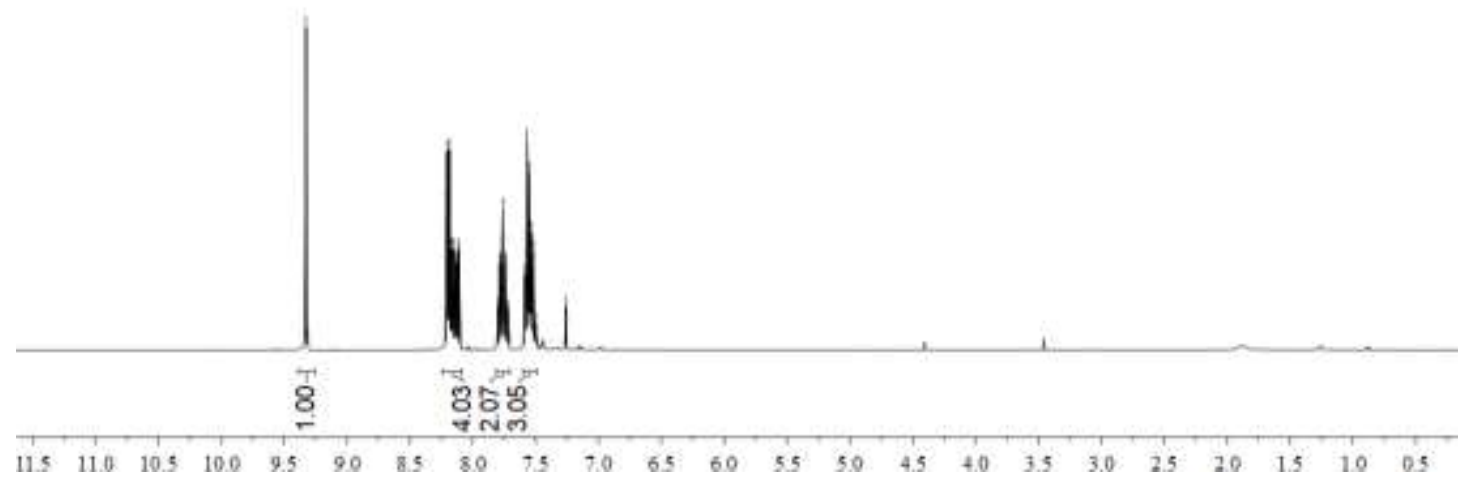

${ }^{1} \mathrm{H} \mathrm{NMR}\left(400 \mathrm{MHz}, \mathrm{CDCl}_{3}\right)$ of $\mathbf{8 a}$

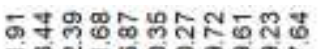

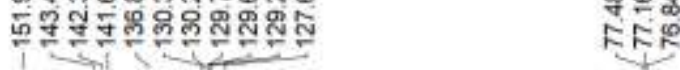<smiles>c1ccc(-c2cnc3ccccc3n2)cc1</smiles>

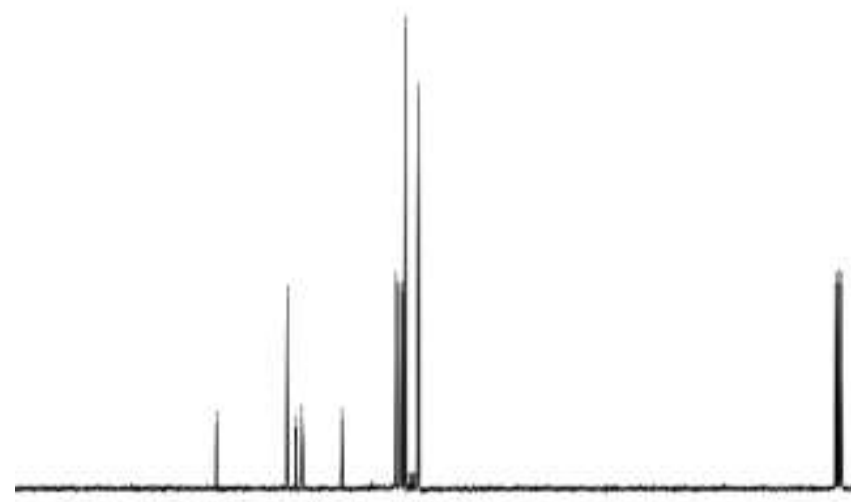

$\begin{array}{llllllllllllll}170 & 160 & 150 & 1+2 & 130 & 120 & 110 & 100 & 90 & 80 & 70 & 50 & 50 & 40\end{array}$ 


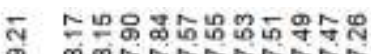

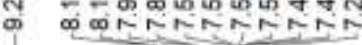

$\mathrm{N}_{N}^{\mathrm{N}} \mathrm{N}^{\mathrm{Ph}}$

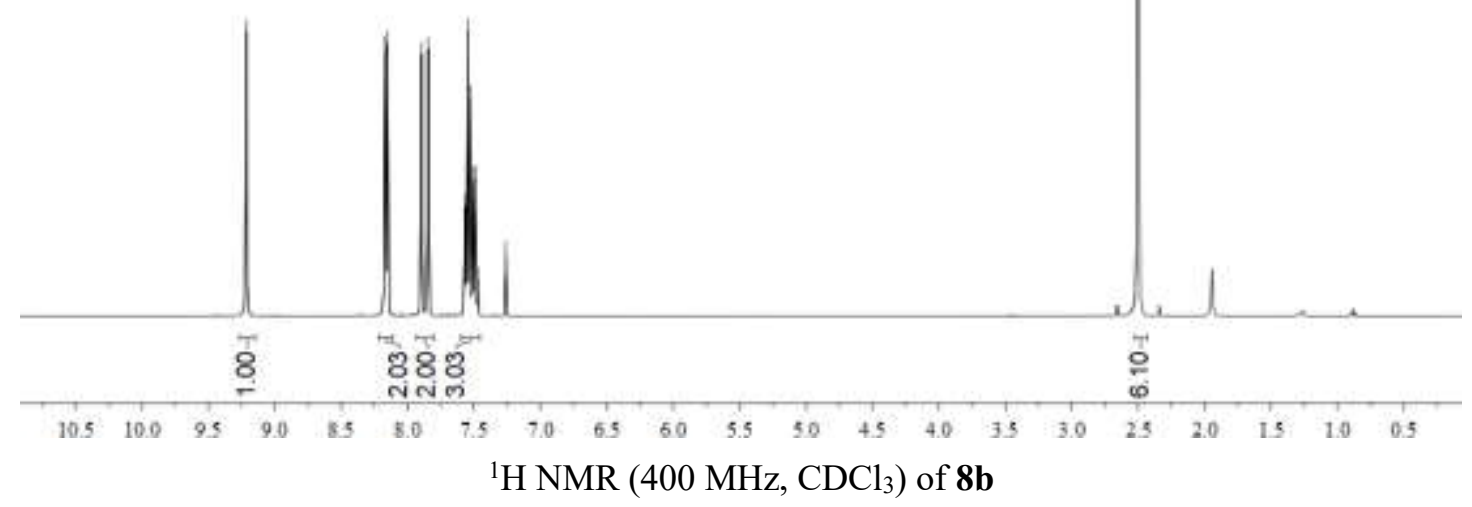

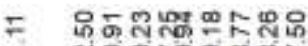

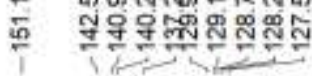

무음

FFP

8 年

ริธิ<smiles>Cc1cc2ncc(-c3ccccc3)nc2cc1C</smiles>

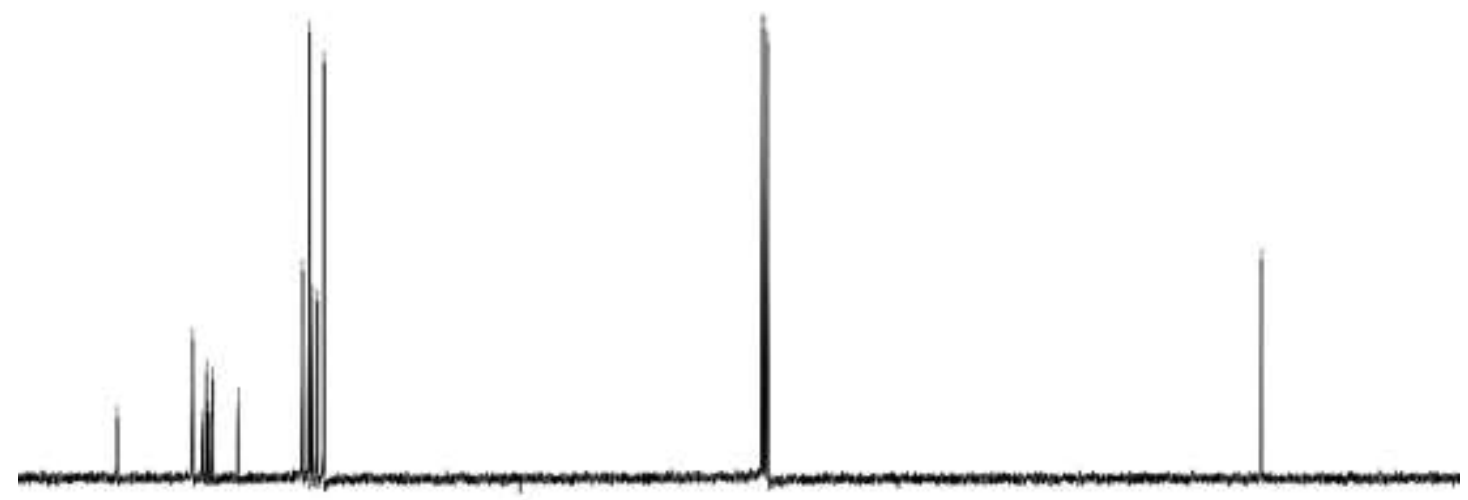

${ }^{13} \mathrm{C}\{1 \mathrm{H}\} \mathrm{NMR}\left(101 \mathrm{MHz}, \mathrm{CDCl}_{3}\right)$ of $\mathbf{8 b}$ 
<smiles>c1ccc(-c2nc3ccccc3nc2-c2ccccc2)cc1</smiles>

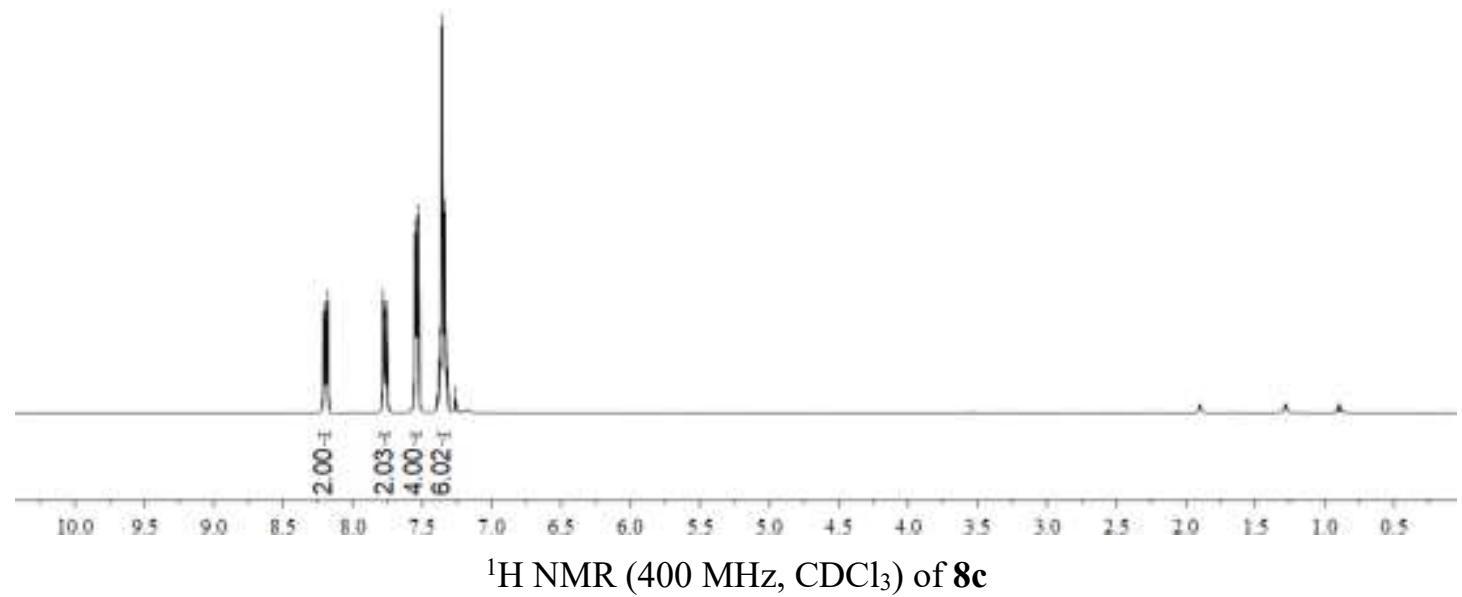

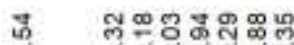

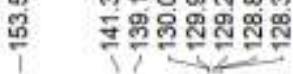

g一ำ

FF?

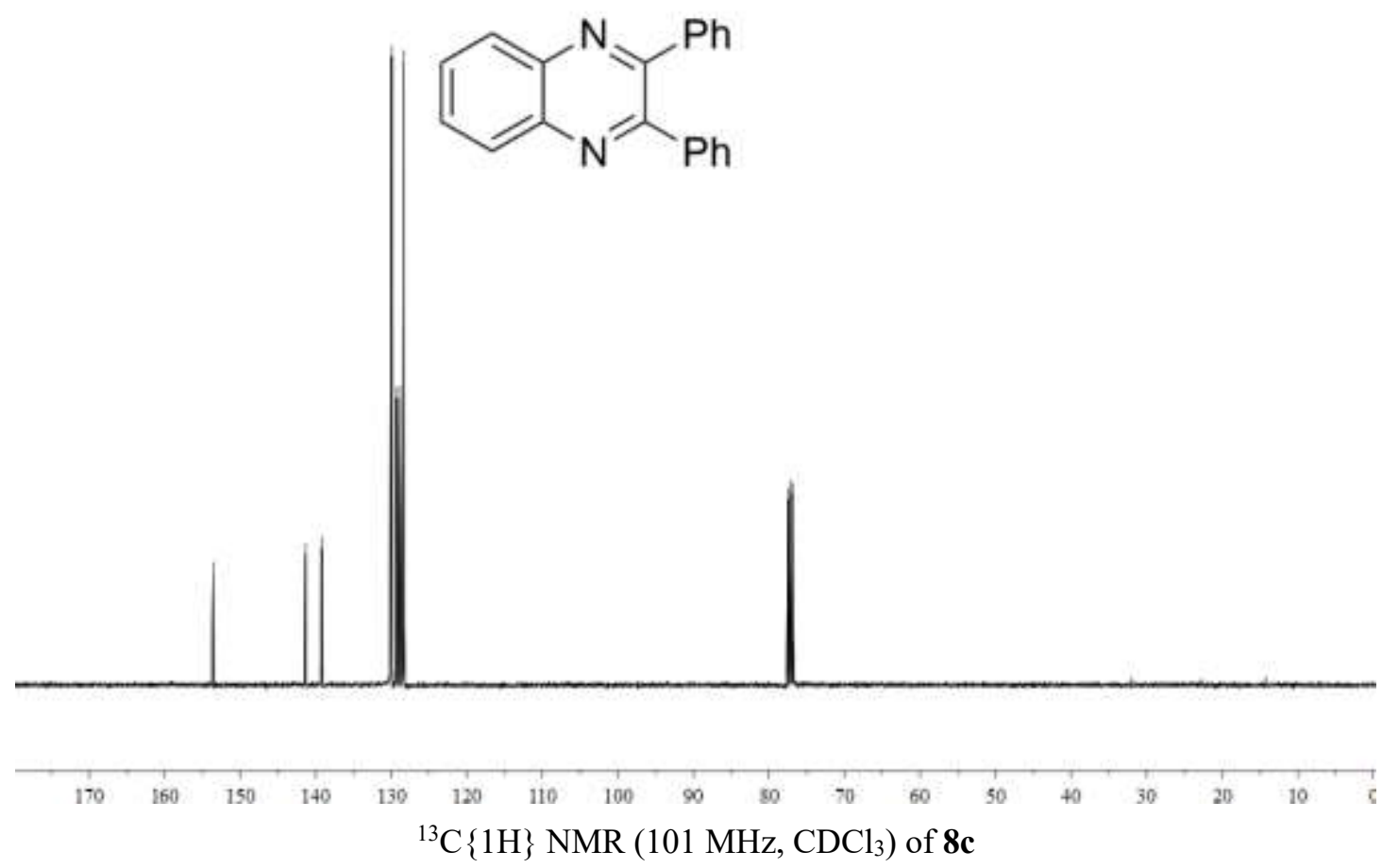




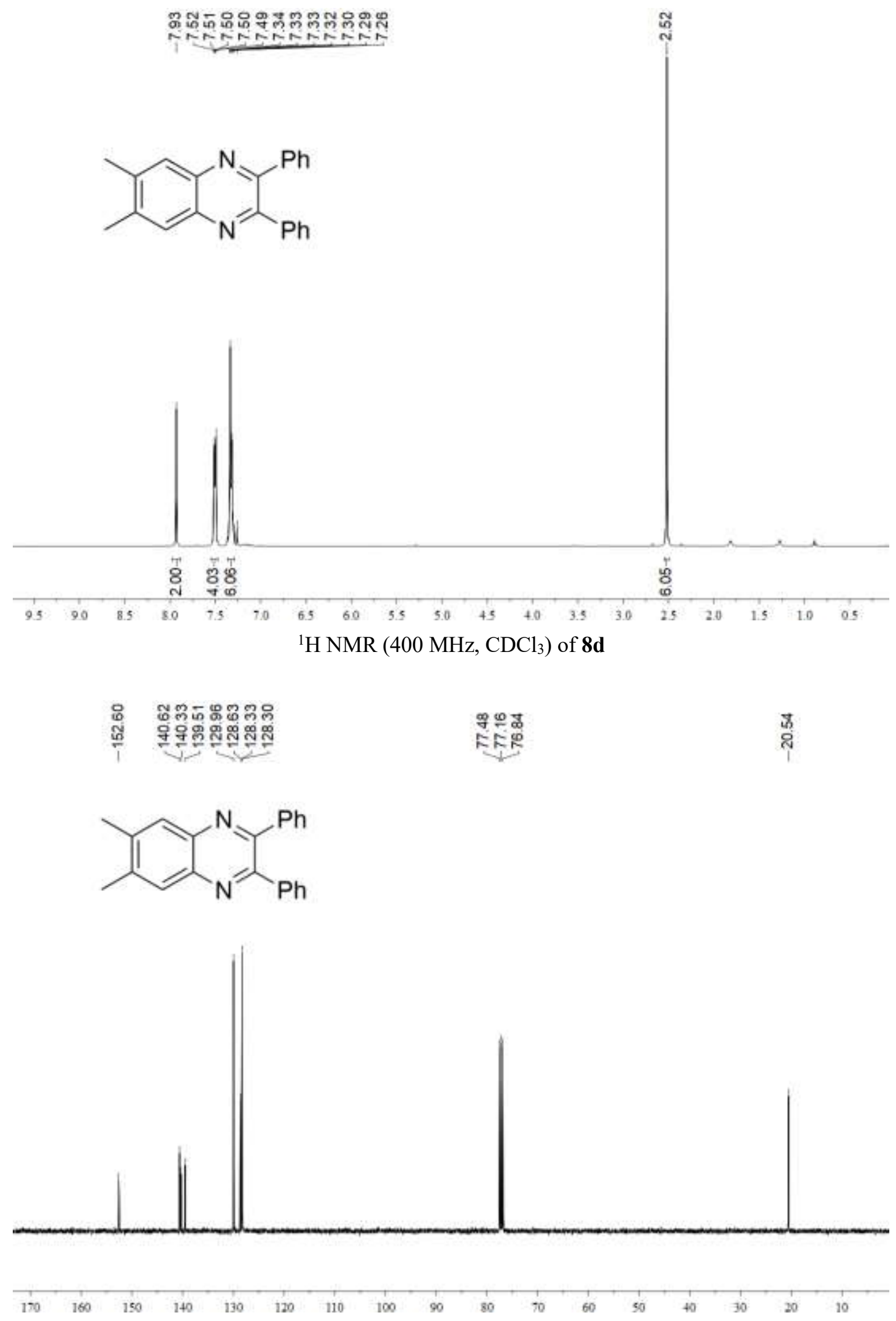

${ }^{13} \mathrm{C}\{1 \mathrm{H}\}$ NMR (101 MHz, $\left.\mathrm{CDCl}_{3}\right)$ of $\mathbf{8 d}$ 


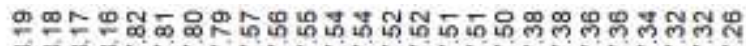

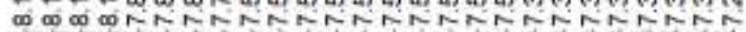<smiles>Fc1ccc2nc(-c3ccccc3)c(-c3ccccc3)nc2c1</smiles>

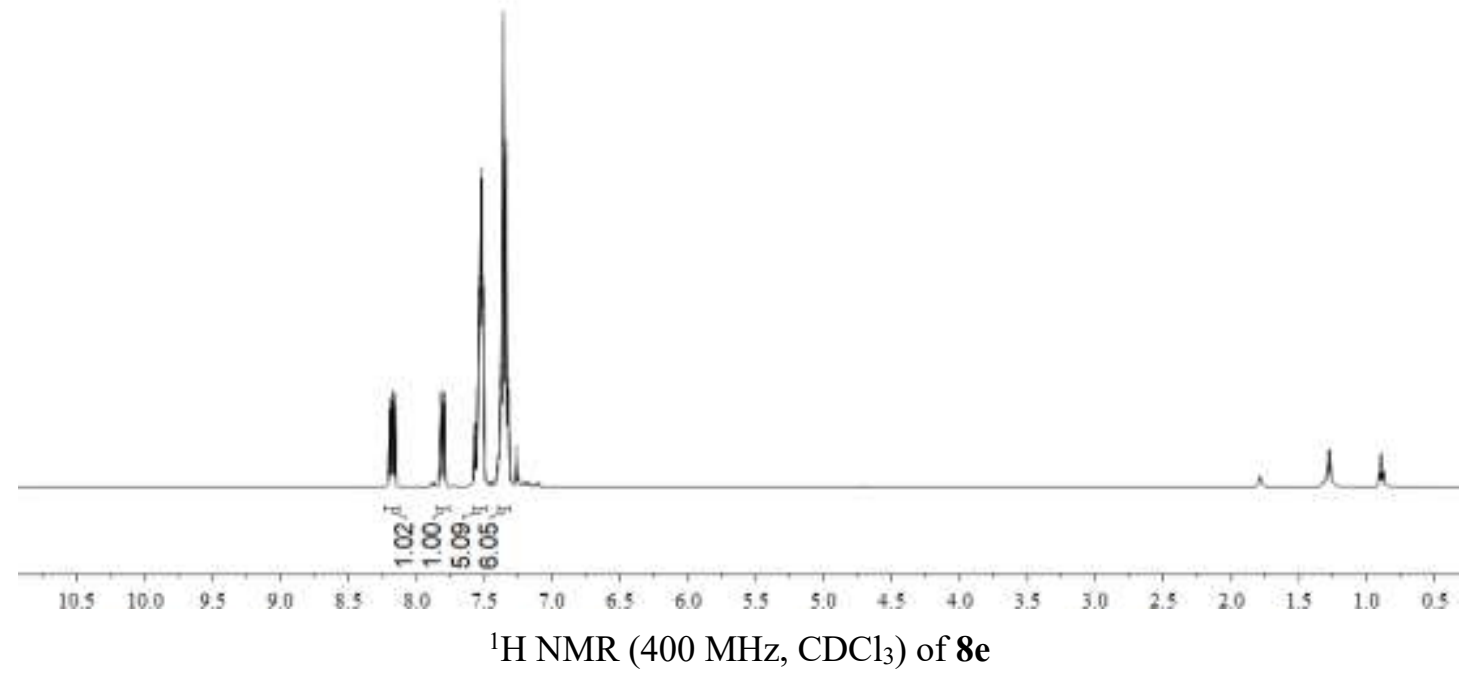

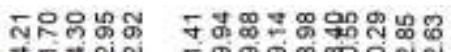

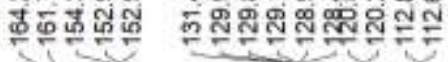

gัตำ

FFP<smiles>Fc1ccc2nc(-c3ccccc3)c(-c3ccccc3)nc2c1</smiles>

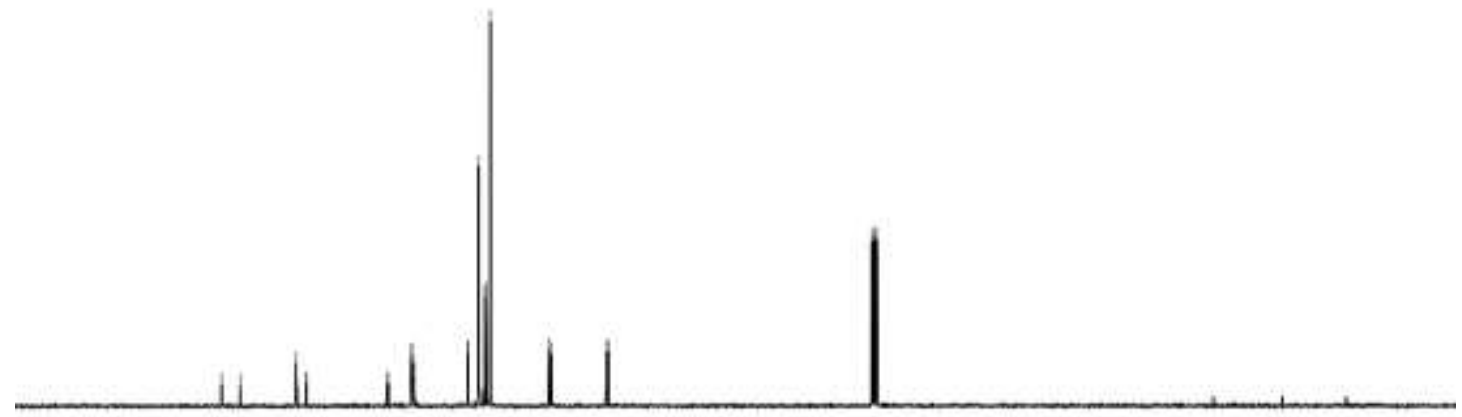

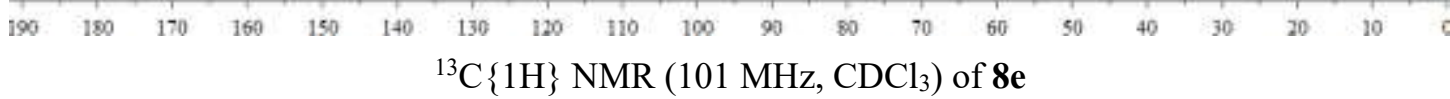


<smiles>Fc1ccc2nc(-c3ccccc3)c(-c3ccccc3)nc2c1</smiles>

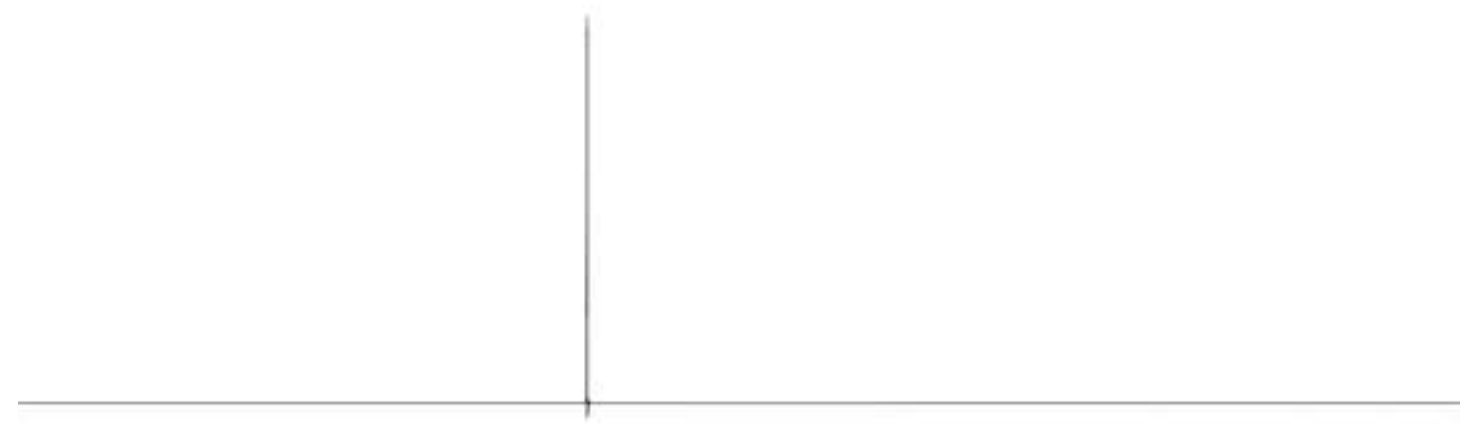

\begin{tabular}{|c|c|c|c|c|c|c|c|c|c|c|c|c|c|c|c|}
\hline 40 & 20 & 0 & -10 & -30 & -50 & -70 & -90 & -110 & -140 & -170 & -200 & .230 & -260 & -290 & -320 \\
\hline
\end{tabular}

${ }^{19} \mathrm{~F}$ NMR $\left(376 \mathrm{MHz}, \mathrm{CDCl}_{3}\right)$ of $\mathbf{8 e}$

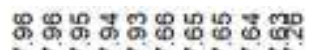

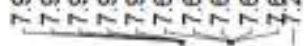

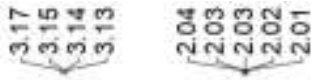<smiles>c1ccc2nc3c(nc2c1)CCCC3</smiles>
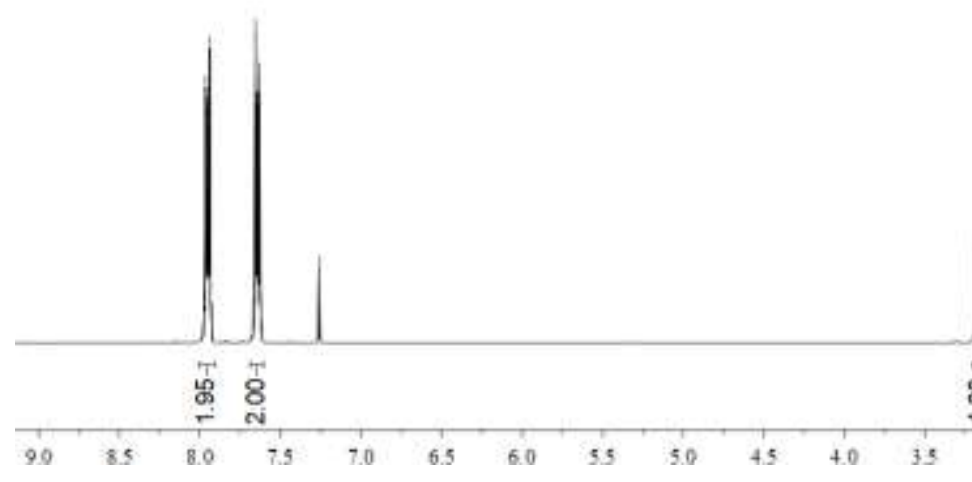

${ }^{1} \mathrm{H}$ NMR (400 MHz, $\mathrm{CDCl}_{3}$ ) of $\mathbf{8 f}$ 
<smiles>c1ccc2nc3c(nc2c1)CCCC3</smiles>
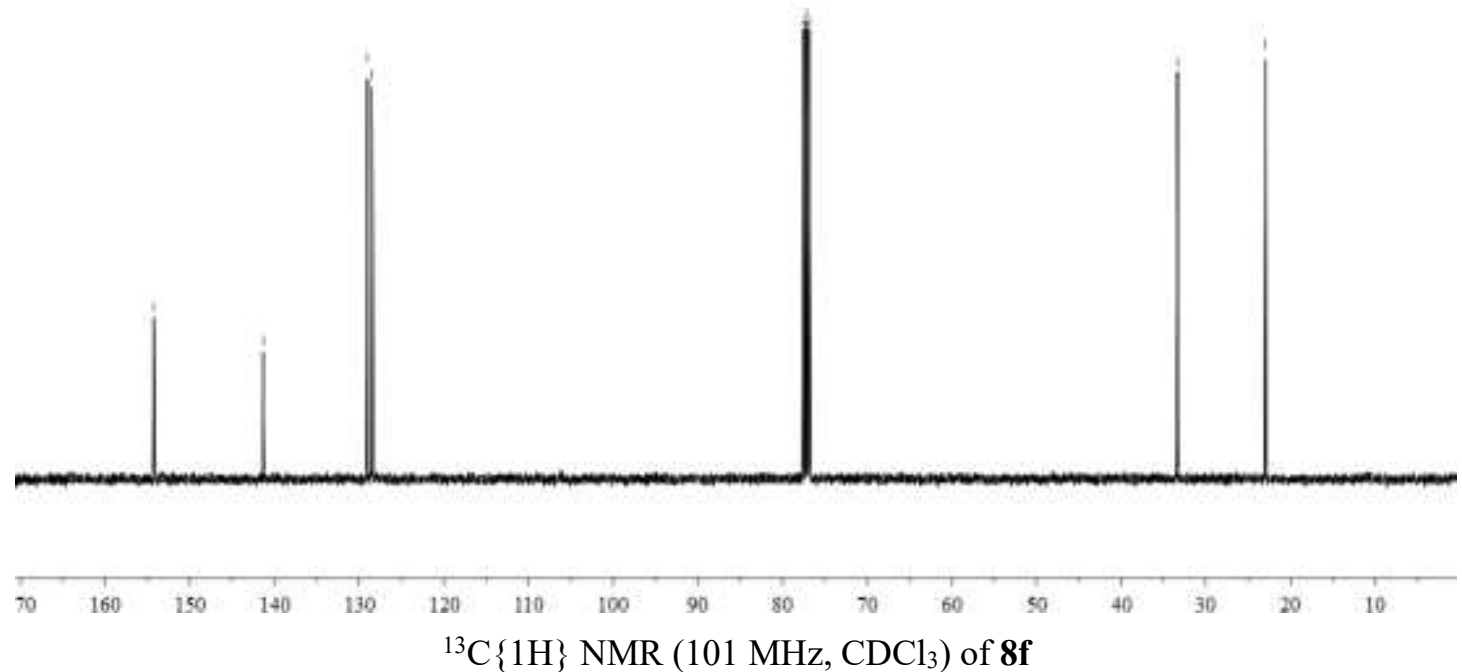

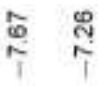

둥ำ<smiles>Cc1cc2nc3c(nc2cc1C)CCCC3</smiles>
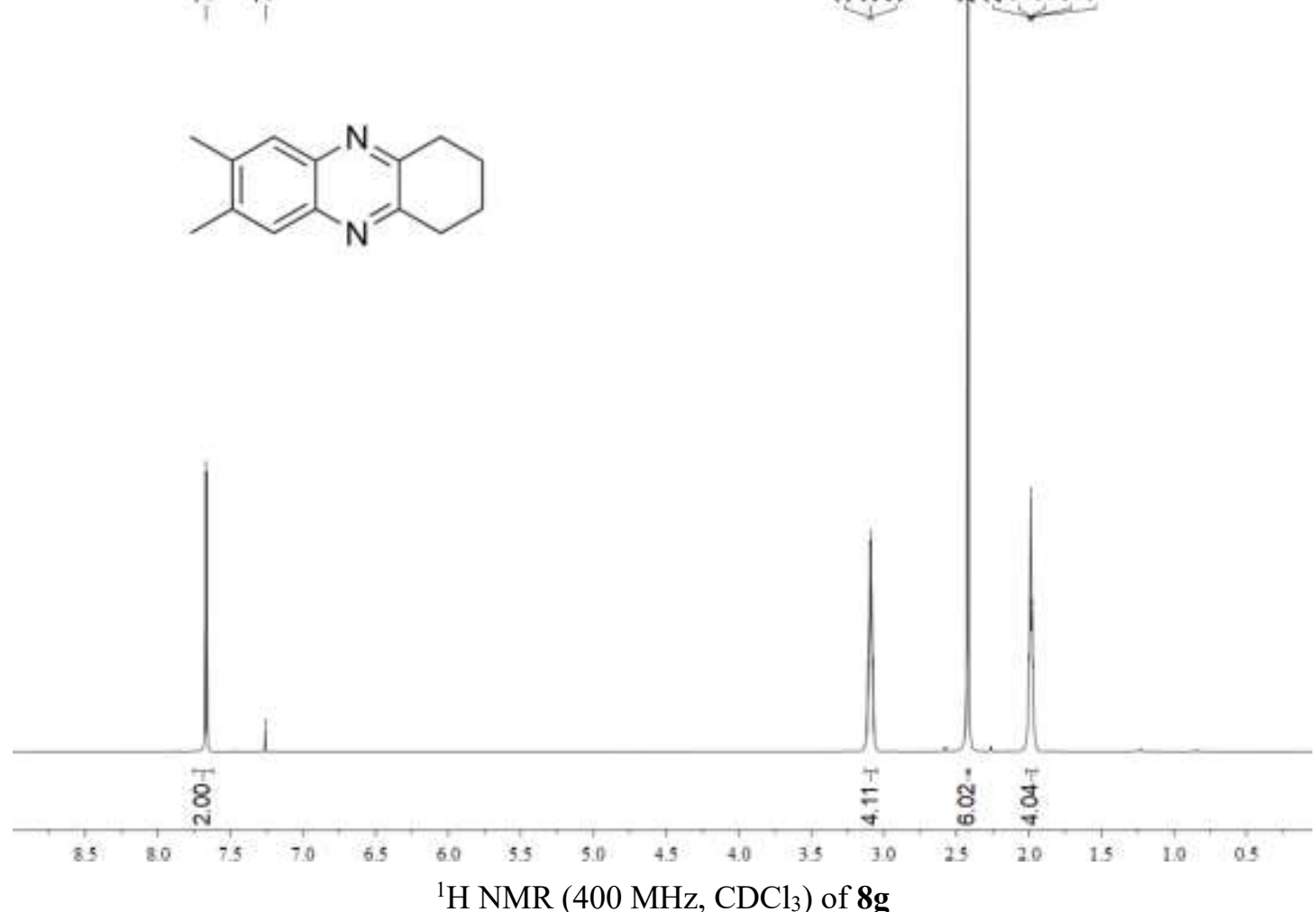

${ }^{1} \mathrm{H}$ NMR (400 MHz, $\mathrm{CDCl}_{3}$ ) of $\mathbf{8 g}$ 
<smiles>Cc1cc2nc3c(nc2cc1C)CCCC3</smiles>
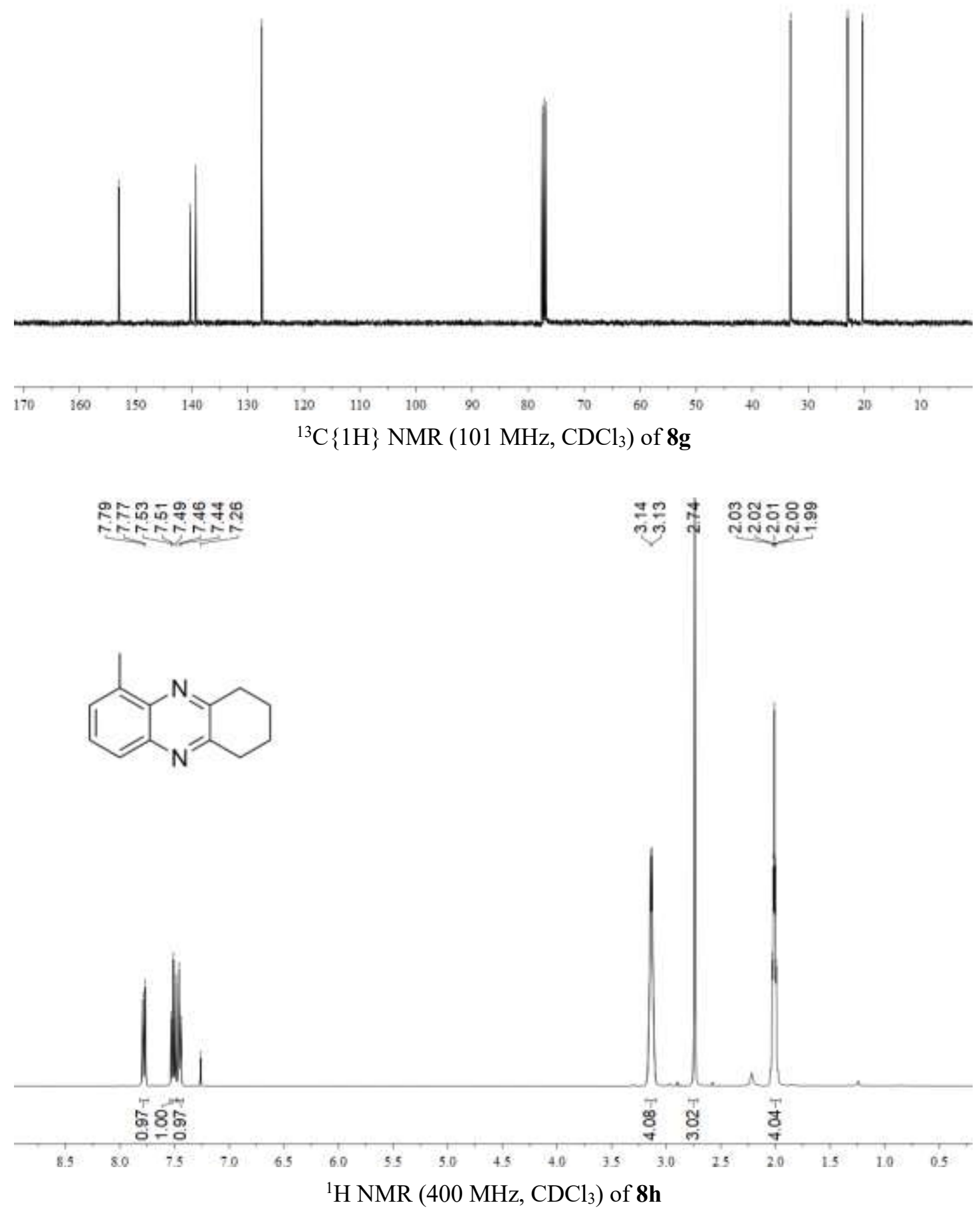
<smiles>Cc1cccc2nc3c(nc12)CCCC3</smiles>
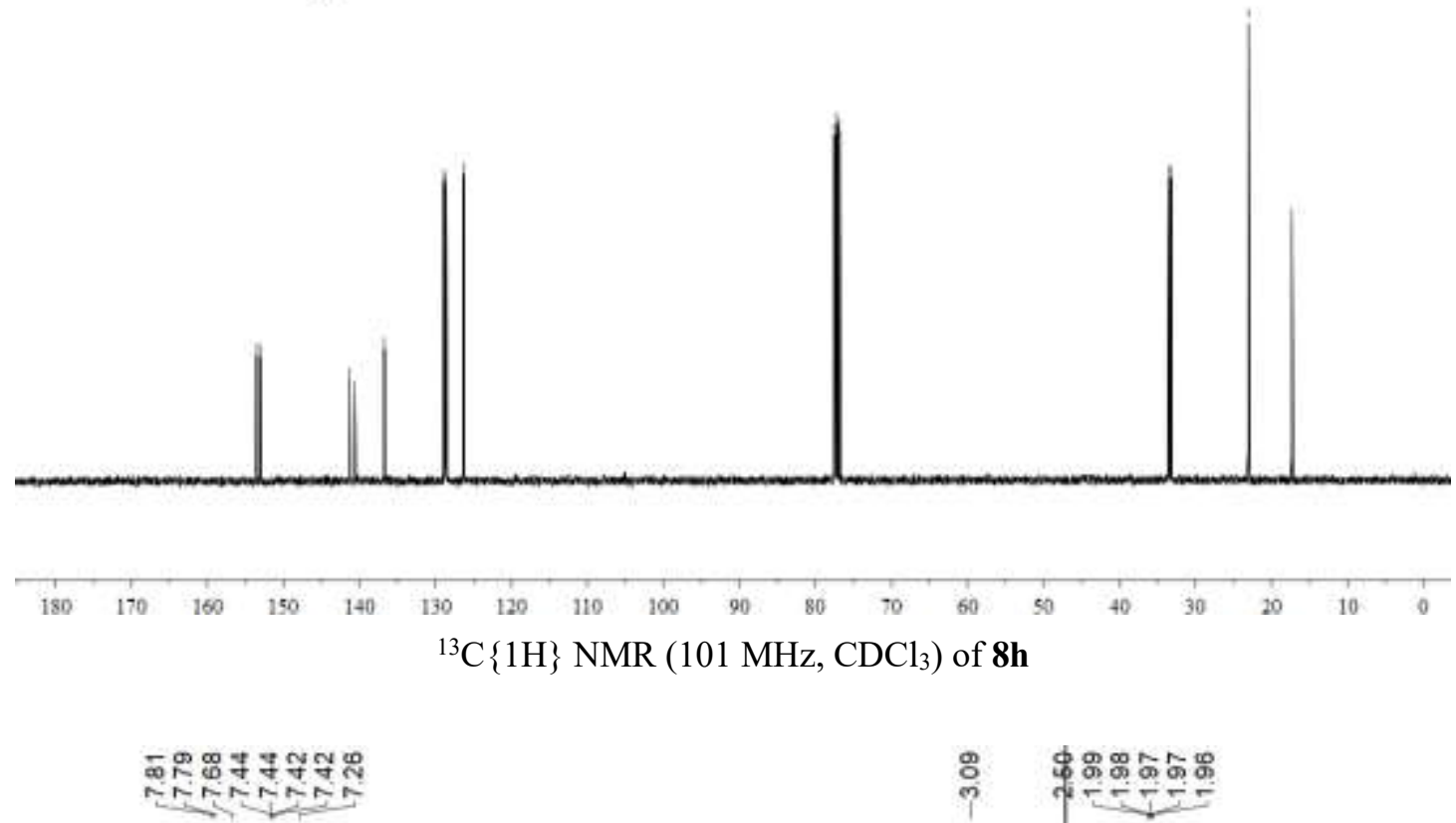

용 $\quad$ \$क<smiles>Cc1ccc2nc3c(nc2c1)CCCC3</smiles>

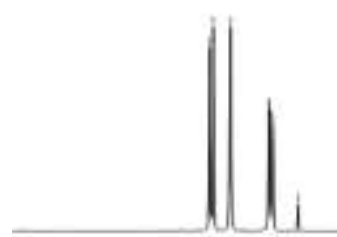

$8 \%$

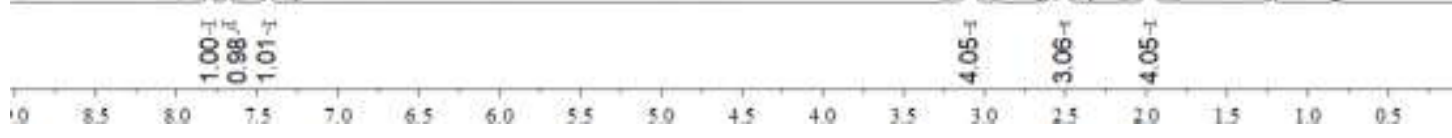

${ }^{1} \mathrm{H}$ NMR (400 MHz, $\mathrm{CDCl}_{3}$ ) of $\mathbf{8 i}$ 


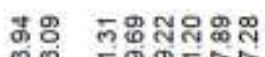

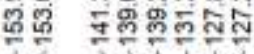

무이

FFE

歭 80

लुळ สู่<smiles>Cc1ccc2nc3c(nc2c1)CCCC3</smiles>
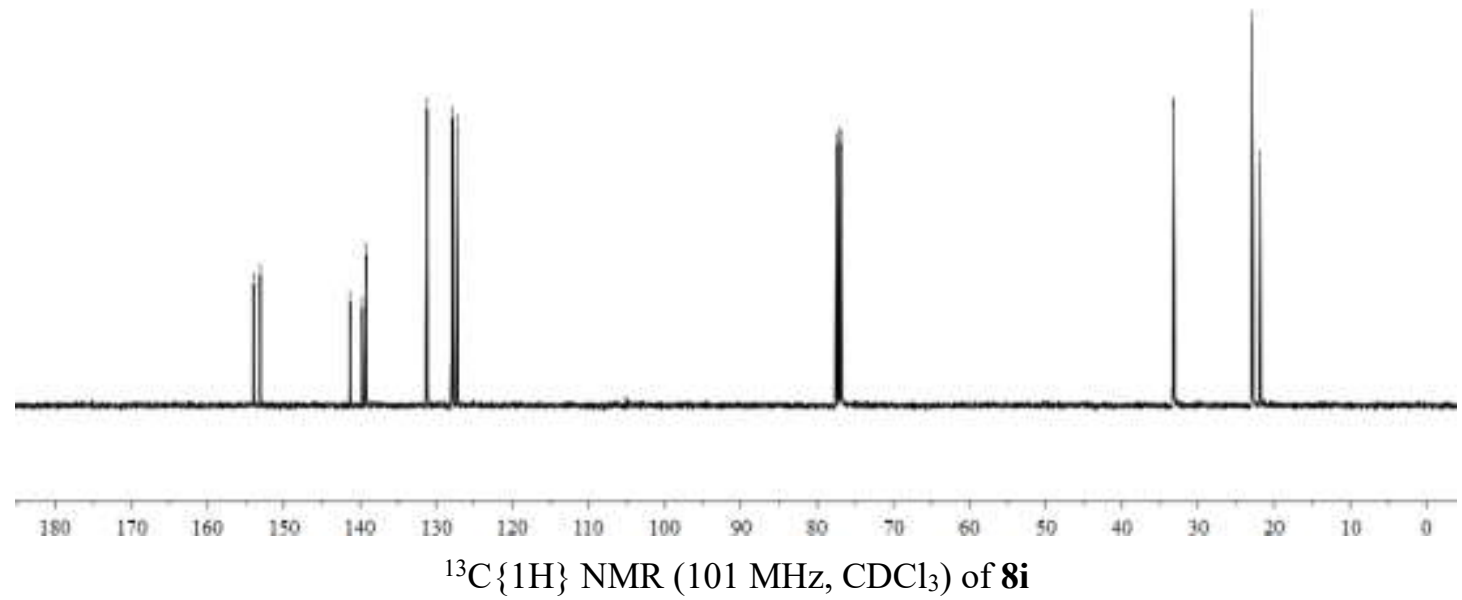

인

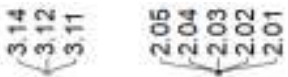<smiles>Clc1cc2nc3c(nc2cc1Cl)CCCC3</smiles>

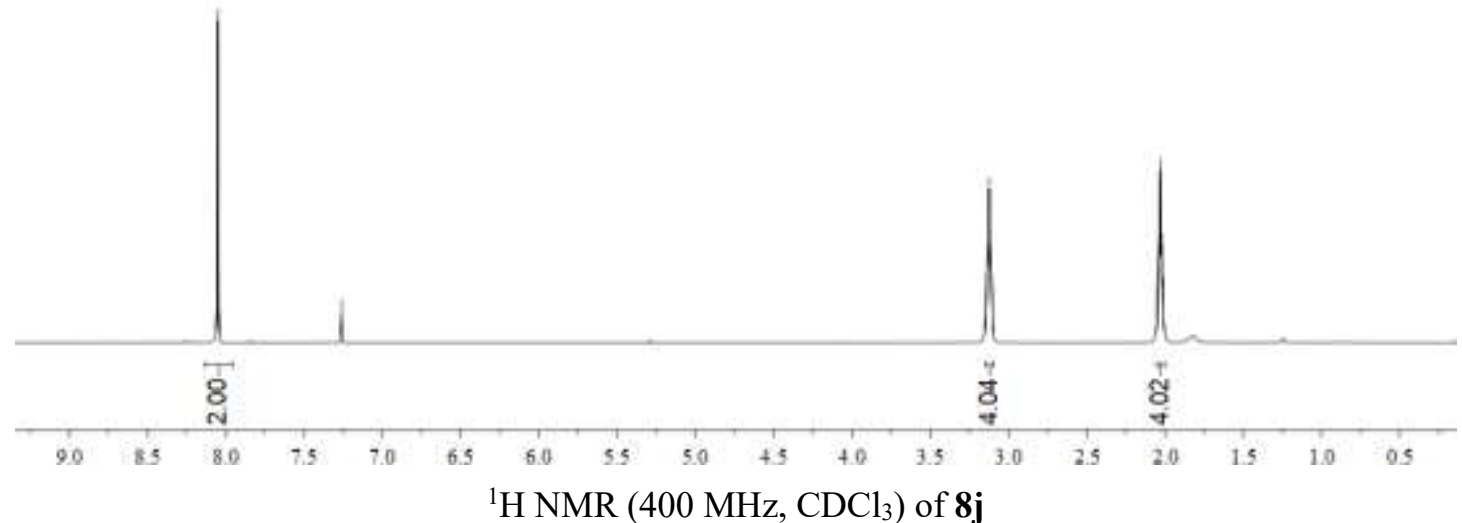


<smiles>Clc1cc2nc3c(nc2cc1Cl)CCCC3</smiles>
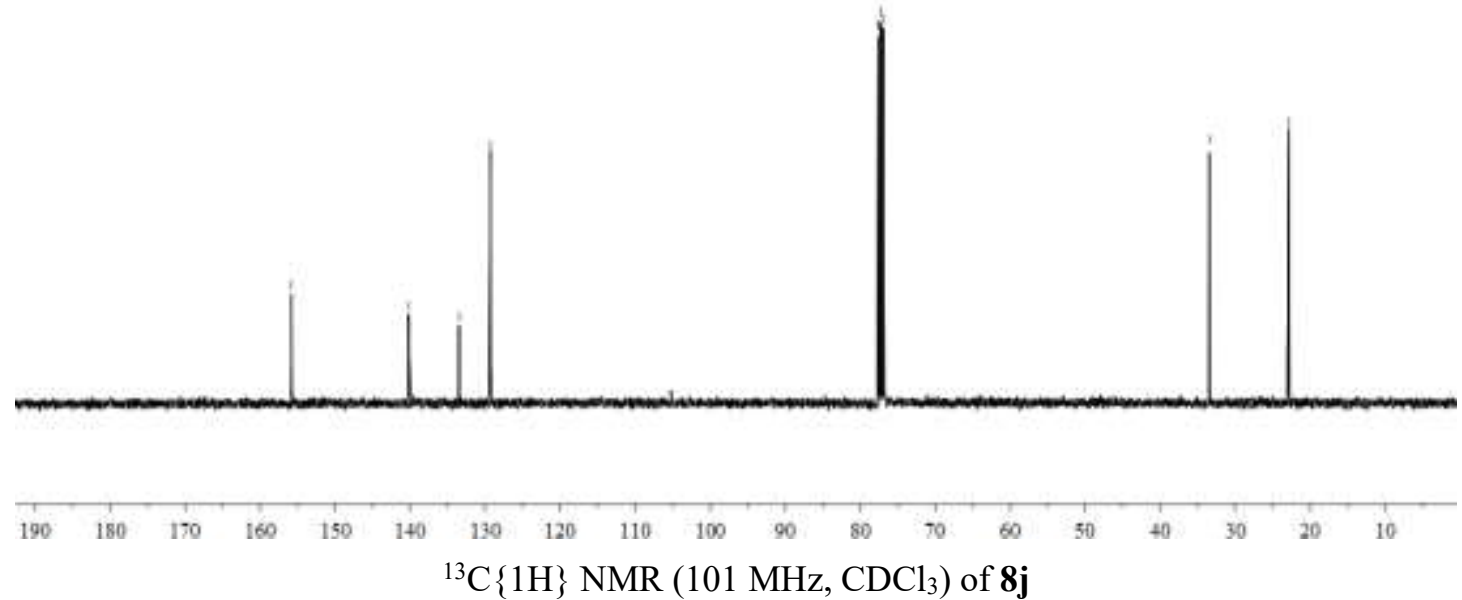

ษษ

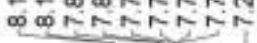

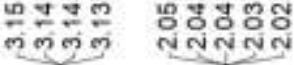<smiles>Brc1ccc2nc3c(nc2c1)CCCC3</smiles>

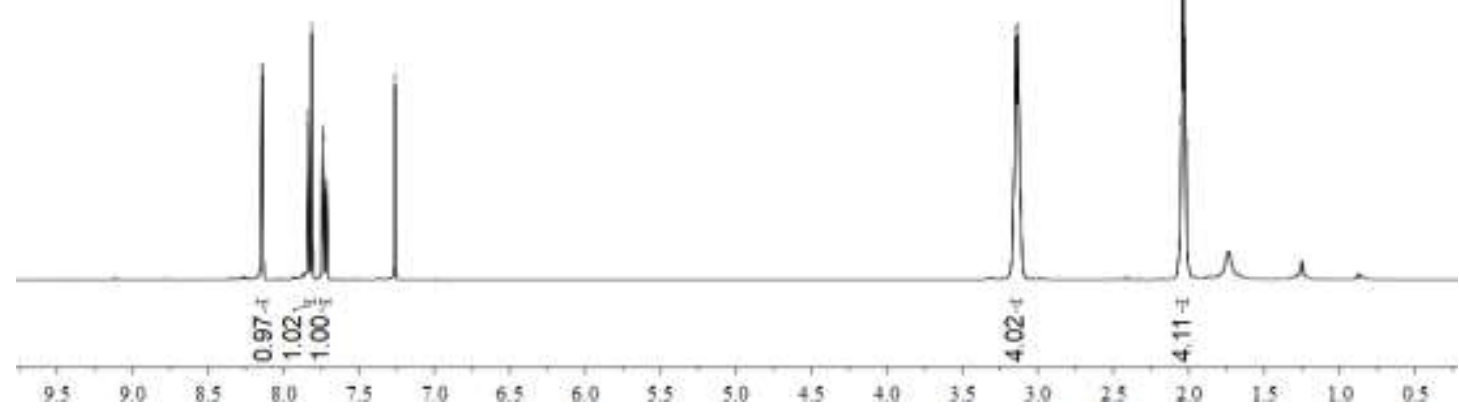

${ }^{1} \mathrm{H}$ NMR (400 MHz, $\mathrm{CDCl}_{3}$ ) of $\mathbf{8 k}$ 

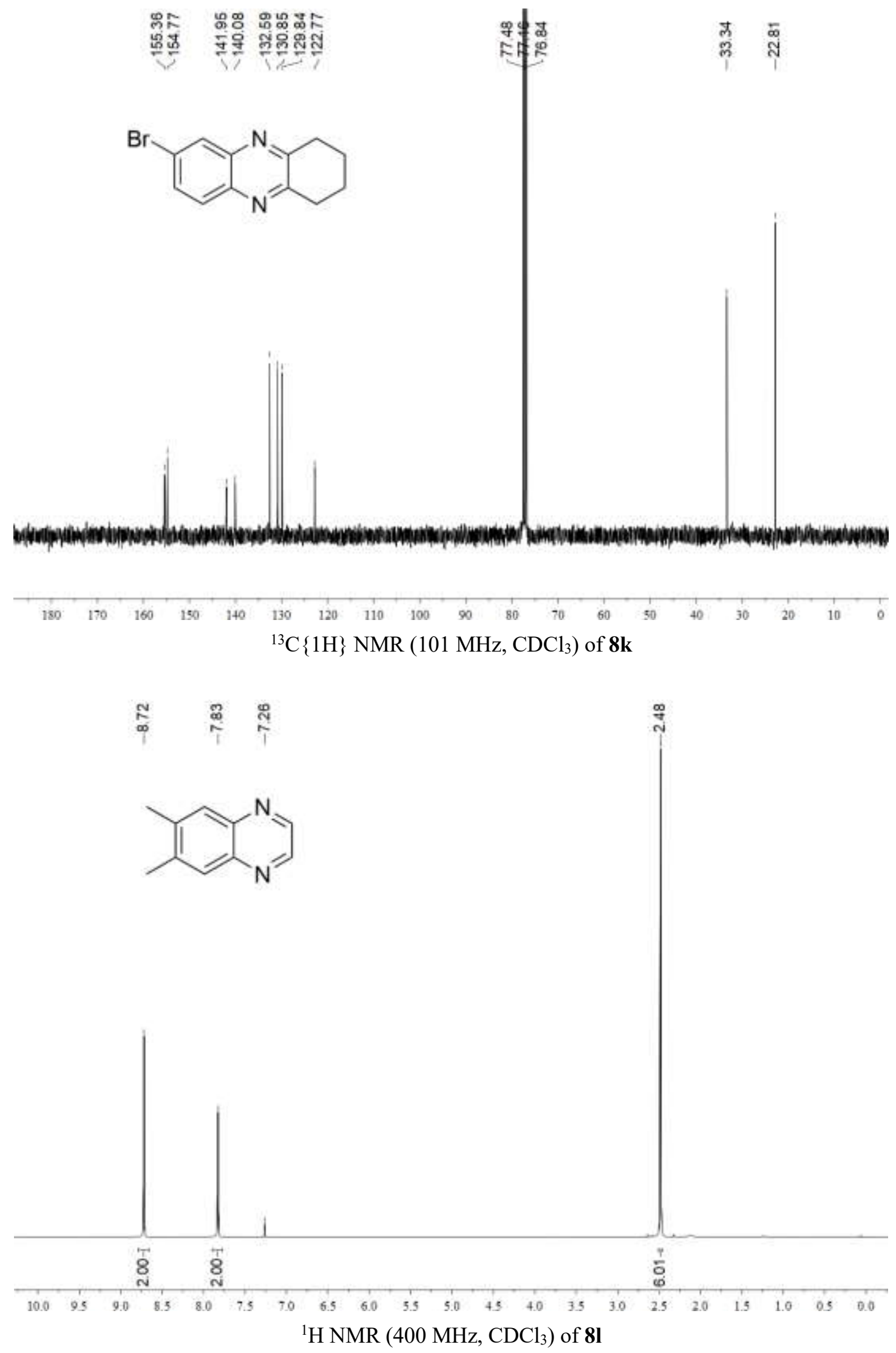
<smiles>Cc1cc2nccnc2cc1C</smiles>
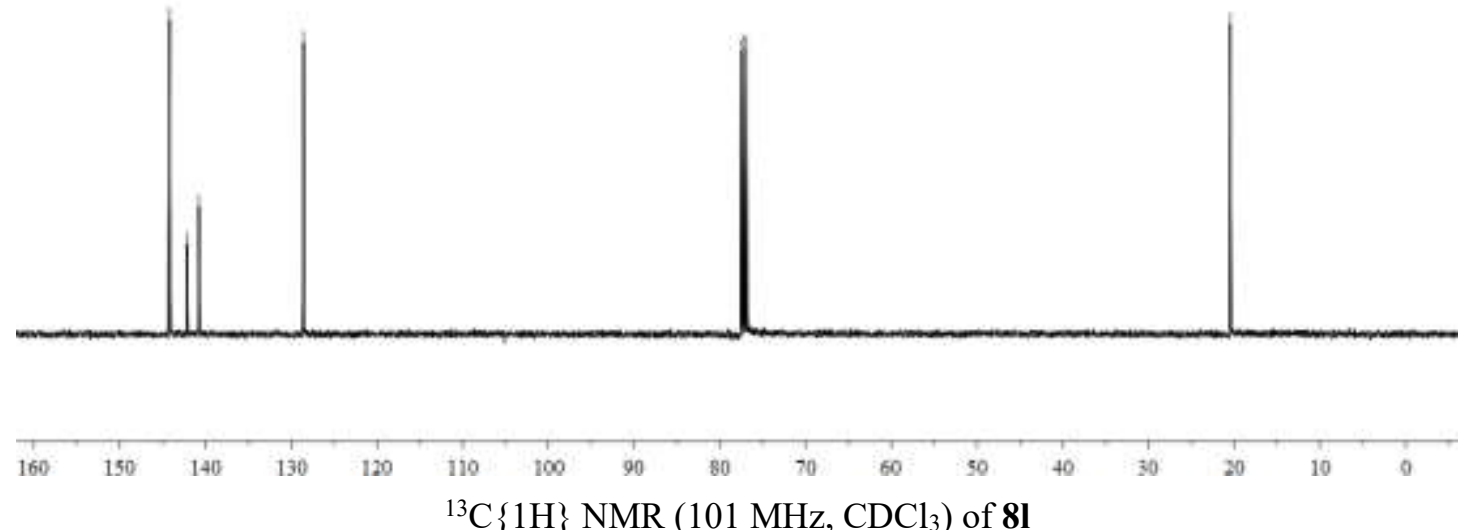

우요요

$\stackrel{8}{10}$<smiles>Brc1ccc(N=Nc2ccc(Br)cc2)cc1</smiles>

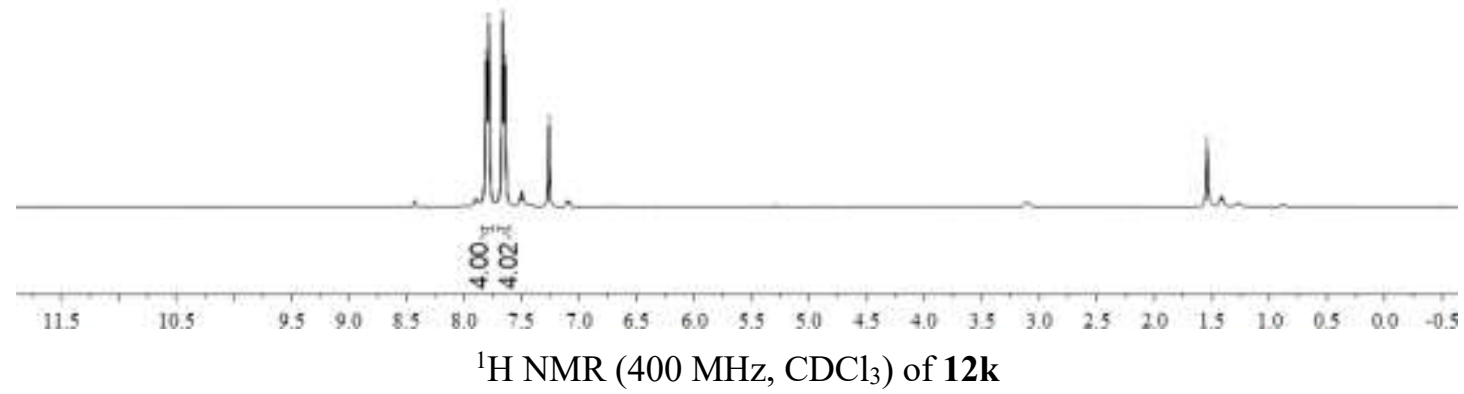


<smiles>Brc1ccc(N=Nc2ccc(Br)cc2)cc1</smiles>
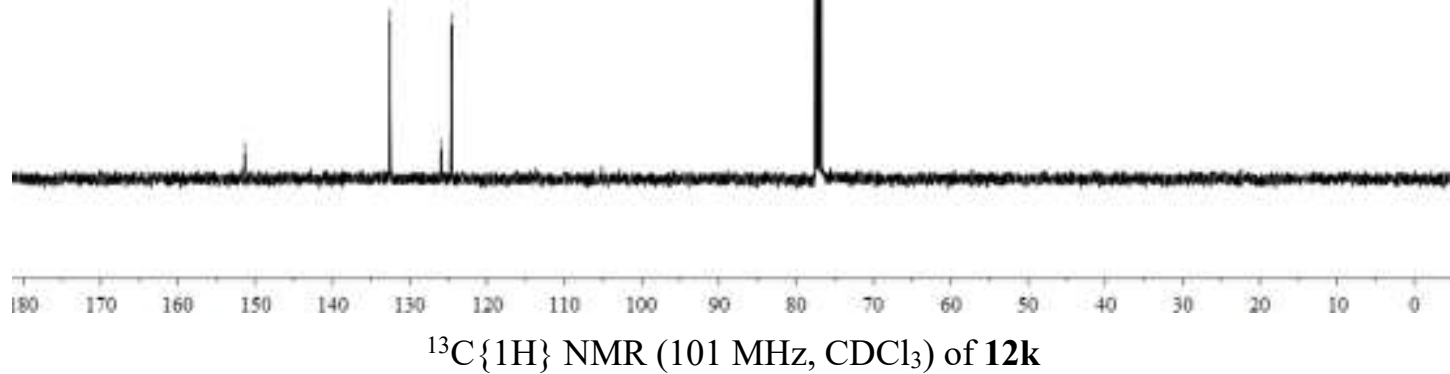

\section{6) HR-MS spectra}

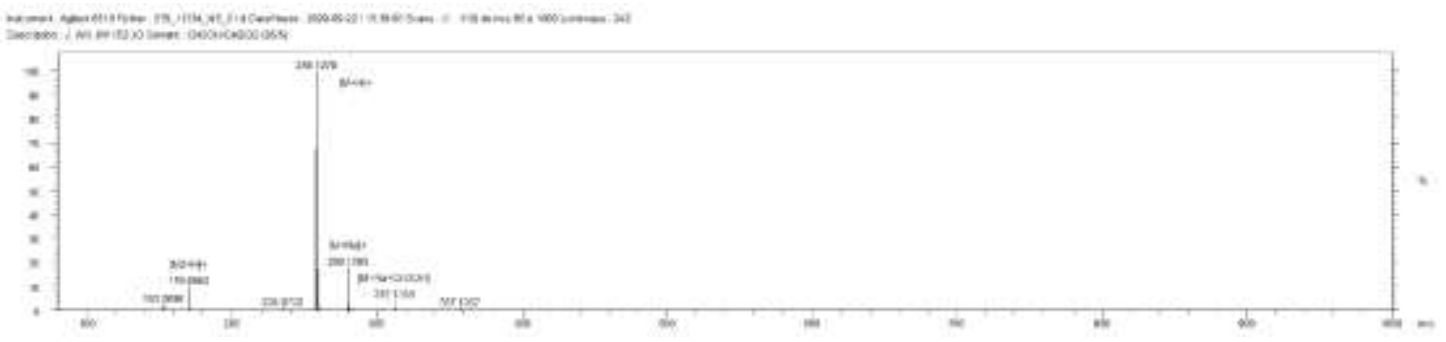

HR-MS spectra of $\mathbf{3 f}$

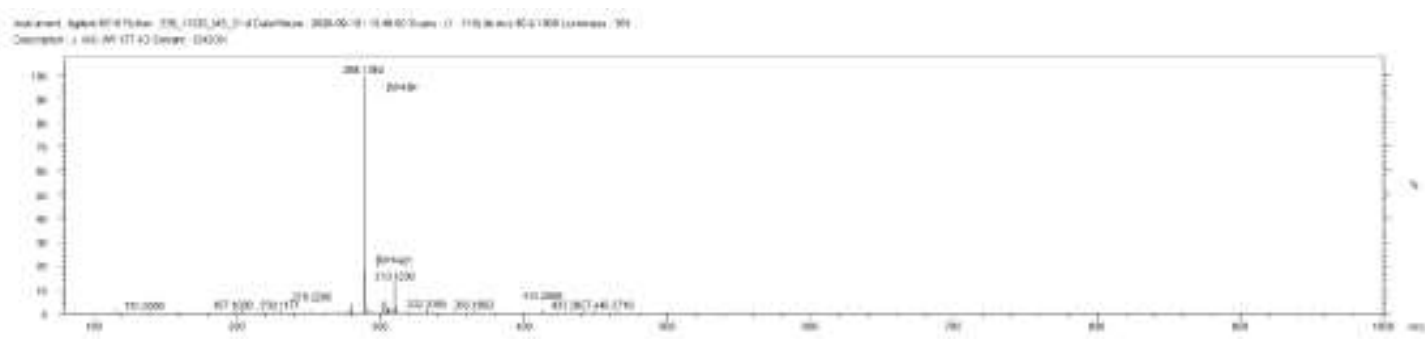

HR-MS spectra of $\mathbf{3 o}$ 


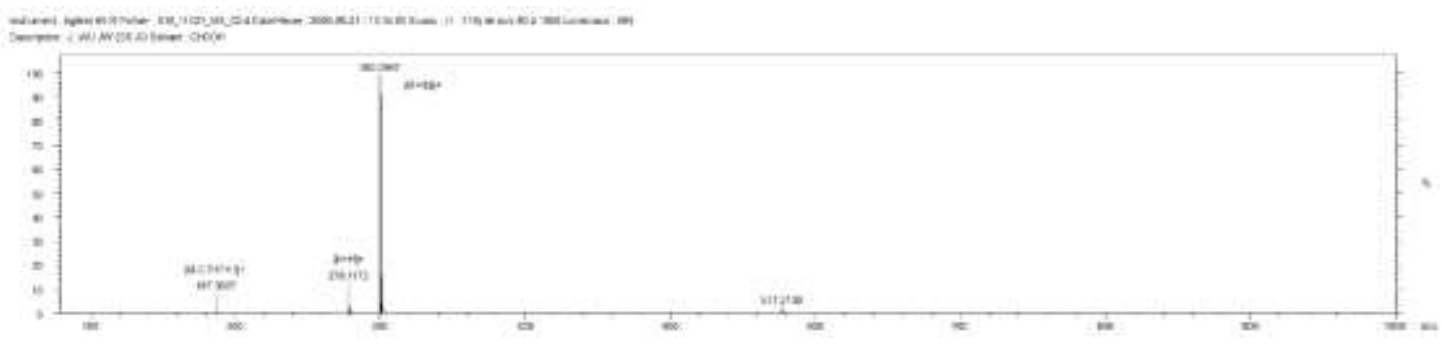

HR-MS spectra of $\mathbf{3 a h}$

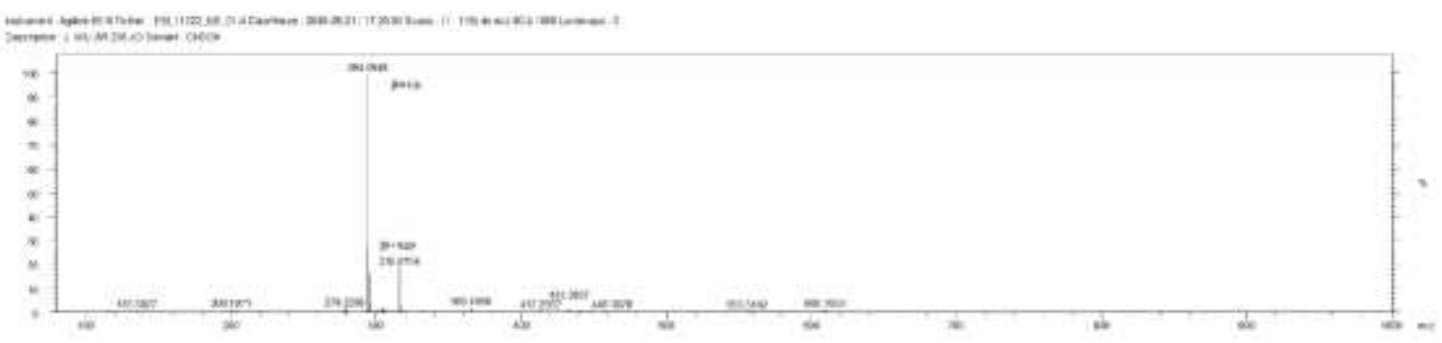

HR-MS spectra of $\mathbf{3 a i}$

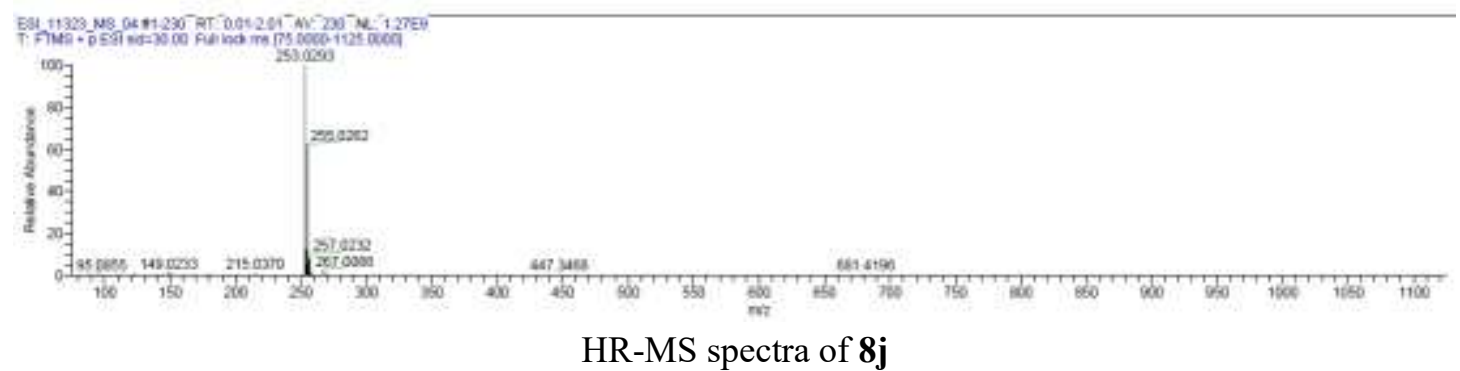

HR-MS spectra of $\mathbf{8 j}$ 